INTER NATIONAL MONETARY FUND
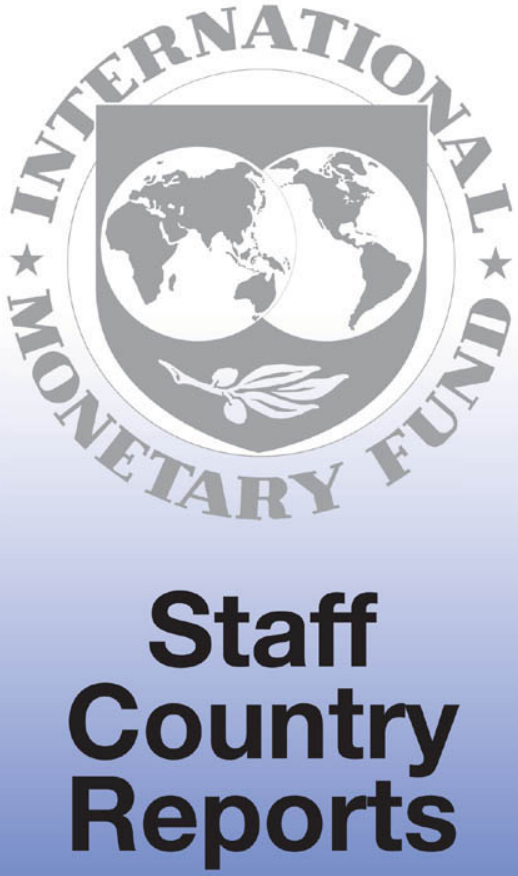


\section{Nepal: Poverty Reduction Strategy Paper}

Poverty Reduction Strategy Papers (PRSPs) are prepared by member countries in broad consultation with stakeholders and development partners, including the staffs of the World Bank and the IMF. Updated every three years with annual progress reports, they describe the country's macroeconomic, structural, and social policies in support of growth and poverty reduction, as well as associated external financing needs and major sources of financing. This country document for Nepal, dated May 2003, is being made available on the IMF website by agreement with the member country as a service to users of the IMF website.

To assist the IMF in evaluating the publication policy, reader comments are invited and may be sent by e-mail to publicationpolicy@imf.org.

Copies of this report are available to the public from

International Monetary Fund • Publication Services

$70019^{\text {th }}$ Street, N.W. • Washington, D.C. 20431

Telephone: (202) 623-7430 • Telefax: (202) 623-7201

E-mail: publications@imf.org • Internet: http://www.imf.org

Price: $\$ 15.00$ a copy

International Monetary Fund

Washington, D.C. 
This page intentionally left blank

(C) International Monetary Fund. Not for Redistribution 


\section{THE TENTH PLAN \\ (Poverty Reduction Strategy Paper) \\ 2002-2007}

\section{Summary}

His Majesty's Government National Planning Commission

Kathmandu, Nepal

May 2003 


\section{Foreword}

The Tenth Plan is government's main medium-term strategic planning document and this summary provides a sharply focused strategies of the Plan for poverty alleviation. The Plan has formulated a poverty reduction strategy based on four pillars -broad based high and sustainable growth, social sector development with emphasis on human development, targeted programs with emphasis on social inclusion and improved governance.

The Plan is an outcome of extended nation-wide consultation participated in by a large number of people from all walks of life. The participatory approach adopted in preparing the Plan, inclusion of the logical framework, identification of prioritized programs and projects and identification of monitorable indicators are some of the important features. Besides, the simultaneous peparation of the Medium Term Expenditure Framework has provided an effective mechanism to link the Plan with the annual budget.

The Plan has emphasized on effective implementation and monitoring mechanism. Some of the mechanisms formulated include (i) preparation of annual poverty monitoring report (ii) initiation of special monitoring mechanism for social inclusion and regional development

(iii) development and monitoring of four monthly intermediate output indicators of major public expenditure components (iv) initiation of immediate action plan-- a list of critical policies for quick implementation (v) designing of a policy matrix to link priority activities of the plan with output indicators and (iv) decentralization. The implementation modalities initiated are expected to succeed particularly in delivering basic services, enhancing the quality of life of the poor people and promoting economic and social inclusion of deprived communities and regions.

We would like to express our gratitude to parliamentarians, ministers, educationists, experts, politicians, members of civil society, and bureaucrats, who have been directly or indirectly involved in the process of formulating the plan. We are also grateful to the donor communities for providing cooperation and support in the process of preparing and finalizing this document.

July 2003

Shankar P Sharma

Vice-chairman

National Planning Commission 


\section{National Planning Commission}

Rt. Hon'ble Prime Minister Mr. Surya Bahadur Thapa

Dr. Shankar Prasad Sharma

Dr. Yubaraj Khatiwada

Chief Secretary Dr. Bimal Prasad Koirala

Secretary of Finance Mr. Bhanu Prasad Acharya

Mr. Bhoj Raj Ghimire
Chairman

Vice-chairman

Member

Ex-officio Member

Ex-officio Member

Member Secretary 
CInternational Monetary Fund. Not for Redistribution 


\section{Acronyms}

ADDCN Association of District Development Committees of Nepal

AGO Auditor General's Office

AIC Agriculture Input Corporation

APP Agriculture Perspective Plan

BOOT Build Own and Operate Transfer

BOT Build Operate and Transport

CAAN Civil Aviation Authority of Nepal

CBS Central Bureau of Statistics

CFAA Country Financial Administration Assessment

CIAA Commission of Investigation of Abuse of Authority

CTEVT Center for Technical Education \& Vocational Training

DC Dalit Commission

DDCs District Development Committees

DDWSS District Development Water Supply schedule

DIMC Decentralization Implementation Monitoring Committee

DNPWC Department of National Parks \& Wildlife Conservation

DOA Department of Agriculture

DOC Department of Commerce

DOE Department of Education

DOH Department of Health

DOHS Department of Health Service

DOI Department of Industry

DOL Department of Labour

DOLIDAR Department of Local Infrastructure Development and Agriculture Road

DOR Department of Road

DOSCI Department of Small and Cottage Industries

DPS Department of Postal Services

DWSS Department of Water Supply \& Sanitation

ERP Economic Reform Program

FCGO Financial Comptroller General's Office

FPAN Family Planning Association of Nepal

GDP Gross Domestic Product

HDI Human Development Indicators

HHS Household Survey

HRC Human Rights Commission

IAP Immediate Action Plan

ICOR Incremental Capital Output Ratio

INGOs International Non-government Organizations 


\begin{tabular}{|c|c|}
\hline IPRSP & Interim Poverty Reduction Strategy Paper \\
\hline ISDP & Internal Security and Development Programmes \\
\hline JEMC & Janak Education Material Center \\
\hline LBFC & Local Bodies Finance Commission \\
\hline LM & Line Ministry \\
\hline LSGA & Local Self Government Act \\
\hline M1 & Narrows Money \\
\hline M2 & Broad Money \\
\hline $\mathrm{MCH}$ & Maternity Child Health \\
\hline MDAC & Ministerial Development Action Committee \\
\hline MIS & Management Information System \\
\hline MLD & Ministry of Local Development \\
\hline MOAC & Ministry of Agriculture and Cooperatives \\
\hline MOCTCA & Ministry of Culture, Tourism and Civil Aviation \\
\hline MOES & Ministry of Education and Sports \\
\hline MOF & Ministry of Finance \\
\hline MOGA & Ministry of General Administrative \\
\hline $\mathrm{MOH}$ & Ministry of Health \\
\hline MOICS & Ministry of Industry, Commerce \& Supplies \\
\hline MOLJ & Ministry of Law and Justice \\
\hline MOLTM & Ministry of Labour and Transport Management \\
\hline MOPPW & Ministry of Physical Planning and Works \\
\hline MOST & Ministry of Science and Technology \\
\hline MOWR & Ministry of Water Resources \\
\hline MOWSW & Ministry of Women and Social Welfare \\
\hline MTEF & Medium Term Expenditure Framework \\
\hline NARC & Nepal Agriculture Research Council \\
\hline NDAC & National Development Action Committee \\
\hline NDC & National Development Council \\
\hline NEA & Nepal Electricity Authority \\
\hline NER & National/Ecological/Regional \\
\hline NERG & NationalEcological/Regional/Gender \\
\hline NERGS & National/Ecological/Regional/Gender/Social Groups \\
\hline NERS & National/Ecological/Regional/Social Groups \\
\hline NERUGS & National/Ecological/Regional/Urban/Gender/Social Groups \\
\hline NERUR & National/Ecological/Regional/Urban/Rural \\
\hline NERUS & NationalEcological/Regional/Urban/Social Groups \\
\hline $\mathrm{NFC}$ & Nepal Food Corporation \\
\hline NGOs & Non-government Organizations \\
\hline NHRC & National Human Rights Organization \\
\hline NLSS & Nepal Living Standards Survey \\
\hline NOC & Nepal Oil Corporation \\
\hline NPC & National Planning Commission \\
\hline
\end{tabular}




$\begin{array}{ll}\text { NRB } & \text { Nepal Rastra Bank } \\ \text { NTB } & \text { Nepal Tourism Board } \\ \text { NTC } & \text { Nepal Telecommunication Corporation } \\ \text { NWSSC } & \text { Nepal Water Supply and Sanitation Corporation } \\ \text { PAC } & \text { Public Account Committee } \\ \text { PAF } & \text { Poverty Alleviation Fund } \\ \text { PERC } & \text { Public Expenditure Review Committee } \\ \text { PIUs } & \text { Project Implementation Units } \\ \text { PRSP } & \text { Poverty Reduction Strategy Paper } \\ \text { PSC } & \text { Public Service Commission } \\ \text { RDBs } & \text { Rural Development Banks } \\ \text { RNAC } & \text { Royal Nepal Airlines Corporation } \\ \text { SAFTA } & \text { South Asian Free Trade Arrangement } \\ \text { SAPTA } & \text { South Asian Preferential Trading Arrangement } \\ \text { SMEs } & \text { Small and Medium Enterprises } \\ \text { SOE } & \text { Statement of Expenditures } \\ \text { TCA } & \text { Telecommunication Authority } \\ \text { TPC } & \text { Trade Promotion Center } \\ \text { UNDP } & \text { United Nations Development Program } \\ \text { VAT } & \text { Value Added Tax } \\ \text { VDC } & \text { Village Development Committees } \\ \text { WTO } & \text { World Trade Organization } \\ \text { WUA } & \text { Water User's Association }\end{array}$




\section{Content}

1. Introduction-The Socio -Political and Economic Context 1 The Tenth Plan's Challenge 2

The Organization of the Summary Paper $\quad \underline{3}$

2. The Tenth Plan Preparation Process $\underline{\underline{5}}$

Traditional Planning Process $\underline{5}$

The Tenth Plan Preparation $\quad \underline{5}$

3. Review of Past Development Efforts $\underline{9}$

Introduction $\underline{9}$

Economic Reforms in the Early Nineties $\quad \underline{9}$

The Ninth Plan $\quad \underline{10}$

Growth Performance $\quad \underline{11}$

Progress in Poverty Reduction and Human Development

Physical Infrastructure $\quad \underline{12}$

Macroeconomic Performance $\quad \underline{13}$

Progress in Policy Reforms $\quad \underline{17}$

Lessons from Past Experience $\quad \underline{21}$

4. The Poverty Situation - Its Key Dimensions And Determinants $\underline{23}$

Introduction

Recent Poverty Trends $\quad \underline{23}$

Current Poverty Situation and Its Characteristics $\quad \underline{24}$

Present Social Disorder and Its Implications

Conclusion $\quad \underline{35}$

5. The Tenth Plan-Goals, Targets and Strategies $\underline{37}$

Introduction $\underline{37}$

Key Goals and Targets $\quad \underline{39}$

The Tenth Plan's Poverty Reduction Strategy $\quad \underline{40}$

Macroeconomic Stability $\quad \underline{42}$

Structural Reform Agenda $\quad \underline{43}$

Broad-Based Economic Growth

Social Sector Development (including Human Development)

Social Inclusion and Targeted Programs $\quad \underline{56}$

Good Governance $\quad \underline{60}$

Improving Financial Management and Accountability $\underline{61}$

Decentralization $\quad \underline{63}$

6. Financing The Tenth Plan $\underline{64}$ 
Introduction $\quad \underline{64}$

Macro-economic Framework $\underline{65}$

The Normal Case $\quad \underline{66}$

The Alternative Case $\quad \underline{70}$

Medium Term Expenditure Framework (MTEF)

7. Implementation Modalities $\quad \underline{77}$

Introduction

Monitoring and Evaluation Arrangements $\quad \underline{80}$

Conclusion $\quad \underline{84}$

Annex 1 Policy Matrix $\quad \underline{88}$

Annex 2 Immediate Action Plan $\underline{117}$

Annex 3 Macro-Economic Indicators $\quad \underline{118}$ 


\section{List of Tables}

Table 1: The Ninth Plan - GDP and Sectoral Growth Rates ....................................................11

Table 2: Ninth Plan-Key Poverty and Human Development Targets and Achievements .....12

Table 3: Vital Physical Infrastructure - Targets and Achievements ...........................................13

Table 4: Ninth Plan -Macroeconomic Performance, 1996/97-2001/02 ………..........................14

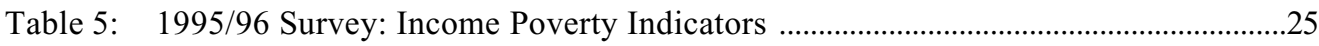

Table 6: Human Development Indicators, 1996 and 2000* _....................................................26

Table 7: Gender Disparities in Key Human Development Indicators, 1996 and 2000_..........28

Table 8: Human Development by Caste and Ethnicity, 1996 …………………………….........29

Table 9: Household Distribution by Their Access to Agriculture Inputs, 1996.........................32

Table 10: Sources of Income of Rural Households, 1996 ………………………….......................32

Table 11: Indicative Targets of the Tenth Plan ............................................................................39

Table 12: Investment requirements of The Tenth Plan (Normal Case) ........................................68

Table 13: Sectoral Allocation of Development Expenditure- Normal Case ................................68

Table 14: The Tenth Plan Macroeconomic Projections- Normal Case Scenario ........................69

Table 15: The Tenth Plan-Macroeconomic Projections-Alternative Scenario ........................72

Table 16: MTEF - Budget Allocations for Priority Sectors, 2002/03-2004/05 ............................74

Table 17: Major Poverty Related Development Expenses ...........................................................

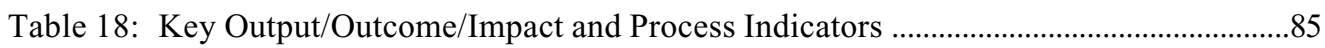




\section{Introduction-The Socio-Political and Economic Context}

1 The overriding objective of development efforts in Nepal is poverty alleviation. In spite of noticeable progress achieved over the past decade, there is still widespread poverty. The Tenth Plan represents a renewed commitment by His Majesty's Government of Nepal to this all-important task. Its sole objective is to achieve a remarkable and sustainable reduction in the poverty level in Nepal from $38 \%$ of the population at the beginning of the Plan period to $30 \%$ by the end of the Tenth Plan, and to further reduce the poverty ratio to $10 \%$ in about fifteen years' time.

2 The reduction of poverty to $30 \%$ by the end of the Tenth Plan is a daunting task by itself. It has been made even more challenging by several recent developments in the country. Among these, the following are particularly important:

i) First, poverty in Nepal has persisted for decades, and it is recognized as a deep-seated and complex phenomenon, for which there are no quick and easy solutions. What has changed particularly over the last decade is the socio-political situation in the country. Following the Democracy Movement of 1990, peoples' expectations have risen; but the economy and government actions, although successful in many areas, have largely failed to fulfill the expectations of poverty alleviation. Significant progress that was made especially in the early nineties was also not sustained. Thus, wide disparities persist in regard to income distribution, social and economic infrastructure and employment opportunities, particularly for an expanding young population. The main reasons for these less than expected outcomes with regard to poverty alleviation are discussed in section IV.

ii) Second, Nepal is currently experiencing complex socio-political situation, which has intensified over the past few years. It has created considerable insecurity in many parts of the country, made difficult for the government agencies and development partners to carry out development activities in such areas. The situation also preempted a significant and rising share of the government's limited financial and administrative resources for maintaining peace and security in the country. The costs so far in terms of human lives, destruction of property and infrastructure, increased security expenditures and foregone development and economic activities have been considerable. There are many underlying causes for the present situation, some of which are political and ideological in nature. Nevertheless, there is little doubt that 
among others, the underlying causes include poverty and its manifestations, (in terms of regional, gender, ethnic and caste-related inequalities), as well as poor governance, and the failure to deliver adequate and essential social services and infrastructure to rural communities and marginalized groups. To bring about a lasting solution to the present problem, the nexus of poverty, poor governance, and marginalization need to be carefully and urgently addressed. A "Ceasefire" in late January and the subsequent resumption of peace negotiations now provide considerable hope for resolution of these tensions. However, any serious disruption of the peace process will destabilize the fiscal situation, severely erode the country's capacity to carry out development work and pose a major threat to social and political stability in the country. Nepal has little time to lose.

iii) Third, the Tenth Plan's campaign against poverty reduction is being launched against the backdrop of a fragile economy. After a decade of fairly robust growth, Nepal's real GDP growth became negative (-0.6\%) in 2001/02, for the first time in nineteen years. In part, this has been due to: (a) The global recession and the after-effects of September 11 (2001) events. (b) More importantly, the present turmoil has been an even bigger destabilizing factor, through increased insecurity, destruction of physical assets/infrastructure, bandhs (strikes) and loss of working hours and loss of business confidence, among others. Together, these developments have adversely affected activity levels in virtually every sector of the economy-industry, trade, construction, tourism, exports, services etc,- as well as savings and investment levels and overall economic growth. In particular, the effects of the disorder on the government budget have been disastrous, (due to slowing revenues and a sharp rise in security-related expenditures) at a time when substantially more (domestic and external) resources are needed to vigorously implement the development/poverty reduction agenda.

\section{The Tenth Plan's Challenge}

3 Nepal is caught up in a vicious cycle of poverty and economic stagnation at present. Poverty is providing a fertile ground for the disorder, which in turn is pushing the economy into a downward spiral, undermining its capacity to vigorously pursue the poverty reduction agenda. The challenge for the Tenth Plan is therefore, to break out of this vicious cycle by designing and forcefully implementing an appropriate strategy to reduce poverty and to eliminate the root causes of the disorder.

4 Notwithstanding these constraints, His Majesty's Government stands ready to take on the challenge of poverty reduction. The Tenth Plan recognizes that, in view of the existing turmoil, ways and means must be found quickly, despite budget constraints, to effectively implement the development agenda aimed at addressing the underlying causes of poverty and regaining public support and confidence, while concurrently pursuing possible approaches to sustain peace and restore law and order. 
5 In this context, as discussed below, the Tenth Plan has formulated an appropriate poverty reduction strategy based on four pillars - to promote faster and pro-poor economic growth, equitable access to social and economic infrastructure and resources for the poor and marginalized groups, social inclusion and targeted programs and improved governance. The Plan emphasizes effective implementation to ensure better delivery of outputs and services to rural communities. To do so, within a tight budget constraint, it has adopted cross-cutting approaches-limiting the role of the public sector and prioritizing public interventions; enhancing the participation of the private sector, NGOs, INGOs, and community-based organizations in development activities; developing alternative delivery mechanisms, particularly through greater devolution of functions, responsibilities and resources to local bodies; and greater community involvement in the formulation and management of key programs aimed at meeting the needs of the rural population. The Plan also emphasizes good governance to minimize leakages and irregularities, and ensure greater accountability through better monitoring mechanisms. To bring about the necessary changes in these areas, economic reforms in a broad range of areas and sectors have been formulated, together with a timebound plan of critical immediate and medium term actions for their implementation. To ensure public acceptance of and support for it, the Tenth Plan has been prepared through a highly participatory and consultative process.

6 The Tenth Plan provides a comprehensive framework, supported by detailed sectoral programs, to carry out this strategy over the next five years. Given the richness of detail of the Plan — over 600 pages in length — a shorter, more sharply focused summary — the PRSP — has been prepared. The latter, apart from its usefulness to domestic audiences, can be readily used by Nepal's development partners as the basis for supporting the Tenth Plan's implementation.

\section{The Organization of the Summary Paper}

7 The Summary Paper begins with a brief discussion of the Tenth Plan's preparation process and highlights its key elements in this regard - country ownership, participatory preparation and the dissemination and feedback process involving virtually all key segments of the Nepali public (Section II). Section III reviews the development efforts undertaken in the recent past, particularly through the Ninth Plan (1997/98-2001/02), and the key lessons learned from this experience. The dimensions of Nepal's poverty problem, its manifestations and determinants, and its linkages with the ongoing social disorder are then discussed in Section IV. Section V outlines the poverty reduction strategy of the Tenth Plan, its key sectoral programs and activities, and complementary policies and reforms, which are deemed necessary to achieve them. The macroeconomic frameworks within which the poverty reduction strategy, programs and activities will have to be implemented, and how these programs will be adjusted from time to time, given the inherent uncertainties of predicting resources, are then discussed in Section VI. That section also briefly discusses how the government intends to cope with the inherent downside risks which are difficult to predict at this stage, and how it will protect priority programs and activities in order to maximize the 
poverty-reducing impact of the Plan. The implementation, monitoring and evaluation modalities that are necessary to ensure effective implementation of the Plan, and key tools and instruments, which will be used in this regard, are discussed in Section VII. The policy matrix of the Plan linking the overall poverty reduction strategy with sectoral programs and activities and the Government's Plan of key Immediate Actions (IAP) are shown as Annex 1 and 2. The macroeconomic framework with projected indicators of the Tenth Plan has been presented in Annex 3. 


\section{The Tenth Plan Preparation Process}

\section{Traditional Planning Process}

8 Nepal has a well-established process for preparing periodic development plans, having prepared nine such plans earlier. Typically, the preparation of the new plan starts with the mid-term review of the ongoing plan, which serves as a base for the Approach Paper for the new plan. The Approach Paper, which provides broad guidelines and targets and an indicative resource framework for the new plan, is approved by the National Development Council (NDC). The plan is then prepared and finalized by the beginning of the new plan period, after discussion and approval first by the National Planning Commission and then by the Cabinet. Traditionally, the plan preparation is led by the National Planning Commission (NPC), which in consultation with the Ministry of Finance sets out the overall resource framework for the plan, sectoral allocations and broad guidelines for the preparation of sectoral programs; while the line ministries themselves are formally responsible for the preparation of sectoral programs. Although the plan typically focuses on the next five years, the Ninth Plan (1996/97-2002/03) also included for the first time a long-term (twenty year) perspective.

9 Though well established, this process has been subject to numerous criticisms: (i) Typically, plan preparation has been a "top down" process, with little involvement of local governments, beneficiaries, civil society or development partners. (ii) There was little participation of, and feedback from, the key stakeholders; and wider societal ownership of the plans was lacking. (iii) While the plans contained overall development and broad sectoral strategies, they were not often well integrated. (iv) They were ambitious and tried to do too much, without adequately recognizing resource or implementation capacity constraints. They also did not adequately focus on implementation, monitoring or evaluation mechanisms. (v) In addition, the plans were not anchored to a sound fiscal framework; and they did not have any built-in mechanisms to adjust programs and activities from time to time, as needed. As a result, there was no clear linkage between resource allocations in the annual budgets and plan activities and targets. Consequently, they were often viewed as unrealistic from the beginning and their usefulness as a development tool for poverty reduction was limited.

\section{The Tenth Plan Preparation}

10 The Tenth Plan represents a major effort to address these shortcomings. Its distinguishing features include the following: (i) It has adopted a participatory and relatively more "bottom up" approach; (ii) It is the product of an extended nation-wide consultation process over two years; and the feedback from the such consultations has been interactively utilized for finalizing the plan's objectives, targets, policies; and programs; (iii) It focuses strategically on 
the overall poverty reduction strategy and seeks to prioritize sectoral programs and activities accordingly; (iv) It emphasizes results and effective implementation and monitoring mechanisms; (v) It incorporates a credible macroeconomic framework by utilizing alternative scenarios; (vi) The latter is supplemented by a rolling Medium Term Expenditure Framework (MTEF), which will be updated every year, and provides for the first time in Nepal, an effective mechanism to link the annual budget with the Five Year Plan and to make periodic adjustments in programs as needed; and (vii) Finally, as the product of a highly participatory process, it can claim a far higher degree of national ownership and acceptance than earlier plans.

11 Of particular importance, the Tenth Plan's formulation benefited from the preparation of additional, closely related, documents-Interim Poverty Reduction Strategy Paper (IPRSP) and the MTEF. When the preparation of the Tenth Plan was initiated in mid 2001, the government decided to prepare an IPRSP, which would be an important input into the Approach Paper for the Tenth Plan; and that the Tenth Plan itself would be the government's full Poverty Reduction Strategy Paper (PRSP). A Steering Committee was set up under the Vice-Chairman, NPC to provide strategic leadership, while technical committees headed by the Secretaries of the line ministries coordinated the formulation of sector strategies and programs, leading to strong inter-agency participation and ownership. The MTEF and the Tenth Plan were prepared concurrently by the same line ministry teams, ensuring close coordination.

12 An extensive consultation process was initiated at various levels to discuss, and solicit feedback on, the ideas and recommendations presented in the drafts of the various papersIPRSP, Approach Paper, MTEF and the draft Tenth Plan itself.

13 At the time of IPRSP preparation, five consultations were held including two exclusively with women's groups. Three public consultations held in the months of August and September 2000 in eastern, central and western Nepal included representatives from all 75 District Development Committees (DDCs), mainly their Chairpersons or Deputy Chairpersons, representatives from socially backward classes, mayors from municipalities, academia from campuses and schools, representatives from NGOs and CBOs, representatives from major political parties and the private sector, women, and ethnic minorities, and participants from remote areas. About $25 \%$ of the participants in these three consultations were women. The other two consultations exclusively with women's groups - one in east Nepal and the other in west Nepal - were held in the months of September/October 2000. Participants were drawn from members of DDCs/VDCs and municipalities and representatives from NGOs, There were also significant representations from backward communities, ethnic minorities including dalits, and remote areas. It is worth noting that women participated actively in both mixed and exclusive women's group discussions, with forceful opinions provided on different social and economic issues that need to be dealt with at the national and local levels. In all these consultations, brief papers were presented, followed by group discussions and additional feedback provided by participants by filling-up a questionnaire. There were 112 participants in the three mixed groups and 94 participants in the women only groups. 
14 These consultations were characterized by frank discussions on broad features and causes of poverty, strategies for poverty reduction, reasons for poor implementation, and measures for ensuring gender equality. Broadly, they emphasized empowering and strengthening local bodies, empowering women, modernizing and commercializing agriculture, promoting basic and technical education, providing basic health and drinking water facilities, reducing corruption, and the need for an efficient and effective bureaucracy. Participants from west Nepal in particular emphasized the need for infrastructure development in their region.

15 Similar consultations were also organized subsequently to solicit opinions from all concerned when the IPRSP was developed as the draft Approach Paper of the Tenth Plan. Thus, in June 2001, five regional consultations were held. Participants numbering between 60 to 80 in each of these consultations in five Development Regions included all Chairpersons/Deputy Vice Chairpersons of DDCs, representatives from ethnic minorities, backward communities and areas, government officials, representatives from academia and private sector, NGOs and CBOs. In view of the need for preparing periodic district plans, and to identify ways to establish linkages between such district plans and the national plan, another discussion was organized in October 2001 in collaboration with the Association of District Development Committees of Nepal with chairpersons and deputy vice chairpersons from all 75 districts of the country. A separate consultative meeting was also organized for the parliamentarians of the country.

16 Major recommendations from these consultations included the need for prioritization of development programs, need for giving greater emphasis to mid and far west regions in development efforts, modernizing agriculture, more effective coordination of the roles of the government, private sector and NGOs, promoting eco-tourism, and the development of basic health facilities and drinking water in rural areas etc.

17 Based on all these consultations, the draft Approach Paper was finalized, and submitted to the National Development Council (NDC) for its comments and approval. The meeting of this national body was held in January 2002. The NDC is composed of all the ministers, representatives from all political parties, chairpersons of different committees of House of Representatives, Secretaries of line ministries, Vice Chancellors, representatives from private sector and academia, ethnic minorities, labor unions, women, NGOs and CBOs at the national level. The Council approved the Approach Paper with some revisions, emphasizing in particular the prioritization of development programs, and effective monitoring of progress in program implementation and poverty reduction.

18 In addition to the above, consultations held specifically in the context of the PRSP/Tenth Plan preparation. The PRSP/Plan also benefited from a large number of consultations organized from time to time by various agencies (such as the ADDCN, various HMG line ministries, donor agencies, NGOs and CBOs) for developing key sectoral programs, thematic chapters and background papers. For example, in formulating the Local Self Government Act (LSGA), the Agriculture Perspective Plan (APP), Water Resource Strategy, Financial sector reforms, Long Term Health Plan and programs for decentralization of primary education and primary health centers, among others, extensive public discussions have been held at national 
and regional levels. These have helped to evolve a broad consensus and wide support for the poverty reduction strategy and structural reforms incorporated in the PRSP/Tenth Plan. While the conflict may have constrained the consultation process in some parts of the western and far-western regions at that time, HMG intends to expand the future consultation process to include all key stakeholders in these areas as an ongoing process.

19 As noted, the Tenth Plan incorporates detailed alternative macroeconomic scenarios, which is a significant departure from Nepal's traditional plan preparation process. It recognizes the need for a more realistic and credible framework for guiding resource allocation decisions in the current environment of social disorder and a fragile economy. It is also supported by a rolling MTEF, which would be updated and revised annually with strong monitoring mechanism. The MTEF represents the first serious effort to prioritize the public expenditure program in Nepal; and provides, in a situation of unpredictable resource flows, an in-built mechanism to ensure that limited resources would be channeled to the Tenth Plan's highest priority sectors and activities through the annual budget. The goal of poverty reduction will be evaluated by monitoring the track record of implementation as well as the output indicators. The progress of these activities will help in achieving the Millennium Development Goals. In addition, the Tenth Plan is supported by two other key initiatives: (a) The Economic Reform Program (ERP) and (b) The Immediate Action Plan (IAP). The ERP represents the Government's efforts to revitalize a flagging economy and to get the Tenth Plan off the ground. And closely related to it, the IAP reflects the emphasis, which the Government places on the quick and effective implementation of the Plan. By identifying critical policies, programs and activities in key areas, and a specific timetable for their implementation, the IAP provides a monitorable checklist for the Plan's implementation, which would be updated on an annual basis as an effective operational tool. 


\section{Review of Past \\ Development Efforts}

\section{Introduction}

20 Though poverty has always been an overriding concern of development efforts in Nepal, it was explicitly stated as an objective only from the Seventh Plan (1985/86-1989/90) onwards. The latter, however, was the first attempt to formulate a separate plan with a longterm poverty alleviation perspective. Towards the end of the Plan period, it was derailed by the Trade and Transit crisis and the resulting economic dislocation in the late eighties. The transition to democracy in 1990, by raising popular expectations and aspirations, gave a new impetus to poverty reduction. The development plans which were formulated subsequentlythe Eighth Plan (1992/93-1996/97) and the Ninth Plan (1997/98-2001/02) — specifically had poverty reduction as their main objective. The Ninth Plan also established long-term targets and development indicators for all sectors based on their potential for alleviating poverty.

\section{Economic Reforms in the Early Nineties}

21 To reduce poverty by accelerating economic growth and expanding employment opportunities, the government in the early nineties initiated an extensive economic reform agenda. Reforms were introduced, for example, to liberalize trade, investment and foreign exchange regimes, unify the exchange rate, rationalize the tariff structure and the tax system, promote exports, strengthen financial and capital markets, foster private sector development, and strengthen public expenditure management.

22 These efforts yielded impressive results early on. They helped to transform the Nepalese economy from a highly regulated to a more open, market-oriented economy; create an energetic private sector and expand its role in such areas as manufacturing, industry, exports, education, health, air transport, finance, and power; and $\mathrm{b}$ improve the country's macroeconomic fundamentals. In particular, it helped to accelerate economic growth in nonagriculture sector (trade, transport, tourism, manufacturing and services); an annual rate of $7.5 \%$, in real terms, in the first half of the nineties; and the share of non-agriculture rose from $51 \%$ to $59 \%$ of overall GDP in that period. As noted below, this helped to create increased employment and income-earning opportunities in urban areas, and kept urban poverty at low levels. According to the 1996 Nepal Living Standards Survey, urban poverty was estimated at $23 \%$, and in the urban Kathmandu Valley at only 4\%, compared to overall national poverty incidence of $42 \%$ of the population. However, these early reforms did not touch the important agricultural sector in a significant way; and consequently had little impact on rural poverty. 


\section{The Ninth Plan}

23 The Ninth Plan's stated goal was to reduce (income) poverty from 42 percent to 32 percent of the population by the end of the Plan period, and to 10 percent by 2016/17. Several other indicators of human poverty — such as illiteracy, infant mortality rate, maternal morality rate, average life expectancy at birth - were also identified and targets set for them (Table 2). To attain this goal, the Ninth Plan postulated a three-pronged strategy: (i) Achieving a high, sustainable and broad-based economic growth rate (a minimum of $6 \%$ p.a. GDP) through liberal and market-oriented policies; (ii) Developing social and rural infrastructure; and (iii) Introducing targeted programs for those communities and areas left behind by the mainstream development process. The Plan also sought to bring down the unemployment rate to $4 \%$ and underemployment to $35 \%$ by the end of the Plan period. The Ninth Plan accorded high priority to the neglected agricultural sector; and its centerpiece - the Agriculture Perspective Plan (APP), formulated in 1995 with a long-term vision - sought to raise agricultural growth rate to 4.0 percent for the Plan period and to $4.9 \%$ over the next 15 years. The APP envisaged increasing cereal and cash crop production in the Terai and livestock products and other high value crops in the hills, through increased use of modern inputs, irrigation, improved research and extension services, rural roads and marketing network. In the non-agricultural sector, emphasis was placed in developing tourism, labour-intensive manufacturing, hydropower and the transport and communications network.

24 The Ninth Plan's implementation, (particularly towards its end), was severely disrupted by the adverse domestic and external developments noted in para 2 above. The resulting dislocations in terms of slowdown in economic growth, diversion of resources for security needs, reduced availability of resources for Plan activities and the difficultie s in carrying out development work in the affected areas severely constrained plan implementation. These apart, as discussed below, there were other important factors, which hampered the Plan's performance.

25 By and large, the Ninth Plan's performance has be en mixed. Given the ambitious nature of the Plan, achievements generally fell short of targets. Nevertheless, as outlined below, significant progress was made in some important areas. For example, some key human development indicators showed notable improvement, while some progress was also made early on in reducing poverty. Key macroeconomic indicators, such as the balance of payments, monetary growth, and control of inflation indicate good progress, while some actions have been taken in implementing policy reforms in key sectors, such as education, health, power etc. which hold considerable promise for the future. Nevertheless, progress in a number of areas has been below expectations, for example in reducing poverty and inequality, in fiscal management, in improving the quality and delivery of essential social services and rural infrastructure, and the effective implementation of announced policies and programs, all of which were critical to the attainment of the primary goal of poverty reduction. 


\section{Growth Performance}

26 Compared to a Plan target of $6.0 \%$ p.a, overall GDP growth averaged only $3.6 \%$ p.a. (Table 1). Agriculture grew at the rate of only $3.3 \%$ p.a, and non-agricultural sector at $3.9 \%$ p.a, compared to a Plan target of $7.3 \%$. Allowing for population growth, (estimated at $2.25 \%$ p.a), per capita income grew at $1.3 \%$ p.a, well below the $3.7 \%$ rate envisaged in the plan as being necessary to make a significant dent on poverty.

Table 1: The Ninth Plan-GDP and Sectoral Growth Rates (In percent per annum)

\begin{tabular}{lcc}
\hline & NINTH PLAN TARGET & ACHIEVEMENT \\
\hline GDP (at factor cost) & 6.0 & 3.6 \\
Agriculture sector & 4.0 & 3.3 \\
Non-agriculture sector & 7.3 & 3.9 \\
- Industry, geology, and mines & 9.1 & 2.0 \\
- Electricity, gas and water & 10.4 & 6.1 \\
- Construction & 5.9 & 4.1 \\
- Trade, hotels and restaurants & 7.4 & 1.4 \\
- Transport and communication & 8.7 & 6.0 \\
- Finance and real Estate & 5.8 & 4.0 \\
- Social services & 7.0 & 6.6 \\
GDP (at market prices) & 6.5 & 3.6 \\
\hline
\end{tabular}

27 Weather-related fluctuations in output in the first and last years of the Plan dampened agricultural as well as overall economic growth. Agricultural production was also affected by ongoing social tension, as a result of insecurities that have been created and disruptions in the supply of key inputs, labour, and marketing and cropping arrangements. Equally important has been the failure to follow through with the effective implementation of the APP by providing adequate support for its key elements (see below).

28 Growth in the non-agriculture sector was initially good; but it declined sharply in the last two years of the Plan due to the deteriorating industrial environment. Initially, Nepal's exports as well as manufacturing activity had grown strongly in the first three years of the Plan. But, subsequently the global slowdown and, even more importantly, the deteriorating security situation at home, have adversely affected virtually all the sectors and activities - exports, manufacturing, as well as tourism, commerce, industry, services, construction etc. Investment levels in both agriculture and non-agriculture sectors also declined. Unplanned cuts in public investment/development spending (which is an important source of demand for private sector activities) also affected non-agricultural growth in the last two years.

\section{Progress in Poverty Reduction and Human Development}

29 In the absence of recent national level household data, (the last Nepal Living Standards Survey - NLSS - was carried out in 1996), it is difficult to provide an accurate and up-to-date measure of the Ninth Plan's progress in reducing poverty. Preliminary estimates made in the context of the mid term review of the Ninth Plan suggest that the poverty ratio declined modestly from $42 \%$ at the beginning of the Plan to about $38 \%$ in $2000 / 01$. This is not surprising, given the slow growth of per-capita incomes, especially in rural areas, in view of continued weak agricultural performance. It is also highly likely that since then, given the 
sharp decline (by about 3\%) in per capita income during 2001-02 and the continued disruptions to investment and economic activities caused by the violence, that the poverty situation in rural areas may have deteriorated significantly over the last year.

30 Progress achieved in Human Development as measured by key indicators, though generally less than the Ninth Plan targets, is commendable in many areas. For example, the infant mortality rate had been reduced from 75 per thousand at the beginning of the Plan period to 64 by FY 2002 (Plan target 61.5), maternal mortality rate from 439 per 100,000 to 415 (Plan target 400), and life expectancy rose from 56.1 to 61.9 (Plan target 59.7). Other notable achievements include: lowering the total fertility rate from 4.6 to 4.1 (exceeding the Plan target of 4.2) and the overall population growth rate to 2.25 (i.e. below the plan target of 2.38). Largely reflecting these achievements, Nepal has been recognized as one of the "successes" in terms of its recent progress in moving up the Human Development Indicators Index. However, it should also be noted that the recent gains have been made from a relatively low base; and that Nepal will need to continue to improve further to catch up with other (smaller) South Asian countries. In other areas, progress has been less impressive: for example, in regard to adult literacy, the Plan achievement is only $49.2 \%$ (compared to a target of $70 \%$ ), while the women's literacy rate is still low at $35.6 \%$. Similarly, the net primary school enrolment ratio is $80.4 \%$ (Plan target 90\%) while the percentage of the population supplied with drinking water is only $71.6 \%$ (Plan target was $100 \%$ ). In addition, there also major concerns about the quality and effectiveness of education, health, drinking water and other social services delivered to communities; and major improvements in these areas are necessary in order to improve living standards and quality of life, particularly of rural communities.

Table 2: Ninth Plan— Key Poverty and Human Development Targets and Achievements

\begin{tabular}{lccc}
\hline Objectives & Base Year & \multicolumn{2}{c}{ Ninth Plan } \\
\cline { 3 - 4 } & $\mathbf{1 9 9 6 / 9 7}$ & $\begin{array}{c}\text { Target } \\
\mathbf{2 0 0 1 / 0 2}\end{array}$ & $\begin{array}{c}\text { Achievement } \\
\mathbf{2 0 0 1 / 0 2}\end{array}$ \\
\hline Percentage of Population Below the Poverty Line & & 32.0 & 38.0 \\
Literacy Rate (Age 15+) in percentage & 32.0 & 70.0 & 49.2 \\
Net Primary School Enrollment & 69.4 & 90.0 & 80.4 \\
Infant Mortality Rate (per 1000) & 74.7 & 61.5 & 64.2 \\
Maternal Mortality Rate (per 100,000) & 439.0 & 400.0 & $415.0^{*}$ \\
Total Fertility Rate & 4.58 & 4.2 & 4.1 \\
Population Growth Rate & 2.3 & & 2.25 \\
Average Life Expectancy & 56.1 & 59.7 & 61.9 \\
Drinking Water Supply (population in percentage) & 61 & 100 & 71.6 \\
\hline
\end{tabular}

* As estimated by the National Planning Commission. This figure will be revised when actual data become available.

\section{Physical Infrastructure}

31 Progress in providing essential infrastructure, such as roads, irrigation, telephone and electricity services, to communities has been mixed. In electricity generation, Plan targets were accomplished. Another major achievement has been the effective implementation of a 
framework for the involvement of the private sector in power generation; and a number of projects involving substantial private investment have been either completed, or are under construction. In the road sector, a major achievement has been the active involvement of District and Village Communities in road construction, utilizing development grants from the central government. However, the quality of construction in these projects is weak; and if appropriate measures are not taken to improve quality, there is a danger of increasing environmental problems. Moreover, in the road sector, although the Plan target in terms of KMs of roads constructed has been exceeded, most of these roads are low priority roads. The primary objective of linking district headquarters by roads has not been achieved, as only 4 districts were connected during the Plan period. Also, progress with regard to operation and maintenance of the road system - one of the highest priorities in the sectors - has not been satisfactory. Progress in telecommunications and irrigation sectors have been behind targets.

Table 3: Vital Physical Infrastructure-Targets and Achievements

\begin{tabular}{llcc}
\hline & Units & Target & Achievement \\
\hline Total Roads & Km & 13564 & 15905 \\
Total Irrigation & Thousand hectares & 1198 & 1121.4 \\
Total number of Telephone lines & Thousand & 643.7 & 328 \\
Telephone service & Per thousand population & 25 & 14 \\
Electricity supply capacity & MW & 598 & 584.5 \\
Population benefiting from electricity & Percent & 20 & $40^{*}$ \\
\hline
\end{tabular}

* including $7 \%$ from alternate energy

\section{Macroeconomic Performance}

32 Macroeconomic performance during the Ninth Plan was reasonably good. During most of years of the Plan period, the balance of payments continued to strengthen, and fiscal, monetary and price stability was maintained (Table 4). However, in the last year of the Plan period, weakening global demand and the domestic violence took their toll. Overall GDP growth, exports and government revenue slowed down, putting pressure on the budget and the balance of payments. The macroeconomic situation has continued to deteriorate during 200203 - the first year of the Tenth Plan period (see below). 
Table 4: Ninth Plan -Macroeconomic Performance, 1996/97-2001/02

\begin{tabular}{|c|c|c|c|c|c|c|c|c|c|}
\hline & \multirow{2}{*}{$1996 / 97$} & \multicolumn{5}{|c|}{$\begin{array}{c}\text { Annual Data }- \text { In current Prices } \\
\text { Cumulative Data } \ln 1996 / 97 \text { Prices } \\
\end{array}$} & \multicolumn{3}{|c|}{ Ninth Plan Period } \\
\hline & & $97 / 98$ & $98 / 99$ & $99 / 00$ & $00 / 01$ & $01 / 02$ & $\begin{array}{c}\text { Ninth Plan } \\
\text { Target }\end{array}$ & $\begin{array}{c}\text { Ninth Plan } \\
\text { Achievement }\end{array}$ & Change (\%) \\
\hline $\begin{array}{l}\text { Economic Growth } \\
\text { GDP Growth (real produce price) } \\
\text { Per Capita GDP Growth (Real) p.a. }\end{array}$ & & $\begin{array}{l}2.9 \\
0.6\end{array}$ & $\begin{array}{l}4.5 \\
2.2\end{array}$ & $\begin{array}{l}6.1 \\
3.8\end{array}$ & $\begin{array}{l}4.8 \\
2.5\end{array}$ & $\begin{array}{r}-0.6 \\
-2.9\end{array}$ & $\begin{array}{l}6.0 \\
3.7\end{array}$ & $\begin{array}{l}3.6 \\
1.3\end{array}$ & $\begin{array}{r}-40.0 \\
-65.0\end{array}$ \\
\hline $\begin{array}{l}\text { Investment and Savings (\% of GDP) } \\
\text { Total Investment } \\
\text { Private Investment } \\
\text { National Savings } \\
\text { Domestic Savings }\end{array}$ & $\begin{array}{l}25.3 \\
17.2 \\
16.0 \\
14.0\end{array}$ & $\begin{array}{l}24.8 \\
16.2 \\
16.2 \\
13.8\end{array}$ & $\begin{array}{l}20.5 \\
13.0 \\
17.2 \\
13.6\end{array}$ & $\begin{array}{l}24.1 \\
15.4 \\
18.8 \\
15.0\end{array}$ & $\begin{array}{l}23.8 \\
14.3 \\
19.0 \\
14.7\end{array}$ & $\begin{array}{l}24.4 \\
14.8 \\
17.4 \\
11.6\end{array}$ & $\begin{array}{c}372.71 \mathrm{a} \\
247.55 \mathrm{a} \\
16.4 \\
14.1\end{array}$ & $\begin{array}{c}310.4 a \\
194.3 \mathrm{a} \\
17.8 \\
13.2\end{array}$ & $\begin{array}{r}-16.1 \\
-20.4 \\
+8.5\end{array}$ \\
\hline $\begin{array}{l}\text { Government Finances (\% of GDP) } \\
\text { Government Revenue } \\
\text { Government Expenditure } \\
\text { Development Expenditure } \\
\text { Government Budget Balance } \\
\text { Foreign Aid (Grants and Loans) } \\
\text { Domestic Borrowing }\end{array}$ & $\begin{array}{r}10.8 \\
18.1 \\
9.5 \\
-7.3 \\
5.4 \\
1.9\end{array}$ & $\begin{array}{r}11.0 \\
18.7 \\
9.6 \\
-7.8 \\
5.5 \\
2.2\end{array}$ & $\begin{array}{r}10.9 \\
17.4 \\
8.3 \\
-6.5 \\
4.8 \\
1.8\end{array}$ & $\begin{array}{r}11.3 \\
17.5 \\
8.4 \\
-6.2 \\
4.6 \\
1.5\end{array}$ & $\begin{array}{r}11.9 \\
19.5 \\
9.0 \\
-7.6 \\
4.6 \\
3.0\end{array}$ & $\begin{array}{r}12.0 \\
19.3 \\
7.6 \\
-7.3 \\
4.7 \\
2.6\end{array}$ & $\begin{array}{r}210.84 a \\
337.29 a \\
189.58 a \\
-126.45 a \\
111.55 a \\
14.90 a\end{array}$ & $\begin{array}{r}172.27 a \\
279.49 a \\
130.13 a \\
106.43 a \\
72.42 a \\
24.54 a\end{array}$ & $\begin{array}{l}-18.3 \\
-17.1 \\
-31.4 \\
-15.8 \\
-35.1 \\
+64.6\end{array}$ \\
\hline $\begin{array}{l}\text { Balance of Payments (\% of GDP) } \\
\text { Export Value } \\
\text { Import Value } \\
\text { Current Account Balance Before Grants } \\
\text { Aid disbursements (Net) } \\
\text { Gross Foreign Exchange Reserves b }\end{array}$ & $\begin{array}{r}8.1 \\
33.4 \\
-9.3 \\
6.4 \\
5.5\end{array}$ & $\begin{array}{r}9.1 \\
29.6 \\
-8.6 \\
6.9 \\
7.7\end{array}$ & $\begin{array}{r}10.4 \\
25.6 \\
-3.4 \\
5.9 \\
9.0\end{array}$ & $\begin{array}{r}13.1 \\
28.6 \\
-5.3 \\
5.1 \\
9.2\end{array}$ & $\begin{array}{r}13.6 \\
28.2 \\
-4.8 \\
4.2 \\
9.6\end{array}$ & $\begin{array}{r}11.3 \\
25.4 \\
-7.0 \\
3.4 \\
10.5\end{array}$ & $\begin{array}{l}12.5 \% \text { p.a. } \\
8.6 \% \text { p.a. } \\
111.5 a \\
71 a\end{array}$ & $\begin{array}{l}12.2 \% \text { p.a. } \\
-2.8 \% \text { p.a. } \\
71.9 \mathrm{a} \\
104.3 \mathrm{a}\end{array}$ & $\begin{array}{l}-35.5 \\
+46.9\end{array}$ \\
\hline $\begin{array}{l}\text { Monetary Data (percent p.a) } \\
\text { Broad Money Growth (M2) } \\
\text { Domestic Credit Growth (at current price) } \\
\text { Net Foreign Assets (NFA) (at current price) } \\
\text { Inflation (percentage p.a.) } \\
\text { Consumer Prices }\end{array}$ & $\begin{array}{r}12.0 \\
13.1 \\
6.6\end{array}$ & $\begin{array}{l}21.9 \\
14.8 \\
38.3\end{array}$ & $\begin{array}{l}20.8 \\
16.4 \\
17.0\end{array}$ & $\begin{array}{l}21.8 \\
17.2 \\
23.8\end{array}$ & $\begin{array}{r}15.2 \\
18.6 \\
9.1\end{array}$ & $\begin{array}{r}5.5 \\
9.8 \\
21.6\end{array}$ & $\begin{array}{c}14.8 \\
16.1 \\
9.15\end{array}$ & $\begin{array}{l}20.0 \\
16.6 \\
21.9\end{array}$ & \\
\hline
\end{tabular}

a Rs. billion $\quad b$ In months of imports of goods and services. 
33 Why then were these good indicators not translated into better poverty reduction and development results during the Ninth Plan? A number of factors help explain the Ninth Plan's modest performance. Following a quick review of the main macroeconomic developments in the next few paragraphs, the key cross-cutting issues which hampered the attainment of better development results are discussed briefly below. Reform actions taken by the Government in the last two to three years in response to the deteriorating economic conditions are then discussed. A detailed review of performance in the key sectors is made in the respective sectoral chapters of the Tenth Plan.

34 Saving and Investment. Overall savings performance was reasonably satisfactory. Even though domestic savings fell somewhat, the national savings rate exceeded the Plan target, as remittances by Nepalese working abroad more than trebled during the Plan period. However, the overall investment was significantly $(16 \%)$ below the Plan target. Private investment fell even more and reached only about $80 \%$ of the Ninth Plan target. Although some areas such as hydropower, airlines, health, education and tourism initially attracted substantial private investment, the overall investment climate was affected by weak domestic demand, political instability, insecurities created by the violence, and administrative/ bureaucratic hurdles.

35 Balance of Payments. A major achievement during the first four years of the Plan period was (i) the rapid growth of exports from 8\% of GDP in 1996/97 at the to nearly 14\% of GDP by $2000 / 2001$. Most of this growth reflected increased exports to India - vegetable ghee, jute products and light consumer goods (e.g. toiletries and processed products) - as Nepal was able to take advantage of the 1996 Indo-Nepal Trade and Transit Agreement, under which India granted duty-free access to certain imports from Nepal. Exports to third countries - in particularly garments, pashmina products and carpets - also increased steadily through 2000/2001. However, exports decelerated sharply in 2001/02 due to the global recession, quota restrictions on Nepal's exports to India, and the deteriorating security situation at home. Nepal's exports to third countries now face an uncertain future due to possible effects of the phasing out of the MultiFiber Agreement and loss of cost-competitiveness in part due to domestic disruptions. (ii) The slowdown in the economy, weak public and private investment, and the deteriorating security situation affected Nepal's imports even more. Imports in $1996 / 97$ prices in fact declined at an annual rate of $2.8 \%$, compared a planned increase of $8.6 \%$ p.a.. (iii) With increasing migration abroad of Nepalese workers in recent years, remittances however have risen rapidly.

(iv) Accordingly, the current account deficit (before grants) improved sharply from around 9\% of GDP in 1996/97 to around 3.4 to 8.6\% of GDP over the Ninth Plan period. (v) Even though foreign aid inflows (net of debt repayments) as a percentage of GDP gradually declined from about $6 \%$ to around $4 \%$ over the Plan period, (reflecting the poor implementation of development programs), nevertheless, Nepal's gross foreign exchange holdings rose steadily from about \$ 850 million in 1996/97 to about $\$ 1.7$ billion, (the equivalent of 13 months' imports of goods and services), in 2001/02. However, the sustainability of this position is questionable, given the growing uncertainties for both exports and the demand for Nepali-workers abroad. 
36 Monetary and Price Developments. Based on GDP (at factor cost) growth of 6\% p.a., an inflation rate of $6.5 \%$ p.a. and a monetization rate of $0.5 \%$ p.a., the Ninth Plan targeted Narrow Money (M1) to grow at 13\% p.a. and Broad Money (M2) at $14.8 \%$ annually. During the Ninth Plan, M1 actually grew by $16.5 \%$ p.a. and M2 by nearly $20 \%$ p.a. The faster growth of money supply was mainly due to the rapid increase in foreign exchange reserves, at an annual rate of $21.9 \%$ (compared with a Plan target of $9.1 \%$ p.a.). Domestic credit grew by $16.6 \%$ p.a., more or less in line with Plan targets. Credit to the private sector grew less rapidly than expected, (given the slowdown in private investment and activity levels), offsetting increased public sector borrowing. A sluggish economy, weak domestic demand, and the free flow of goods across the open border helped to keep inflation in check, at $6.3 \%$ p.a. compared to a Plan target of $6.5 \%$ p.a.

37 Fiscal Performance. The Ninth Plan had envisaged an ambitious development program, which it sought to finance through large increases in revenue and external aid, while limiting domestic borrowing in order to maintain macroeconomic stability. While it succeeded in achieving the latter goal, it failed to effectively implement the development program. This was due to a number of factors: (i) Although the revenue/GDP ratio rose by one percentage point from $10.8 \%$ to $12.0 \%$, revenue collections fell $19 \%$ below Plan targets due to the weakening of the economy and imports, deteriorating industrial environment and security situation, and weaknesses in the tax structure. (ii) Regular expenditures rose significantly faster than revenue growth from $8.6 \%$ of GDP to $10.7 \%$, as security expenditures increased sharply, particularly in the last two years. (iii) Consequently, the revenue surplus available for financing the development programs, was sharply reduced from a Plan target of Rs.63 billion in 1996/97 prices, (equivalent to $33 \%$ of planned development expenditures), to only about one-third of that level. (iv) Similarly, disbursements of foreign assistance (grants and loans) fell far short of the Plan target of Rs. 111.5 billion in 1996/97 prices, to Rs. 71.9 billion, i.e. $35 \%$ less than expected. Unrealistic aid targets, counterpart funding shortfalls and poor implementation of donor-assisted programs were the major reasons for this shortfall. All of these factors together created a major shortfall in financing the development budget, which was cut back by two percentage points of GDP over the Plan period. In 1996/97 prices, actual development spending reached only about two thirds of the Ninth Plan target. Thus, many programs/activities were significantly under-funded. Agriculture, irrigation and forestry, which are crucial for the alleviation of rural poverty, were the most severely affected. While the government was generally able to protect the social sectors' share in development spending, the absolute level of spending on these programs still fell far short of Plan targets.

38 Apart from financing shortfalls the Ninth Plan's mixed implementation performance was also due to several other reasons. First, continued political instability from the mid nineties onwards created a poor environment for development. With frequent changes of governments and officials, little attention was given to the effective implementation of the plan and economic reforms, which were critical to attaining its goals. Second, public expenditure management itself was poor. Apart from having ambitious targets, the Plan included too many activities, which were not sufficiently prioritized; and the Plan lacked an effective mechanism (such as a rolling MTEF), to make adjustments as necessary to the resource constraints. Third, there were serious governance problems. Corruption and leakages 
increased, as did the politicization of the civil service, and misallocation. Fourth, service delivery by public sector agencies was weak. Although decentralization of central government functions and responsibilities to local governments and communities was expected to help improve service delivery, this did not happen as rapidly as envisaged. Fifth, monitoring mechanisms to ensure effective implementation of programs/activities and accountability were weak. Sixth, These deficiencies in turn contributed to the unsatisfactory aid disbursement performance. In many areas even committed aid funds could not be utilized because of slow progress of projects and programs.

39 Agriculture - the major focus of the Plan's poverty reduction strategy - is an excellent typology of, the Plan's mixed performance. There were significant improvements within the sector: output growth was satisfactory in the middle three years of the Plan, a noticeable shift to cash crops was taking place, and progress has been made in involving the private sector in input distribution, among others. But, there were also major shortcomings: (i) Agriculture sector, as noted, was severely under-funded. (ii) The key inputs, which are central to the APP strategies were not effectively provided. For example, the groundwater (shallow tubewell) development program was poorly implemented both because of differing Irrigation sector priorities and inconsistent subsidy policies. Similarly, the development of agricultural roads network lagged behind; and the pocket extension and research approach, (which is essential for developing high value horticultural products in suitable locations in the hills), was poorly implemented. (iii) In addition, a major problem was the fragmentation of responsibilities for APP implementation among a number of ministries and departments, and the lack of coordination among them.

40 Private sector development has been an important part of the Ninth Plan Strategy; and the mixed performance of the Plan also reflects the lack of sufficient progress in this area. While political instability, attacks on some business establishments and the implosion of some industrial sub sectors have eroded business confidence; the poor implementation of policies governing the private sector continues to be an important constraint on private investment. A survey of private sector firms carried out in 1999 identified several such impediments including, among others, excessive bureaucratic delays in the provision of government services, lack of clarity of laws and unpredictability in the enforcement of government policies, discretionary implementation of tax laws, excessive documentation requirements, and labour laws that prevent retrenchment of workers (encouraging firms to employ more casual labour). To address this situation a regulatory framework reflecting clarity of laws and predictability of government policies, procedural simplification and reduction in discretionary powers of the authorities will be made the basis for making the private sector vibrant and dynamic.

\section{Progress in Policy Reforms}

41 Although important policy changes were initiated in some areas, by and large, progress in implementing critical reforms was slow, given the continued political uncertainties and weak commitment. The Ninth Plan's progress in this regard is discussed briefly below. 


\section{Governance, Decentralization and Civil Service Reforms}

42 Decentralization was a major thrust of the Ninth Plan. In terms of creating a legal and institutional framework, considerable progress has been made: For example, the Local Self Governance Act (LSGA) was enacted in 1999. This was followed up with more specific recommendations by PERC. A high level Decentralization Implementation Monitoring Committee (DIMC) was set up to oversee its implementation; and it has approved the fiscal decentralization framework. Capacity building programs were undertaken with donor assistance in selected districts to strengthen local bodies; and 45 districts have already prepared periodic district development plans. However, progress in implementing decentralization during the Ninth Plan has been limited by : (i) The overall resource constraint at the national level; (ii) Delays in transferring functions and responsibilities to local governments, and lack of agreement on operational modalities; and (iii) Institutional capacity and accountability considerations, among others.

43 Civil service reform. The proposed measures aimed at: (i) right-sizing the civil service by reducing staff, decentralizing functions and responsibilities, contracting out some peripheral activities to private sector and streamlining government departments and offices; (ii) improving incentive structure through wage reforms and merit-based performance and promotion system; and (iii) improving efficiency and accountability of civil servants. There has been some progress in implementing the reforms. These include restriction of frequent transfer of civil servants, computerized data base in the civil service records department, freezing of more than 12,000 vacant positions, initiation of voluntary retirement scheme and streamlining of government's central organization and establishment of civil service rewards and development of evaluation center. A civil service census has been under preparation and public sector salaries were increased substantially in 2001. In the meantime, the Government has also initiated a long-term and comprehensive Governance Reform Program (GRP) with the objective of making the civil service more results and people oriented. Lack of political commitment and resources, and political changes have hampered effective implementation so far; but renewed commitment to implementation is necessary to improve public sector efficiency.

44 Governance has continued to be a persisting problem resulting to inefficiency in utilization and leakage of public resources. Although Nepal has good public accountability mechanisms including an active Public Accounts Committee (PAC), an independent Auditor General's Office (AGO), a Financial Comptroller General's Office (FCGO) and an independent Commission for Investigation of Abuse of Authority (CIAA), follow up actions to enforce their effectiveness have been limited. Towards the end of the Ninth Plan Period, four anti-corruption legislation were passed by the parliament, which was a significant step towards addressing corrupt practices. In addition, a Judicial Property Probe Commission was also established to address the problem of corruption. Some of the recommendations made by the Public Expenditure Review Commission (PERC) were adopted and the recommendations made by a recent Country Financial Accountability Assessment are being implemented. The CIAA has already initiated actions to combat corruption, which hold considerable promise for the future. 
45 Tax Reform. To improve revenue collection, a major tax reform program was introduced. Its main elements included: (i) The introduction of a Value Added Tax (VAT) and extending its coverage to include many small and medium enterprises; (ii) Improving the import valuation system for customs and requiring payments to be made through banks; (iii) Revising the Income Tax Act in order to consolidate tax laws and simplify payments procedures; (iv) Strengthening the tax administration by amalgamating the Departments of Taxation and VAT into one; and (v) Strengthening anti corruption measures. These measures, however, had little impact in the short term in improving the Ninth Plan's revenue performance. But, they should help improve the elasticity and transparency of the tax system over the medium term.

46 Public Expenditure Reform. Several important steps to strengthen public expenditure management, in the last two years. A Public Expenditure Review Commission (PERC) was set up in 2000/01; and its key recommendations have been subsequently implemented. These included, among others: (i) Streamlining and rationalizing the role of the government, ministries and departments with a view to improving service delivery; transferring functions and responsibilities to local governments, and reducing administrative costs; (ii) Prioritizing the public expenditure program and reducing the number of projects and programs; (iii) Civil service/governance reforms to improve accountability and right-sizing key government ministries and departments; (iv) Strengthening cost control, financial management and internal auditing systems; and (v) Accelerating the decentralization program, especially in education, health and agricultural extension services. PERC also recommended the formulation of Medium Term Expenditure Framework, which was subsequently adopted as the basis of the 2002/03 Budget. The MTEF introduced important reforms, including a more realistic budget framework, a serious prioritization involving a major reduction in the number of projects/ programs, greater focus on implementation and monitoring of expenditures, and linking fund releases to performance. The MTEF is expected to be a regular part of the budgeting and planning process, and now provides an extremely useful mechanism for adjusting the Tenth Plan and the budget to the changing resource situation.

47 Financial Sector. Reforms in this sector have been deemed essential for ensuring solvency of the banking system and for providing adequate and predictable credit flows to sustain a vibrant private sector. However, for a variety of reasons, the implementation of the reforms has been slower than expected. A Financial Sector Strategy Statement was prepared in 2001 and its key recommendations are now being implemented. These include: (i) Strengthening the autonomy and authority of the Nepal Rastra Bank; (ii) Enhancing its capacity for supervision and regulation of commercial banks; (iii) Concurrently, the two major banks (which own nearly $60 \%$ of the banking assets) have been placed under external management in order to address their deep-rooted management and financial problems and possible restructuring needs. However, much remains to be done to complete the reform program.

48 Infrastructure Reforms. During the Ninth Plan, important reforms were initiated to encourage private sector participation in infrastructure, particularly in power, telecommunications, education, health and rural infrastructure. These hold considerable 
promise for the future, even though their impact during the Ninth Plan Period has been uneven among sectors. The more important initiatives include the following:

- Hydropower policy was revised to allow the private sector entry into a full range of power sector activities i.e. generation, transmission and distribution. Considerable private investments have already taken place under the previous policy in a number of power generation projects. But progress has been constrained by the insecurity caused by the civil disorder.

- Telecommunications progress has been made in opening up the sector for private investment. A new Telecommunications Act was enacted to introduce competition in basic, cellular and value added services and the private sector is now involved in their provision. A private operator was also selected to provide basic telecommunications services to 534 rural communities i.e. roughly one-fourth of the rural communities which are under-served. Thus the monopoly which the public sector agency-Nepal Telecommunication Corporation (NTC)_enjoyed has been broken; and a Telecommunications Authority has been set up to oversee the sector.

- In Education and Health, private sector participation in providing alternative educational and health care services increased significantly over the plan period. However, the quality of education services provided particularly through the public sector needs to be enhanced. But the coverage in health sector has significantly increased. To improve service delivery through community participation and management, handover of village level schools and health facilities to communities is being implemented in a phased manner from 2002/03 in selected districts; and as experience is gained, it is expected to be replicated in other areas. In education, the government has also announced new programs to: (i) provide free education upto tenth grade for all girls and for those boys of oppressed, backward and below poverty line; (ii) providing education in mother languages (of communities) upto the primary level: (iii) regulating fees in private schools; (iv) providing scholarship in private/boarding schools to students from "oppressed and backward communities" and (v) the setting up Rural Education Development Fund (finance by a levy of 1.5 percent of the income of private/boarding schools) which would be utilized for funding the education of marginalized communities.

- In Transport, new policies initiated to meet the Ninth Plan's goals included the creation of a separate institutional mechanism (DOLIDAR) for the construction of agriculture roads, dele gation of responsibility and resources to local authorities to construct local roads; and the formulation of a Public Infrastructure Construction and Transfer Policy to promote private sector participation. These initiatives so far are yet to produce the desired results. While there has been considerable progress in terms of road construction by local bodies, considerable technical support and supervision are necessary to ensure appropriate planning and road quality in order to avoid environmental problems.

- In Agriculture and Irrigation, as noted earlier, important policy changes have been introduced to promote private sector participation in input supply and investment, 
with mixed results. Private sector participation in fertilizer and seed distribution has increased significantly with the removal of subsidies (and the monopoly) given earlier to the Agricultural Inputs Corporation. However, there are a number of problems to be overcome, (for example, ensuring better quality of private supplies), in order to effectively implement this policy and increase fertilizer usage.

\section{Lessons from Past Experience}

49 The Ninth Plan was not an unqualified failure or a success. As noted, its performance was mixed. There was some initial good progress in terms of economic growth and macroeconomic stability, and some promising reform initiatives late in the Plan period. Nevertheless, the Plan did not achieve good results in relation to its primary goal of substantially reducing poverty.

50 Some interesting lessons have been learnt from the Ninth Plan's experience, which can be helpful to make the Tenth Plan successful. These include, among others, the following: (i) Three essential requirements for ensuring good progress in poverty reduction are (a) political stability; (b) strong government commitment and political will to effectively implement the poverty reduction agenda; and (c) good governance, in terms of service delivery, transparency and accountability. All three are closely inter-connected; and they collectively provide a conducive environment in which development efforts can produce good results. However, they could not be realized, (instead, they deteriorated) during the Ninth Plan period. (ii) Within such an environment, the Plan itself needs to be credible and realistic, and firmly anchored to the realities of resource availability. Otherwise, a Plan cannot be implementable and becomes a wish-list of projects and activities. This was also largely the case with the Ninth Plan. (iii) To make it operational in such an environment, a Plan needs to be well prioritized and supported by mechanisms (and political will) which would allow the key priorities to be protected and funded within the resource constraints. This did not happen, and a considerable part of actual public spending was diverted to lower priority activities in many sectors. (iv) To ensure progress towards poverty reduction, the Plan would need to be resultoriented, specify actions to achieve outputs and service delivery targets, and include mechanisms to monitor progress and ensure accountability. Such mechanisms were weak. (v) Finally, recognizing that the role of the central government and its agencies would need to be limited, (if for no other reason than capacity constraints), the Plan had envisaged decentralization to local governments and the active involvement of communities (as well as the private sector, INGOs, NGOs and CBOs) in the management and delivery of essential services. This would have also helped to ensure wider participation in, and ownership of, the poverty reduction agenda. However, despite the creation of a good legal framework, there was little progress in effectively implementing these promising approaches.

51 Some further lessons have been learnt from the implementation of the Ninth Plan. First, broad-based economic growth is a must for poverty reduction; and without reasonable growth in agriculture and rural economic activities, GDP growth can not be broad based. Second, liberal economic policies provide opportunities for private sector development; but appropriate interventions are also necessary for inclusive development, i.e. targeted programs 
focusing on the deprived, poor, vulnerable and socially excluded groups. Third, along with economic growth, access to education, health, safe drinking water and rural infrastructure (like roads, electricity and irrigation) are important for better human development outcomes. And fourth, without good governance, these initiatives can not ensure delivery of goods and services in an equitable, effective and efficient manner. Allocation of resources and creation of institutions alone have not helped to enhance access of the people to basic services. These issues have to be adequately addressed to achieve any meaningful reduction in poverty. These are the reasons why the Tenth Plan builds its poverty reduction strategy on four basic pillars: (a) broad based economic growth, (b) social sector development including human development, (c) targeted programs, including social inclusion, and (d) good governance for effective, equitable and efficient delivery of public goods and services. These are discussed in detail in the subsequent sections. 


\section{The Poverty Situation - Its Key Dimensions And Determinants}

\section{Introduction}

52 Poverty in Nepal is widespread with $38 \%$ of the population living below the poverty line. Segments of the poor are hardcore poor barely eking out subsistence on fragile, vulnerable ecosystems; and large areas of the country lack even the most basic infrastructure. And there are wide variations in poverty levels based on ruraturban divide, geography, gender, and ethnic groups and occupational castes.

53 This section analyses the dimensions of the poverty situation in Nepal and its key determinants. It begins with a brief discussion of data sources and poverty trends. It then reviews the poverty situation from a multi-dimensional perspective, including income poverty, human development indicators, and gender, ethnic and caste-related differences, which help to bring out the social exclusion aspects of the poverty problem. The major causes of income and human poverty and exclusion are then discussed. The concluding sub-section discusses the possible linkages between the poverty situation and the ongoing civil disorder.

54 Most of the data on which the analysis is based are derived from the Nepal Living Standards Survey (NLSS), which was carried out in 1996. Another NLSS has been recently carried out in early 2003 but its results will not be available for several months. In the context of the mid-year evaluation of Ninth Plan, a smaller sample survey was undertaken in 2000; but it is not comparable with the 1996 survey, nor adequate to provide the basis for poverty analysis. (Thus PRSP benchmark of $38 \%$ poverty head count is not survey based, but estimated on the basis of economic growth in the last few years relative to the 1996 NLSS survey data. The poverty benchmark would be revised when the data analysis of the current NLSS II survey is completed in early 2004). The human development indicators are based in Nepal Human Development Reports for 1996 and 2001 prepared by the United Nations staff. Sufficiently detailed published survey data are not available for analyzing gender, ethnic and caste-related poverty differentials; and the analysis in this section relies on the findings of researchers who used the 1996 NLSS and other sources.

\section{Recent Poverty Trends}

55 Assessing what happened to poverty over time is useful for understanding the current poverty situation in Nepal. But in the absence of comparable survey data, it is hard to reach definitive conclusions. There were three nation-wide surveys before the 1996 NLSS. The first in 1976/77 estimated that 33 percent of the population fell below the poverty line, that poverty was mostly prevalent in rural areas, and that it was most intense in the Mid Western and Far 
Western development regions. The 1984/85 household survey estimated the poverty rate at 42 percent, and concluded that the disparities among geographical and development regions remained more or less the same as before. The third survey in 1991 covered only the rural areas. It also indicated widespread rural poverty, and that it was most severe among the landless and small farmers.

However, these surveys were not directly comparable with the 1996 NLSS, or with each other, since they all used different methodologies to collect data on incomes and consumption and to define measures of poverty. But when different methodologies are applied to the 1996 NLSS data to replicate as closely as possible the methodologies used in the earlier surveys in order to obtain broadly comparable estimates, some tentative conclusions can be drawn: (i) There is no evidence of a decline in poverty in Nepal as a whole between 1976/77 and 1995/96; and (ii) There is also no evidence of a decline in poverty between 1984/85 and 1995/96. In fact there is some evidence of an increase in poverty during that period, but such an increase cannot be stated with a high degree of confidence. (iii) There is some evidence of a decline in rural poverty between 1991 and 1995/96. This suggests that while there may have been some improvement in rural areas in that period, it was not enough to compensate for the deterioration that took place in the previous fifteen years.

56 Apart from poverty incidence, a few other conclusions emerge from the Poverty Assessment with regard to overall trends: (i) The absolute numbers of the poor appear to have increased sharply. Assuming a constant incidence of 42 percent in both 1976 and 1996 and with population growing at an average of $2.6 \%$ p.a. in the intervening period, the number of the poor is estimated to have grown from 5.7 million in 1976 to about 9.2 million in 1996 - an increase of about 3.5 million. (ii) In regard to urban-rural differentials, urban areas, particularly the Kathmandu Valley, appear to be better off in 1995/96 than in the earlier decade. In contrast, rural areas generally appear to have been worse off than in 1984/85, but better off in 1995/96 than in 1991. This evidence suggests as noted, a significant deterioration in the late eighties, followed by some improvement in the early nineties. Some rural areas central hills and central Terai - appear to have benefited from the rise in per-capita incomes in the Kathmandu Valley. However, other areas, notably the Mid West and Far Western regions, appear to have become worse off, or least not any better. These areas, the poorest in 1984/85, also remained the poorest in 1995/96 also. (iii) The Poverty Assessment also indicated that the distribution of income appears to have become more unequal everywhere between 1984/85 and 1995/96. This was also true of the distribution of consumption, but to a lesser degree.

\section{Current Poverty Situation and Its Characteristics ${ }^{2}$}

\section{Income Poverty}

57 Apart from its high incidence, poverty situation in Nepal is characterized by wide variations between urban and rural areas, ecological zones, development regions, gender and

2 This analysis is based on the 1995/96 NLSS data, as it is the latest nation-wide survey available. 
ethnic and caste groups. The 1995/96 Household Survey data provide useful information in this regard (Table 5). Several important conclusions can be drawn from Table 5.

Poverty in Nepal is largely a rural phenomenon. In $1995 / 96,44 \%$ of the rural population was living in poverty. Poverty was significantly lower, only $23 \%$, in urban areas. Indeed in the Kathmandu Valley, (where the vast majority of the population falls in the upper quintiles of the national income and consumption distribution), the poverty rate was only $4 \%$; poverty in other urban areas (excluding the Kathmandu Valley) was about 34\%, still significantly lower than the nationalaverage ( $42 \%$ ) and rural poverty incidence. Judging by the absolute numbers of the poor, the predominantly rural nature of the poverty problem is even more striking. According to the survey data, over $90 \%$ of the poor live in rural areas! When ecological zones are compared, poverty in both the (low land) Terai and the Central Hills is close to the national average. But poverty in the Mountain region is much higher- $56 \%$. The survey data also show wide variations in poverty within rural areas. For example, poverty rate is the highest in the more remote rural areas - the Mid-Western and Far-Western hills and mountain regions where it is as high as $72 \%$. The rural Mid-Western and Far-Western Terai regions are also much poorer (53\% incidence) than the national average.

Table 5: 1995/96 Survey: Income Poverty Indicators (Poverty Line: Rs. 4404 per person per year)

\begin{tabular}{lccc}
\hline Ecological Zone & $\begin{array}{c}\text { Poverty Incidence-Percentage of } \\
\text { People Living Below Poverty Line (\%) }\end{array}$ & $\begin{array}{c}\text { Poverty Gap-Depth/ } \\
\text { Intensity of Poverty \% }\end{array}$ & $\begin{array}{c}\text { Severity of } \\
\text { Poverty \% }\end{array}$ \\
\hline Mountain & 56 & 18.5 & 8.2 \\
Hill & 41 & 13.6 & 6.1 \\
Terai & 42 & 9.9 & 3.4 \\
Rural/Urban & & & \\
Urban & 23 & 7.0 & 2.8 \\
Rural & 44 & 12.5 & 5.1 \\
Nepal & 42 & 12.1 & 5.0 \\
\hline
\end{tabular}

Source: World Bank (1999) Nepal; Poverty at the Turn of Twenty First Century.

58 Table 5 also shows the depth/intensity of poverty and its severity. The poverty gap analysis shows how far below the poverty threshold income/consumption level the poor are concentrated on average, i.e. whether they are close to, or significantly below, the poverty line. Thus, larger the poverty gap, greater is the depth/intensity of poverty. The severity measure is similar to the poverty gap measure in construction, but gives greater weightage to those who are further below the poverty line (ie, the hard core poor). Again, higher the numerical value of the index, the deeper and more severe is poverty. The estimates in Table 5 show that while the poverty gap and severity measures are only $7.0 \%$ and $2.8 \%$ respectively for urban areas, the corresponding values are over $12 \%$ and $5 \%$ for all of Nepal, and are far higher for the Hills (13.6\% and 6.1\%) and the Mountain areas (18.5\% and 8.2\% respectively). Thus, all three estimates (incidence, intensity and severity) suggest that poverty is more rampant, deeper and severe in rural (as compared to urban) areas, and that it is much worse in the Hills and the Mountains as compared to both urban areas, as well as the (rural) Terai. 


\section{Human Development Indicators}

59 Apart from income levels, poverty levels can be measured more broadly in terms of access to basic social and economic infrastructure, which help improve the quality of life at various levels of income. Among these, education is by far the most important, since it would enable the poor to climb out of poverty over time; but others such as access to healthcare, safe drinking water etc. contribute to improved living standards and life expectancy. Nepal has made significant progress over the past two decades in terms of such human development indicators. Table 6 below (derived from Nepal Human Development Reports 1996 and 2001) shows both the current situation and recent progress in this regard.

Table 6: Human Development Indicators, 1996 and 2000*

\begin{tabular}{|c|c|c|c|c|c|c|c|c|}
\hline & \multicolumn{2}{|c|}{$\begin{array}{c}\text { Adult Literacy } \\
\text { Rate (above } 15 \\
\text { years) }\end{array}$} & \multicolumn{2}{|c|}{$\begin{array}{l}\text { Average Life } \\
\text { Expectancy }\end{array}$} & \multicolumn{2}{|c|}{$\begin{array}{l}\text { Percentage of } \\
\text { Population Having } \\
\text { Drinking Water }\end{array}$} & \multicolumn{2}{|c|}{$\begin{array}{l}\text { Human Development } \\
\text { Indicators (Index } \\
1.00 \text { ) }\end{array}$} \\
\hline & 1996 & 2000 & 1996 & 2000 & 1996 & 2000 & 1996 & 2000 \\
\hline \multicolumn{9}{|l|}{ Ecology Zone } \\
\hline • Mountain & 27.5 & 44.5 & 52.7 & 49.8 & - & 79.2 & 0.271 & 0.378 \\
\hline • Hill & 40.2 & 55.5 & 58.0 & 65.1 & - & 76.2 & 0.357 & 0.51 \\
\hline • Terai & 35.9 & 46.8 & 59.5 & 62.4 & - & 83.4 & 0.344 & 0.474 \\
\hline \multicolumn{9}{|l|}{ Urban/Rural } \\
\hline • Urban & 63.5 & 69.0 & 55.0 & 71.1 & 62.0 & 92.3 & 0.518 & 0.616 \\
\hline • Rural & 34.5 & 48.0 & 53.7 & 58.7 & 61.0 & 78.1 & 0.306 & 0.446 \\
\hline - Nepal & 36.7 & 50.7 & 55.0 & 59.5 & 61.0 & 79.9 & 0.325 & 0.466 \\
\hline \multicolumn{9}{|l|}{ Dev. Region } \\
\hline • Eastern & & 43.4 & & 62.0 & 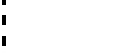 & 77.7 & & 0.484 \\
\hline - Central & & 47.1 & & 61.3 & 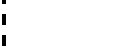 & 85.1 & & 0.493 \\
\hline • Western & & 48.3 & & 62.8 & ' & 83.8 & & 0.479 \\
\hline - Mid-West & & 50.4 & & 53.2 & & 65.5 & & 0.402 \\
\hline - Far-West & & 42.6 & & 52.1 & & 82.3 & & 0.385 \\
\hline
\end{tabular}

* As the data for this table was derived from different reports, they may not tally with similar other data reported in other sections of this document.

Source: Nepal Human Development Reports, 1996 and 2001

60 Despite significant progress in recent years, human development indicators are still low for Nepal; and they show significant urban/rural and geographical variations which duplicate the income poverty differentials noted earlier. For example: (i) The HDI for urban areas (0.616) far outstrips that for rural areas $(0.446)$, because of far better access in urban areas to services, resources and opportunities. (ii) Similarly, there are significant differences among ecological zones. HDI for mountains (0.378) is far below that for the hills (0.51). The broad scattering of communities in the mountains sharply limits access to services and resources and severely disadvantages people who live there. Human development in the hills is higher than in the Terai (and the national average), in part because many large towns and cities (including Kathmandu Valley) are located in the hills. (iii) Among the development regions, HDI is highest for the central region (0.493), followed closely by the Eastern (0.484) and Western (0.479) regions. This is largely due to the fact that most of Nepal's trading centers and productive economic activities are concentrated there. In contrast, the Mid-Western (0.402) 
and Far-Western (0.385) regions, far from the center of power, have been traditionally neglected. Despite recent efforts to include them in the country's modernization process, these areas (except for Mid-Western Terai) have also made the least progress in terms of the level of improvement in HDI between 1996 and 2000.

\section{Gender-Based Disparities}

61 Spatial disparities in incomes and human development are important elements of the poverty profile in Nepal; but its complexity cannot be comprehended without looking at major undercurrents, which cut across spatial patterns - such as gender, ethnicity and casterelated differentials - which exacerbate the intensity and depth of poverty for the affected groups.

62 In regard to income poverty, since the NLSS data have been collected at the household rather than the individual level, it is difficult to establish directly that women as a group are poorer than men in terms of per capita income. However, NLSS data do show that female headed households are poorer than male-headed households. They also spend less on consumption. While female-headed households constitute $13.2 \%$ of all households at the national level, there are 13 districts - mostly in the mountains and more remote hill areas (where there is high male migration) - in which the ratio is higher than $20 \%$; and this is probably one of the factors contributing to the higher poverty incidence in the mountain region noted earlier.

63 Women's active participation in paid employment is limited in Nepal. They currently account for only a third of the paid labor force. And when they enter the labor market, their wages even for the same type of work continue to be lower than men's. Adjusting for differences in hours worked per day, women agricultural workers earn 20 percent less than $\mathrm{men}^{3}$.

64 For the majority of women who live in male-headed households, there are sociological factors, which constrain their access to household income and resources. Although the structure of gender relations varies significantly among different social groups in Nepal, generally it is men who traditionally inherit family land, and who, for the most part control the allocation of household income and assets. Women's legal right to inherit parental property is still limited. In addition, in most rural areas customs and social practices can create greater vulnerability for women than for men. A woman's share in household assets and income (and even basic food security) is far more uncertain than a man's.

65 Human development indicators show existing male/female disparities clearly. Nepal has made significant progress in increasing female life expectancy as well as in improving female literacy levels, and primary and secondary school completion rates. Yet, large gender gaps remain (Table 7). For example, despite recent improvements, the adult literacy rate for women in 2000 was just over half that of men. This was also true of the indicator for average years of schooling. However, in the case of life expectancy at birth, females have finally caught up with men, reversing an aberration in health statistics which Nepal earlier shared with a few countries in the world. 
Table 7: Gender Disparities in Key Human Development Indicators, 1996 and 2000.

\begin{tabular}{|c|c|c|c|c|c|c|c|c|c|c|c|c|}
\hline & \multicolumn{4}{|c|}{ Life Expectancy (years) } & \multicolumn{4}{|c|}{ Adult Literacy (\%) } & \multicolumn{4}{|c|}{ Average School Going Years } \\
\hline & \multicolumn{2}{|c|}{1996} & \multicolumn{2}{|c|}{2000} & \multicolumn{2}{|c|}{1996} & \multicolumn{2}{|c|}{2000} & \multicolumn{2}{|c|}{1996} & \multicolumn{2}{|c|}{2000} \\
\hline & Male & Female & Male & Female & Male & Female & Male & Female & Male & Female & Male & Female \\
\hline Mountain & 52.7 & 50.4 & 48.6 & 51.1 & 44.2 & 11.8 & 61.9 & 26.6 & 2.27 & 0.71 & 3.71 & 1.33 \\
\hline Hill & 58.0 & 55.5 & 65.4 & 64.7 & 58.4 & 24.3 & 72.3 & 39.5 & 3.42 & 1.61 & 3.97 & 2.18 \\
\hline Terai & 59.5 & 57.0 & 61.7 & 63.2 & 52.3 & 19.9 & 60.2 & 32.5 & 3.10 & 1.25 & 3.71 & 1.93 \\
\hline Urban & 63.2 & 60.3 & 71.4 & 70.8 & 76.7 & 51.5 & 81.2 & 56.9 & 5.63 & 3.88 & 6.01 & 3.80 \\
\hline Rural & 53.7 & 51.3 & 58.2 & 59.3 & 52.0 & 19.5 & 63.6 & 32.3 & 2.93 & 1.15 & 3.40 & 1.66 \\
\hline Nepal & 55.0 & 52.4 & 59.3 & 59.8 & 54.3 & 21.3 & 65.8 & 35.4 & 2.55 & 1.13 & 4.45 & 2.25 \\
\hline
\end{tabular}

Source: Nepal Human Development Reports, 1996 and 2001.

66 In terms of the empowerment dimension of poverty reduction, Nepali women are still largely without influence in the public domain. Their representation in Nepal's influential civil service and in all three levels of elected government lags far behind men. Women make up only a little more that 7 percent of the civil service and only $4 \%$ of the officer level staff. And for those accepted as officers, progress to the higher levels is evidently slow. As in many countries throughout the developed and developing world, women are also under-represented in Nepal's elected government. After the last elections they made up only about 6 percent of the lower house and 15 percent of the upper house (where some of the seats can be nominated by the King). In the lower District and Village level bodies, women have even less voice. The Local Self Governance Act requires a minimum representation of women in the District Councils and the District Development Committees, most of the women representatives are those that are nominated by their parties to meet the quota. And, very few of them end up in the District Development Committees or any of its sub-committees where budgetary decisions are made; and therefore have little influence on program and expenditure priorities.

\section{Ethnicity and Caste-Based Disparities}

67 Nepal is a pluralistic society with diverse ethnic, caste, linguistic and religious communities - the consequence of several waves of migration over 2000 years. Nepal has about 60 recorded caste and ethnic groups (mostly Indo-Aryan and Mongol) and 70 languages and dialects (mostly Indo-Aryan and Tibeto-Burman). There are many indigenous ethnic ("Janajaties") and caste ("Dalits") groups who have been historically disadvantaged, and who continue to lag behind in their income and asset levels, educational achievements and human development indicators, and to the extent to which they are represented in the power structure.

68 Some of the key data sources, such as the NLSS, aggregate data for groups (such as Newars and Madeshi) which actually contain different castes and ethnicities. This makes it difficult to establish accurately income levels of all castes and ethnicities. There does not seem to be a simple straightforward one-to-one correlation between rank in the traditional caste system and poverty level; but there are broad linkages. The poverty level among the upper social castes (Newars, Brahmins and Yadavs) is generally much lower than that of the groups which are lower in the social ladder. In general the Janajati groups have higher poverty levels (ranging from 45 to 59 percent) than the national average, while the Dalits have poverty levels as high as $65-68 \%$. There are some notable deviations from this generalization. The upper caste Chhetris have an above average poverty rate of $50 \%$, while the Muslims, although 
low in the social hierarchy, are relatively better off in terms of poverty incidence. And the indigenous Limbus have the highest rate of poverty (71\%).

69 The data in Table 8 (Human Development Indicators for these different groups) tell a similar story. For every indicator, Janajati groups fall below the national average and well below that for the Brahmins, Chhetris and Newars. The situation with the hill Dalits is even worse. Taking the average Human Development Index for Nepal as 100, the ratio of Brahmins and Newars is 135.9 and 140.7 respectively compared with 92.2 and 73.6 for hill Janjatis and Dalits.

70 While most of the Dalits in Nepal can certainly be classified as disadvantaged, there is considerable variation in the welfare status of different Janajati groups. Janajati groups like the Gurungs, Limbus and Rais who traditionally went for service in the Indian and or British army have higher educational and income indicators as do groups like the Thakali and Sherpas who have done well in trading and other businesses. It is likely that if these groups were removed from the tabulations in Table 8 above, the HDI indicators for other Janajati groups would be considerably lower. Among the more disadvantaged Janajati groups with large populations are the Tharu, Tamang and Kham Magars; along with 16 other smaller groups.

Table 8: Human Development by Caste and Ethnicity, 1996

\begin{tabular}{lrrrrrrrrr}
\hline $\begin{array}{l}\text { Human Dev. } \\
\text { Indicators }\end{array}$ & Nepal & Bahun & Chhetri & Newar & $\begin{array}{c}\text { Hill } \\
\text { Janjatis }\end{array}$ & Madhise & $\begin{array}{c}\text { Hill } \\
\text { Dalit }\end{array}$ & Muslim & Other \\
\hline Life Expectancy (yrs) & 55.0 & 60.8 & 56.3 & 62.2 & 53.0 & 58.4 & 50.3 & 48.7 & 54.4 \\
Adult Literacy (\%) & 36.7 & 58.0 & 42.0 & 54.8 & 35.2 & 27.5 & 23.8 & 22.1 & 27.6 \\
Mean yrs Schooling & 2.3 & 4.7 & 2.8 & 4.4 & 2.0 & 1.7 & 1.2 & 1.4 & 1.9 \\
Per Capita Income (NR) & 7673 & 9921 & 7744 & 11953 & 6607 & 6911 & 4940 & 6336 & 7312 \\
HDI Indices & & & & & & & & & \\
Life Expectancy Index & 0.500 & 0.597 & 0.522 & 0.620 & 0.467 & 0.557 & 0.422 & 0.395 & 0.490 \\
Educational & 0.295 & 0.490 & 0.342 & 0.462 & 0.280 & 0.221 & 0.186 & 0.178 & 0.226 \\
Attainment Index & & & & & & & & & \\
Income Index & 0.179 & 0.237 & 0.181 & 0.289 & 0.152 & 0.160 & 0.110 & 0.145 & 0.170 \\
Human Dev. Index & 0.325 & 0.441 & 0.348 & 0.457 & 0.299 & 0.313 & 0.239 & 0.239 & 0.295 \\
Ratio of National HDI & 100 & 135.9 & 107.3 & 140.7 & 92.2 & 96.3 & 73.6 & 73.7 & 90.9 \\
\hline
\end{tabular}

Source: "A Strategy to Empower Nepal's Disadvantaged Groups", Document 1, Page 7 (based on data of the Nepal Human Development Report, NESAC, 1999.

71 Caste and ethnicity-based disparities in education are also striking. For example, in 1991, there were 6 ethnic groups and 16 caste groups with adult literacy rates below 25\%, compared to a national average of $39.6 \%$. There are also similar disparities in educational attainments at the graduate level. According to the 1991 Census data, $89 \%$ of the graduate population came from high and middle ranking castes (including the Newars) from the hills and Terai, while the traditional ethnic groups accounted for only $6 \%$ of the total and Dalits another $3 \%$.It is likely that with the social awakening following the political changes in 1990 this situation may have improved somewhat; but more recent information is not available to confirm it.

72 With the restoration of democracy in 1990, efforts were made to assist Janajati groups in their economic and social development and to voice their concerns. The number of civil society groups dedicated to welfare, advocacy and political action on behalf of both groups has grown exponentially. In response to the demands of these groups, the government established a Dalit Development Commission during the Ninth Plan. Similarly a National 
Janajati Development Committee was established in 1997 and recently restructured to a more powerful and independent Adibasi Janajati Utthan Pratisthan (Indigenous and Ethnic Groups Upliftment Academy) in 2002.

73 Yet, neither the civil society groups nor the government bodies have yet had much success in significantly improving the educational, economic or welfare status of the Dalit and disadvantaged Janajati population. Neither group has had much success in joining the civil service nor gaining elected office at any level of government. Rough estimates of ethnicitywise participation in the civil service, public office and political leadership in the country show that participation of communities in public office is not reflective of Nepal's caste and ethnic profile. For example, high caste Brahmins and Chhetris have more than twice the level of participation in relation to their population share and the Newars nearly three times their population share. In contrast, the hill Janajati have only 32 percent and Dalits even less - only 3 percent of the participation they would have if they were represented in proportion to their population share in the country.

\section{Determinants of Poverty-Proximate Causes}

74 Given its complexity and diversity, it is difficult to find a few simple explanations for Nepal's poverty problem. Among the obvious ones which contribute to it are such factors as limited resource endowment, ill health a land-locked and rugged terrain, and centuries of political and economic isolation, all of which have kept the economy at a subsistence level without, (until a few decades ago), even the minimum social and economic infrastructure. While these factors explain the low initial economic base and its mirror image-widespread poverty, they alone cannot explain the lack of progress in combating poverty, particularly over the past two decades.

75 The experience of other countries which have been successful in substantially reducing poverty clearly demonstrates that achieving sustainable, high and pro-poor growth is a necessary condition for poverty reduction. In conjunction with a deceleration of the population growth rate, (an additional requirement for countries like Nepal which are already burdened with high population growth), it would help increase per-capita incomes steadily. This however, has not happened in Nepal consistently across the economy, even though respectable overall economic growth rates were achieved in the early nineties. As noted, real GDP at factor cost rose at an annual rate of $4.9 \%$ through the early nineties, and at a slower rate of $3.6 \%$ p.a. during the Ninth Plan period. But, notwithstanding recent progress in reducing birth rates, the population growth rate $(2.25 \%$ p.a. $)$ still remains high; and consequently, per capita income has risen at about $1.9 \%$ p.a. since the early nineties. This is still not a poor achievement!

76 From a poverty reduction perspective, however, the pattern of growth has not been propoor. Much of this growth took place outside agriculture, and outside rural areas where $86 \%$ of the Nepali population and over $90 \%$ of the poor live. Over the past $\mathbb{Z}$ years, nonagricultural activities (which in Nepal are primarily centered in urban areas, particularly the Kathmandu Valley) grew by almost $6 \%$ p.a. in real terms even with the recent slowdown. In contrast, the agricultural sector grew at an annual rate of only $2.3 \%$ p.a. on average, about the 
same rate as population growth. Thus there was no perceptible improvement in rural per capita incomes for a long period to make a difference in reducing rural poverty.

77 This differential growth pattern over the last two decades helps to explain the prevailing urban-rural divide. The non-agricultural sector (manufacturing, trade, tourism and services) grew rapidly in the early nineties, driven by the growth of exports, public investment and demand for urban services. Thus, incomes and employment opportunities rose rapidly in urban areas. This is probably the major explanation for the extremely low poverty rate $(4 \%)$ in the Kathmandu Valley, and the glaring poverty disparities between urban and rural areas. In addition, since the urban areas (particularly Kathmandu) are also viewed as centers of investment, with rising property values, financial services and infrastructure, most of the substantial inflows of remittances noted earlier eventually end up in urban, rather than rural areas.

78 Notwithstanding some improvements over the past few years in the use of modern inputs and some diversification into cash crops, overall agricultural growth has remained low. An important reason for this is the slow growth, and in the case of some crops even a decline, in productivity. A review of agricultural data for major food crops from 1985/86 through 1998/99 shows that both production and productivity stagnated or only marginally increased, except for wheat which showed a modest gain. But over a longer period from 1961-63 to 1991-93, yields actually decreased by 0.07 percent. And, among the three ecological regions, the yield levels are the lowest in the mountains, followed by the Hills while the Terai has the highest yield. In the case of major food crops, area expansion has also been quite limited.

79 Several factors have contributed to both these trends: small uneconomical farm size - the median land holding in 1996 was only 0.65 ha-lack of progress in providing year-round irrigation, (only $15 \%$ of the cultivated land is irrigated year round resulting in excessive exposure to the vagaries of the weather), low use of modern inputs (fertilizer and improved seeds) and extension services, among others. As noted, during the Ninth Plan, the APP sought to address these constraints, but with little success, as it was poorly implemented.

80 These factors help to explain the poor performance of agriculture and why rural poverty is worse than urban poverty. But, they by themselves do not explain the disparities within the rural economy. Table 9, based on the 1996 NLSS data, provide useful insights on rural income disparities. The poorer households in the rural economy are consistently more handicapped than others in terms of the quality of the land they cultivate and access to and use of inputs. For example: (i) The median landholding of the bottom 25 percent of households is only 0.51 ha, only about three-fourth of the rural average; (ii) Within that, the proportion of ploughed land suitable for growing rice is only about $37 \%$, i.e about one-fourth less than the rural average; (iii) Year-rounds irrigation is available only for about $11 \%$ of the land, (i.e. about one-third less than the average; and (iv) Their use of modern inputs and access to institutional credit are substantially less than the rural average. (v) While access to Extension and Veterinary agents have been limited for most rural households, the poor have far less contact (less than half) compared to the household average. (vi) Not surprisingly, the poorer households are located further away from roads, i.e. they have less access to markets 
for their products, as well as to all of the inputs noted earlier. (vii) Also, incomes from agriculture are positively correlated with the level of schooling completed by the head of the household. And yields are positively correlated with levels of education above primary. In other words - "while the poor do not differ from the rest (in rural areas) in terms of their dependence on agriculture, they do differ in terms their opportunities to make a living off the land. Poor land quality and limited access to inputs limit returns from agriculture for the poor".

Table 9: Household Distribution by Their Access to Agriculture Inputs, 1996.

\begin{tabular}{lcccc}
\hline Household Income & $\begin{array}{c}\text { Ploughed (Khet) } \\
\text { Land as Percent } \\
\text { of Total } \\
\text { Cultivated Land }\end{array}$ & $\begin{array}{c}\text { Year-Round } \\
\text { Irrigated } \\
\text { Land As Percent } \\
\text { of Cultivated Land }\end{array}$ & $\begin{array}{c}\text { Chemical } \\
\text { Fertilizer } \\
\text { Bought from } \\
\text { AIC (in kg/ha) }\end{array}$ & $\begin{array}{c}\text { Percent of } \\
\text { Household with } \\
\text { Institutional } \\
\text { Loans }\end{array}$ \\
\hline Bottom 25 Percent & 37 & 11 & 10 & 8 \\
25-50 Percent & 53 & 14 & 19 & 16 \\
50-75 Percent & 57 & 15 & 30 & 16 \\
Upper 25 Percent & 54 & 18 & 39 & 16 \\
Average & 51 & 15 & 26 & 14 \\
Sample Household (No.) & 2550 & 2550 & 2679 & 3373 \\
\hline
\end{tabular}

Source: World Bank (1999): Nepal Poverty at the Turn of the Twenty First Century.

81 All rural households, though deriving much of their household income from agriculture (including earnings as paid farm labor), also earn from non-agricultural sources through selfemployment and wage employment (Table 10). But the dependence on agriculture is significantly higher for the poorer households. This is also suggestive of the fact that opportunities for non-agricultural employment are limited in rural areas; and with their low educational achievements and skills, it is difficult for the poor to obtain higher-paying nonfarm employment and break out of the poverty cycle.

Table 10: Sources of Income of Rural Households, 1996

\begin{tabular}{lccccc}
\hline & \multicolumn{2}{c}{ Agriculture } & \multicolumn{3}{c}{ Non-agriculture } \\
\cline { 2 - 6 } & $\begin{array}{c}\text { Self- } \\
\text { Employment }\end{array}$ & $\begin{array}{c}\text { Wage- } \\
\text { Employment }\end{array}$ & $\begin{array}{c}\text { Self- } \\
\text { Employment }\end{array}$ & $\begin{array}{c}\text { Wage- } \\
\text { Employment }\end{array}$ & $\begin{array}{c}\text { Other } \\
\text { Sources }\end{array}$ \\
\hline Bottom 25 Percent & 50 & 19 & 5 & 16 & 10 \\
25-50 Percent & 48 & 18 & 7 & 12 & 15 \\
50-75 Percent & 49 & 13 & 8 & 13 & 16 \\
Top 25 Percent & 43 & 7 & 11 & 15 & 23 \\
Average & 47 & 14 & 8 & 14 & 16 \\
\hline
\end{tabular}

Source: NLSS, 1996

82 Despite recent progress, the level of social development in Nepal is low even by South Asian Standards. This in turn has had a direct impact, (as evident from the human development indicators noted earlier), on poverty and inequalities in living standards between different geographical regions and socio-economic groups in Nepal. Inadequate social service delivery is seen to be one of the primary reasons for the poor to remain poor in the rural areas. The key social and economic infrastructure such as health, education, drinking water and 
energy show the following general characteristics: (a) the poor in general have less access to social services; (b) except for access to primary schools, no other services are comparable in terms of rural coverage; and (c) even in the primary schools, accessibility, enrolment rates, dropout rates, etc, are significantly worse in rural areas. In the like manner, internal efficiency of social service delivery is also low. Only about $18 \%$ of the primary school children complete the primary cycle on time. The situation is similar in the secondary schools also. Approximately $60 \%$ of primary school teachers are still untrained. School supervision system is weak and non-wage expenditure in education is extremely low. Similarly, health services at the rural health institutions are either unavailable, or their quality is very poor, mainly due to the absence of health personnel and medical supplies.

83 Public expenditure programs have played a key role in most countries in accelerating economic-growth and addressing poverty incidence. In Nepal, the effectiveness of public interventions has been undermined by a number of deficiencies: weak prioritization, inadequate project screening, weak monitoring and supervision and lack of results orientation, among others. Public resources have not been consistently allocated and spent to support poverty reduction in rural areas. To the contrary, public expenditure programs have been generally urban-biased. For example, education sector's budget that goes in primary education has remained inadequate and 30 percent of the public expenditure in health was allocated until recently to urban hospitals. Despite significant growth in the budget for the social sectors including health and education, per capita expenditures on these sectors is still low, as compared to most developing countries; and they need to be made more equitable to address rural needs.

84 Political instability and weak governance have been major impediments to effectively addressing rural poverty. Frequent changes in governments with short time horizons have weakened the administration, increased corruption and leakages and lack of accountability, and undermined the effective implementation of programs. The worst casualties in this process have been rural communities, who are far removed from the center of power. Although there have been recent efforts to promote decentralization and community participation, these are only now beginning to show results.

85 All of these factors which have led to differences in poverty levels between urban and rural areas apply equally to regional income and human poverty differentials across the development regions. In addition, a few other factors help explain the depth of regional variation, particularly in the Mid-western and Far-Western regions:

i) Geography and its consequences - inaccessibility and relative isolation - have been a primary cause. Until the East-West Highway was completed in the late nineties, there were no road links with these two regions. Indeed, until that time, access to them was possible mainly through (north-south road links with) neighboring India. Even now, within Nepal north-south road links with the mountain areas of both regions are lacking. The consequences have been continued isolation, lack of integration with the Nepalese economy, poor access to markets for their limited products, and little development activities there-hence poor infrastructure, education and health facilities, drugs and medicines and even basic food to ensure food security. 
And public sector agencies which have been given the responsibility (and transport subsidies) for supplying basic food and supplies (NFC) and agricultural inputs (AIC) have remain highly inefficient. Given the high transport costs, and thinly spread population lacking resources, the private sector has had little incentive and interest to operate in these regions. In contrast, the Eastern region is well served with road links not only with Nepal but also with neighboring countries, facilitating trade, commerce and industry; and its proximity to relatively developed educational centers in India has served as a catalyst for social development, and education in particular. As noted in Table 6, the Eastern region's human development indicators are almost as good as (and in some respects better than) the Central region's.

ii) The Mid-western and Far-Western regions, being sparsely populated have less political representation in Parliament, lack sufficiently large power blocks and, being far removed from the center of power, the ability to influence resource allocation decisions. It is not surprising that between 1996/97 and 2000/01, these two regions together received only $11-12 \%$ of total government expenditures.

86 These regions thus have been traditionally neglected, and not because of their ethnic and caste characteristics. In fact, except for ethnic belts in the mountains (Bhotes) and in the Terai (Tharu), most of the two regions are in habited by Nepali language speakers, with the upper caste Chhetris being the most numerous. Thus, all communities in these two regions have suffered; and this probably is an important factor contributing to the relatively high poverty incidence in these regions.

87 While all of these factors have equally affected the ethnic and caste-based communities, a major additional factor contributing to their relative backwardness has been the effects of social stratification noted earlier. In an isolated and closed society, generally those in the upper rungs of the social ladder had better access to social and economic infrastructure and opportunities for economic advancement. Those at the lower levels, particularly the Dalits, were left behind. And, when the modernization process began in the fifties, the urbancentered development pattern that emerged left the isolated regions and the socially disadvantaged communities further behind. A major element of the poverty reduction strategy of the Tenth Plan is to begin to close this gap as rapidly as possible by mainstreaming the deprived communities and regions in the development process.

\section{Present Social Disorder and Its Implications}

88 The prolonged national crisis has remained as the biggest threat to national development. Starting in 1996 from Mid-Western districts, the violence spread rapidly to many parts of the country. Until January 31, 2003, when a truce was arrived at. It severely disrupted economic activity and development work in many areas. Moreover, a prolongation of the present situation could seriously impede the government's efforts to substantially reduce poverty over the next few years. This section briefly reviews the genesis of the disorder, its linkages with the prevailing poverty and inequalities, and its implications for the Tenth Plan strategy. 
89 While there are undoubtedly social and economic grievances contributing to the present situation of disorder, its causes are far more complex.

90 Whatever the motivation for the beginning of the social disorder, there is little doubt that persistent poverty and inequalities have provided a fertile breeding ground for the present crisis. Some of the reasons which helped fuel the crisis could be: (i) Weak impact of various development activities on some areas of the country; (ii) Inadequate delivery of social services in some of the remote and isolated areas; (iii) The slow pace of decentralization and inadequate community involvement; and (iv) Inadequate resource allocation for the remote areas and regions.

91 The changing social and political situation in the country has enormous implications for the Tenth Plan. To prevent further turmoil and violence the government is committed to establish peace and security as its highest priority, and concurrently win back the faith and confidence of its public. It can do so only by showing that it is trying to be differentefficient, functional and able to deliver basic services to the poor, and that it is trying hard to meet the expectations of its citizens. It will make special efforts to roll back poverty and reduce inequalities, and bring the deprived regions and communities into the mainstream of development. The Tenth Plan provides the government with the means to do so-a workable strategy, modalities to implement it, and the tools to monitor progress - within the severe resource constraints Nepal is facing.

\section{Conclusion}

92 The foregoing analysis clearly indicates that poverty in Nepal is a widespread, complex and multi-dimensional phenomenon. Poverty is deeper, more intense, and more severe in rural (as compared to urban) areas; and even more so in the hills and mountains and in the Western and Far Western regions. There are also clear gender, ethnic (and regional) disparities. Other indicators of human poverty (as measured through key socia 1 indicators) also closely correspond with, and confirm this rural, gender, ethnic and regionally oriented poverty pattern. The analysis also shows a clear nexus among the key variables/determinants of poverty. The level and intensity of poverty is closely linked to the pace and pattern of economic growth in urban and rural areas and economic/income generating opportunities associated with such growth. (Rural poverty is worse primarily because agricultural growth the primary source of income and employment generation in the rural economy - has stagnated in per capita terms over the past few decades). Even within rural areas, the poorer segments of the population have less access to fertile land, irrigation, modern inputs, credit, and marketing and road infrastructure. Similarly, a key determinant of the level and intensity of both income and human poverty is access (or the lack of it) to basic social and economic infrastructure. The rural areas are badly underserved in terms of quality and coverage of basic education, healthcare, drinking water, roads and access to other infrastructure and markets. Poverty is also closely related to the degree of social, political and economic inclusion/exclusion. Women and ethnic groups by and large are left out of the mainstream of development, because they lack voice, empowerment, representation and access to economic opportunities and resources. Similarly the remote districts and regions are further away from centers of power and influence and are the most neglected. Another key determinant, which 
cuts across and exacerbates the impact of these factors on the poverty pattern, is weak governance, which includes ineffective government, poor resource allocation, week implementation and service delivery performance, and corruption and leakages, among others. To effectively address this complex problem and to bring about a significant and lasting reduction in poverty, a comprehensive well-designed strategy, which will be effectively implemented and monitored, has been formulated by the Government. This strategy is discussed in chapter $\mathrm{V}$. 


\section{The Tenth Plan-Goals, Targets and Strategies}

\section{Introduction}

93 The foregoing evaluation of the Ninth Plan and the poverty situation clearly demonstrates that past development efforts have fallen behind to meet the expectations of poverty reduction. Poverty is more widespread particularly in rural areas; and that it is deeper and more severe among women, ethnic groups and Dalits, and those living in backward areas Mid and the Far Western and Mountain areas. Poverty could not be reduced to a desired level due to the failure to achieve high and sustained broad-based economic growth particularly in rural areas; inadequate human development commensurate with heightened desires and needs of the people, in large part due to less than satisfactory implementation of public actions to effectively provide essential social and economic services and infrastructure to the poor and backward communities and areas; poor accountability, economic malpractices, and poor implementation and monitoring of development programs. The impact of development on the deprived areas and communities has been limited. In the absence of effective policies for ensuring social and economic inclusiveness, the poor and deprived communitie s could not come to the mainstream of the development process. In addition, the recent spells of violent activities and disorder have badly slowed down development activity and service delivery by the government. They have also adversely affected the poor and backward areas and communities even more than others.

94 In this context, the Tenth Plan's sole objective is to bring about a remarkable and sustainable reduction in the poverty level in Nepal over the next five years. To this end, His Majesty's Government has formulated a "four pillar" poverty reduction strategy, which squarely addresses the main causes and determinants of poverty identified in the preceding poverty analysis. The strategy, which is discussed in more detail below, is based on four overarching approaches: achieving sustained high and broad-based economic growth, focussing particularly on the rural economy; accelerating human development through a renewed emphasis on effective delivery of basic social services and economic infrastructure; ensuring social and economic inclusion of the poor, marginalized groups and backward regions in the development process; and vigorously pursuing good governance both as a means of delivering better development results and ensuring social and economic justice. Particularly noteworthy, the Tenth Plan seeks, as an integral part of its poverty reduction strategy, to bring the marginalized sections of the population and backward regions into the mainstream of development, and to make visible progress in reducing existing inequalities.

95 In designing and carrying out its poverty reduction strategy, the Tenth Plan/PRSP has adopted a number of new approaches and initiatives, which represent a radical departure 
from past plans and strategies. The more important of these, discussed in greater detail in the next few chapters, include the following: (a) The poverty reduction strategy itself is significantly different. (i) While emphasizing sustainable high economic growth as in the past, the PRSP focuses more sharply on accelerating income and employment growth in the rural economy where the majority of the poor live. (ii) The emphasis on social inclusion and on improving governance is altogether new. (iii) So is the commitment to effective implementation of programs and better delivery of social and economic services and infrastructure as the primary means of accelerating human development, particularly among the poor and neglected groups and areas. (b) In carrying out the strategy, the Tenth Plan/PRSP explicitly recognizes the fiscal and implementation constraints, unlike previous plans, which sought to do everything. This pragmatic approach has led to the identification of new modalities of implementation and service delivery for ensuring better development results: (i) In particular, the role of the Government has been redefined; and public interventions will be limited and focussed on areas where they can yield the maximum social benefits (ii) The Plan relies heavily on the private sector, NGOs, INGOs and Community Based Groups (CBOs) for carrying out economic activities, infrastructure development and service delivery wherever possible, both in partnership with central and local governments and agencies and to complement the role of the government. (iii) Strong emphasis is also placed on decentralization and maximizing the involvement of local governments and community groups for identifying development activities and allocating resources for them in accordance with people's needs, for strengthening service delivery and for ensuring better program management, accountability and transparency through people's participation. (c) The PRSP also seeks to ensure strict adherence to a sustainable macroeconomic framework, setting annual budgets and spending plans within realistic levek. For this purpose, alternative macroeconomic scenarios have been developed as a broad framework to guide future spending decisions. (d) The PRSP/Tenth Plan also place strong emphasis on prioritizing resource allocations annually through a rolling Medium Term Expenditure Framework, so that the key poverty reduction priorities can be protected despite shortfalls in resources. (e) To bring about the necessary changes in key areas, detailed structural and sectoral reform programs have been developed, together with a program of key Immediate and Medium Term reform actions. (f) Finally, reflecting its emphasis on better implementation and service delivery, the Tenth Plan stresses the need for effective monitoring and evaluation arrangements, together with appropriate benchmarks and intermediate goals/targets for key activities, so that performance can be evaluated and monitored on a regular basis.

96 The rest of this Section outlines the Tenth Plan's objectives and targets, the main elements of its poverty reduction strategy, and policies and programs in key sectors to support this strategy. Alternative macroeconomic scenarios and mechanisms for adjustment of the public expenditure program are discussed in Section VI. Section VII outlines the implementation and monit oring modalities which are necessary to ensure that the Plan will be able to achieve its goals, outputs and results in reducing poverty. 


\section{Key Goals and Targets}

97 The Tenth Plan's key goals and targets are set out in Table 11. The Normal Case scenario aims to reduce the overall poverty ratio from $38 \%$ estimated at the end of the Ninth Plan (2001/02) to $30 \%$ by $2006 / 07$. Indicative targets for key human development variables include: raising literacy to 63 percent, reducing the infant mortality rate to 45 thousand births, raising life expectancy to 65 years, increasing access to drinking water for 85 percent of the population, electricity to 55 percent, and telephone facility to almost all village development committee. If these social and infrastructure goals are achieved, a 10 percent improvement in the human development indicators is possible. To reduce the overall poverty rate through the creation of income and employment generating activities in the key sectors, an overall GDP growth rate of $6.2 \%$ p.a. at factor cost is also envisaged, together with a substantial improvement in agricultural growth to around $4.1 \%$ per annum.

98 These should be regarded as indicative targets only. Some of these targets, particularly, those for education and health, are ambitious. In order to achieve them, much stronger efforts than in the past will have to be made by providing the necessary inputs and resources. Nevertheless, the Tenth Plan recognizes that the availability of resources, the extent to which the planned programs can be implemented and the degree of commitment with which they are pursued will have an important bearing on whether these targets will be achieved or not. Given the uncertain fiscal prospects and the security situation, an alternative Lower Case scenario is therefore assumed in the Tenth Plan. This lower case scenario will be used as the basis for formulating the budget and the MTEF, and as the resource situation improves, it will be appropriately adjusted. While every effort will be made during the preparation of annual budgets and mid year reviews to protect the Plan priorities, nevertheless, it is realistic to assume that achievements with regard to economic growth, service and infrastructure delivery and poverty reduction will be lower under the Lower Case (Table 11, column 4). Thus, the incremental targets in the Lower case are expected to be lowered by about $15 \%$ for infrastructure and by about $10 \%$ for the social sectors. This is broadly in line with the reduced availability of resources under the Lower case and the efforts that will be made to give priority to the social sectors in resource allocation under such a scenario.

Table 11: Indicative Targets of the Tenth Plan 


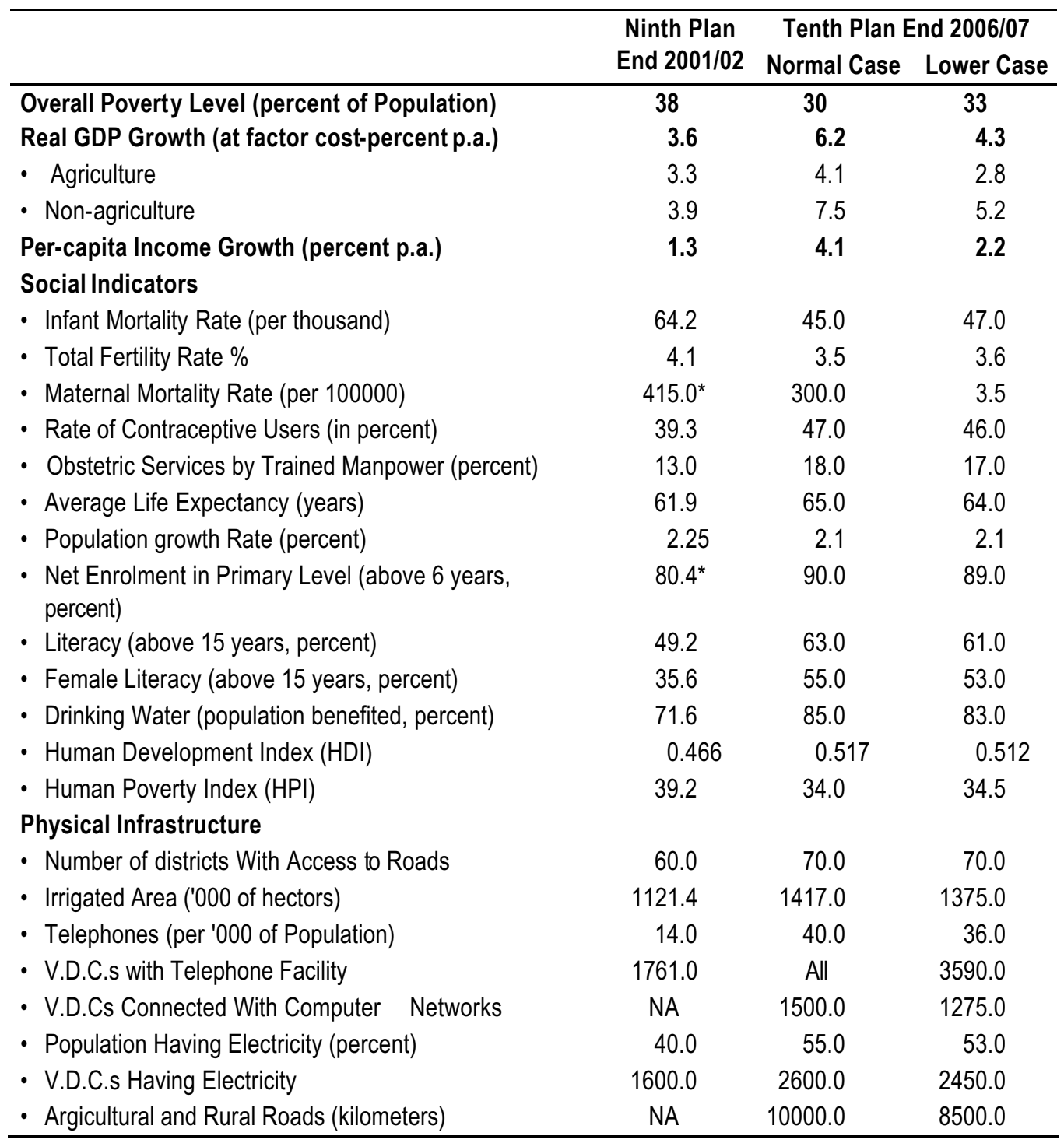

* As estimated by the National Planning Commission. These figures will be revised when actual data become available.

\section{The Tenth Plan's Poverty Reduction Strategy}

99 Given the nature of Nepal's poverty problem and the social/political context, the Tenth Plan's poverty reduction strategy has been guided by a few key considerations: First, as noted, the poverty reduction strategy needs to be ruratoriented. While supporting other areas of the economy with strong potential for income and employment growth, the growth strategy will need to be broad based and pro-poor, and focus on rural/agricultural growth. Second, priority should be given to actions and interventions, which can give quick results, as compared to investments that may take a long time. This requires careful balancing of short term as well as longer term needs. Third, given the country's Imited administrative and implementation capacity, (as well as implementability of programs in some areas), the Plan will need to have a strong strategic focus; and concentrate on a few important approaches and supporting interventions which, if effectively implemented, can deliver quick results to the 
rural poor. Fourth, the Plan will need to be interpreted as a strategic and flexible document. While the overall strategy provides a broad framework and strategic interventions for poverty reduction, and the key priorities themselves will need to be protected in terms of budget allocations and funding, such interventions and policies will need to be reassessed from time to time, and revised if necessary, in order to achieve the poverty reduction goals. A number of such initiatives have already been taken in the first year of the Plan, such as the MTEF, education sector reform package and, the emergency relief program, among others.

100 Cognizant of these needs, the Tenth Plan's poverty reduction strategy is built on of four pillars: (i) Broad based economic growth; (ii) Social sector development including human development; (iii) Targeted programs including social inclusion, in order to bring the poor and marginalized groups into the mainstream of development, together with targeted programs for the ultra poor, vulnerable and deprived groups (who may not adequately benefit from the first two pillars); and (iv) Good governance. All four pillars are essential for improving the lives of the poor, and for mainstreaming the very poor deprived groups, and thus for promoting inclusive development. In implementing the four-pillar strategy, the Plan also stresses strategic cross-cutting approaches with regard to: (a) redefining the role of the State, and limiting public interventions; (b) enlisting the private sector to play a leading role in employment and income generation and together with NGOs, INGOs and CBOs, in complementing government efforts in service delivery functions in key areas, as well as in implementing key activities; (c) promoting community participation in and management of activities at the local levels; and (d) accelerating the decentralization process, which is also a key element under good governance.

101 These four pillars of the poverty reduction strategy should not be seen as separate and self-standing. To the contrary, they are closely inter-related. For example, international experience clearly demonstrates that improvements in literacy and health and nutritional status, by enhancing skills and productivity and reducing family size, contribute to higher economic and per-capita income growth. Conversely, without achieving sustainable high growth rates, it may not be possible for Nepal to undertake the planned levels of public (and private) spending that are needed to undertake basic social and physical infrastructure development programs in rural areas. Second, the four pillars address different aspects of the same problem - poverty, broadly defined to include income poverty, human poverty and exclusion. Thus, while the first pillar tries to address income poverty directly, the second pillar tries to expand access to basic services and amenities which help to improve quality of life and human capability at given income levels. Both are equally important for mainstreaming the poor. The third pillar is not an isolated attempt to address the needs of the poor and deprived through targeted programs alone. It should be viewed as part of an integrated approach to bring the poor within the mainstream of development. Finally, the fourth pillar is essential for ensuring that the programs/activities included under the first three pillars achieve their intended results. Indeed, without good governance, (control of corruption and leakages, and mechanisms to ensure accountability), the objectives of other pillars cannot be really achieved. In addition, the fourth pillar, which also includes participatory involvement of local governments and communities in the development process, will help considerably in addressing social exclusion aspects of poverty also. How the four-pillar 
strategy will be implemented and their implications for sectoral programs and activities are discussed in more detail below.

\section{Macroeconomic Framework}

102 A poverty reduction strategy emphasizing high and sustained economic growth can be pursued only if public action can help build policies and institutions needed for higher growth. Economic growth requires a framework, which can encourage and expand private investment and activities. In this context, creating an appropriate enabling environment and incentive framework are the main elements for fostering private sector development. And, to this end, ensuring macroeconomic stability is of paramount importance. The latter is also necessary for assuring sustainable bvels of public investment to support the key elements of the poverty reduction strategy, (such as human development and social inclusion programs).

103 The Tenth Plan has been prepared at a difficult time. GDP is estimated to have declined by $0.6 \%$ in the base year of the Tenth Plan 2001/02. Political instability, violence, and social disorder have challenged the economic situation in the country. External demand for goods and services and tourist arrivals have remained volatile for Nepal especially after the event of September 11, 2001. The pace of recovery of the domestic economy will depend on both the attainment of sustained peace in the country and a rebound in the global economy.

104 Recognizing these constraints and risks, the Tenth Plan has incorporated a sustainable macroeconomic framework to support high and broad-based economic growth with low inflation. Two alternative scenarios projecting possible upper and lower boundaries with regard to resource availability and implementability are discussed in Section VI. These assume that the Nepalese currency will continue to be pegged to the Indian currency, the Government's domestic borrowing will be managed conservatively, and that foreign exchange reserves will be maintained at a level of nine months of merchandize imports. The overall fiscal deficit is projected to be at around 5\% of GDP, financed largely through foreign aid. Macroeconomic policy will be accompanied by a deepening of structural reforms in key areas including the financial sector, public enterprises and trade competitiveness which are crucial for removing constraints to private sector-led growth; and reforms will be undertaken to improve the efficiency and quality of public administration and services. An integral part of this macroeconomic framework is the Medium Term Expenditure Framework, which the Government introduced in FY 2003 (for the first time in Nepal) in order to implement the Tenth Plan in a difficult macro-fiscal environment. The expenditure prioritization in the MTEF and how it helps to protect the Tenth Plan's poverty reduction priorities are discussed in some detail in Section VI below.

105The importance of macroeconomic stability can hardly be overemphasized for promoting either economic growth or poverty alleviation. Maintenance of satisfactory macroeconomic fundamentals is also a necessary precondition for the operation of a marketoriented economy and also for promoting private investment. The core objectives in this regard, as outlined in the Tenth Plan, are to maintain fiscal discipline, ensure efficiency of 
public resources, sustain monetary and external stability and, as discussed below, strengthen the financial system.

106 To maintain fiscal discipline, prudent expenditure policies will be pursued and domestic resource mobilization will be improved. The annual budgets will be set at realistic levels consistent with implementation capacity and resource projections and borrowing targets outlined in Section VI. To ensure efficiency of public resources, the MTEF will be widened to cover all ministries, and the prioritization of projects/programs improved so that the key poverty reducing pro-poor activities identified in the Tenth Plan/PRSP are indeed given priority (as P1s) in the expenditure program. The MTEF will be further expanded to cover regular expenditures (which are currently excluded); and the expenditure classification will be improved on the basis of recurrent and capital expenditures. To improve domestic resource mobilization, the recommendations of the fiscal commission for tax reforms will be implemented, tax exemptions and tax rebates will be reduced, customs valuations will be revised periodically, and tax administration will be strengthened through a move towards an autonomous tax administration. Besides, government arrears to/from the public utilities will be cleared. To maintain monetary and external stability, a prudent monetary policy will be pursued: (i) Money supply growth will be contained at a desirable level. (ii) Both domestic borrowing as well as bank financing of the government will be limited in line with the macroeconomic framework outlined in Section VI. (iii) Open market operations will be used as a major instrument; and any excess liquidity in the economy due to inflow of foreign assets will be mopped up by issuing Central Bank bonds. To strengthen the external sector, greater autonomy of the Central Bank in exchange rate formulation and the management of the foreign exchange regime will be encouraged.

\section{Structural Reform Agenda}

In order to bring about economic transformation, public actions have to be made more efficient and effective. Constraints which inhibit private sector's competitiveness need to be removed and programs to improve the conditions of the poor should be given priority. To this end, the Government will strengthen the reform programs already initiated in many areas and introduce new reforms geared to supporting rapid growth. Some of these reforms are: (i) expenditure management, (ii) financial sector reform, (iii) fiscal reform, (iv) measures aimed at improving the competitiveness of the private sector including foreign trade and labour reform, (v) governance, including civil service reform and decentralization, and (vi) promoting private sector's involvement in infrastructure development. These reforms will help reinforce and strengthen the market-oriented strategy followed by Nepal in the past decade. They will also help in focusing the role of government on areas where markets function poorly or would result in inequitable outcomes.

107Ensuring macroeconomic stability and improving the incentive framework particularly through reform programs mentioned above will enhance the environment for higher investment and cost effective service delivery. It will also help increase opportunities for, and capabilities of, the poor to earn a decent income. A growing economy increases income- 
earning opportunities for the poor. The role of the state in fostering an environment conductive to growth is pivotal in this regard.

108 The government will also promote opportunities for growth through coordinated efforts in key sectors, such as agriculture, irrigation, tourism and infrastructure development. Rural infrastructure - such as roads, electricity, telecommunication facilities - not only will help in improving access to markets and inputs, but also help increase accessibility and the quality of living and service delivery in the remote areas of the country. The growth of agriculture, which is the source of livelihood of most of the people in rural areas, will assist the poor by increasing income generating activities and gainful employment opportunities. The benefits of eco-tourism are enormous in a country like Nepal, where the potential for tourism is immense; and accordingly, the Government has given high priority to it.

109 Poverty impact of growth, however, cannot be maximized until the income earning capabilities of the poor are improved by addressing the deficiencies in human development such as low education and ill health. The removal of these deficiencies is not only a means of reducing income poverty, but also of improving their social well-being. Therefore, programs to support effective delivery of education, primary health, and enhanced access to clean water have been given priority.

\section{Broad-Based Economic Growth}

110 The meed for high and broad-based growth does not require much explanation. The experience of Nepal and other countries shows that growth has a positive impact on poverty alleviation. Growth that improves income distribution appears to further reinforce the positive impact of growth on poverty. In this context, a growth strategy that can benefit all income groups (including poor and deprived segments of society) will have two major components. First, since more than 80 percent of the population are engaged in agriculture, agriculture must be made to grow by at least 4 percent p.a.; and second, private sector led nonagricultural growth must also be emphasized, for the reasons mentioned earlier.

111 The sources of (higher) growth would be increased productivity in both agriculture and in non-agriculture sectors, and a recovery in manufacturing, exports and tourism, along with the expected improvement in the domestic and external environment. Similarly, the adoption of policies to boost trade and industrial sectors and improved public resource management, among others, would help trigger higher and sustainable growth.

In the case of agriculture, improved irrigation facilities, uninterrupted supplies of chemical fertilizer and expansion of rural credit, along with the rural roads and higher resource allocations would help achieve annual agricultural production growth of the order of 4.1 percent. Creating a better environment for private sector development, including macroeconomic stability, would also help accelerate private sector investment in the country. Industry, tourism and services activities would also benefit from the improved law and order situation, increased demand in rural areas (associated with higher agricultural growth), and higher public investments associated with increased development activities and rehabilitation and reconstruction needs. In particular, measures to promote domestic and internal trade can 
be an important source of non-agricultural growth. These include ongoing initiatives such as: (i) lowering trade transport costs through developing Inland Container Depots, strategic roads development, and implementing the multi-modal transport strategy; (ii) improving customs administration; (iii) developing power for potential exports towards the end of the Plan period; and (iv) carefully negotiating accession to World Trade Organization to bind Nepal to the global community in an advantageous manner. Under the normal case, these factors are expected to raise non-agricultural growth to 7.3 percent per year. Of course, if some of these crucial assumptions, particularly with regard to the improvement of internal security and the external environment remained unrealized, the economic growth would turn out to be lower, as suggested in the Lower Case scenario.

112 Prioritizing and refocusing policies and activities in the agriculture, irrigation, forestry and power (rural electrification) sectors are crucial for achieving agricultural growth targets. The major objectives set for the agriculture sector are to increase agricultural production, productivity and incomes, both to reduce poverty of rural farmers and increase food security. The Tenth Plan also seeks to promote agro-biodiversity conservation and environmental protection, in addition to encouraging the adoption of need-based technology. Likewise, one of the major objectives is to promote domestic agro-products in local as well as in foreign markets.

113 The growth strategies for agriculture are to modernize, diversify and commercialize crop and livestock production by expanding the use of technology, and increasing the access of farmers to modern agricultural inputs and credit. Similarly, promoting the participation of private sector and NGOs/INGOs in service delivery, market promotion and infrastructure development are other major strategies.

114 The major thrust in the agriculture sector will be directed at ensuring the successful implementation of the Agriculture Perspective Plan (APP). The APP aims to increase cereal and cash crop production in the Terai and develop livestock, horticulture and specific high value crops in the hills. The main activities in this regard include package programs that promote smooth supply of fertilizers, provision of irrigation facilities, and expansion of rural agricultural roads, rural electricity and improving the marketing network. Policies and activities conducive to carrying out research and development will also be adopted.

115 The major outcomes which are expected from the effective implementation of programs in the agriculture sector are that the production systems will be more diversified and agricultural growth will increase by 4.1 percent p.a., and livestock by 4.9 percent p.a. Food insecurity and malnutrition will also be reduced. Market access for agricultural products, as well as farmers' incomes and consumption levels, will increase.

116 The major objectives in the Land Reform and Management sector are to ensure sustainable land use and management, update and maintain land records/information, and increase access of the poor to land resources and ensure effective utilization through enhancement of their skills. Main strategies that will be pursued to achieve these objectives are: preparation of land use guidelines and policies; and effectively implementing new land ceilings, together with resettlement of freed "Kamaiyas" (bonded labor) on surplus land. The 
key policies and programs that are envisaged include the following: Prepare integrated land use policies, guidelines and Acts, (for example, to discourage keeping land fallow, discourage fragmentation of holdings, developing new legislation to promote co-operative and contractual farming etc); Develop a national geographic information system, carry out plot surveys, and establish a computerized land information system; (this would also help eliminate dual land ownership and prepare the basis for progressive taxation of land); and Strengthen land management, manpower development and training programs. It is expected that the implementation of these policies and activities would help strengthen the institutional basis for agricultural development (by improving land use and management), establish an upto-date land information and mapping system, and help develop effective land management services.

117 The core objectives of the Irrigation sector in the Tenth Plan are to promote year round irrigation in the arable land area of the country and to ensure the sustainable management of developed irrigation systems.

118 The main strategies adopted by the Plan to achieve these objectives are to expand new irrigation facilities with focus on APP where year-round irrigation is feasible, and to rehabilitate and strengthen public and community based irrigation systems, focusing attention on the preservation and full utilization of the existing irrigation systems.

119The major policies and activities to achieve these goals include: (i) expanding small surface irrigation in the hills and surface and ground water facilities in the Terai; and (ii) repair/rehabilitate and maintain the existing farmer managed and public irrigation systems. Irrigation laws will be revised to grant WUAs the legal powers to collect irrigation charges. In the case of large and medium scale public irrigation systems, their management will be increasingly transferred to the private sector. Increased involvement of NGOs and the private sector in new irrigation development will also be encouraged.

120 The expected outcomes are that 50 percent of total irrigated land will receive year round irrigation facilities by 2005, while farmers/WUAs will be able to manage irrigation systems up to 500 ha during the same period. In the longer run, maintenance, efficiency and utilization of irrigation facilities are expected to improve significantly.

121 Rural electrification has an important role to play in accele rating both agricultural and rural development. It could have a catalytic effect on agricultural growth by accelerating shallow tubewell irrigation. In addition to supporting for the development of agro business, the extension of rural electrification would also help modernize cottage industries and improve the living standards of rural households. Accordingly, key programs are aimed at expanding grid-based rural electrification, promoting small projects where grid-based expansion is not possible, and enhancing the capacity of cooperatives for management at local levels. To achieve the objective of increasing rural coverage from 40 to $55 \%$ over the Plan period, the government's strategy envisages internal unbundling of NEA's activities as well as initiating an explicit subsidy policy for grid-based rural electrification. 
122 The development of the forestry sector is especially important for promoting livestock, making compost fertilizer, conserving environment and for watershed management by conserving ground water resources. Community and Leasehold Forestry programs have been very successful in the country in creating income-generating opportunities for the poor. In this context, the 'user-group approach' is particularly useful in mainstreaming poor and deprived communities in forestry sector activities. Given its high success, the leasehold programs would be further expanded. Integration of the concept of sustainable development in all the development processes for balancing population and environment and identification of comparatively advantageous areas for achieving high and sustainable economic growth through adaptation of community-based natural resource conservation, utilization and improvement are focused in consideration of strategic environment assessment and capability enhancement. Various program interventions will be carried out so that land use is planned and managed at the national and local levels such that resource bases and ecosystems are improved, with complementarity's between high- and low- lands, that forest biomass grows, that agricultural and forest lands are protected from urban sprawl, and that biodiversity is conserved at the landscape level by recognizing threats from habitat fragmentation, unmanaged solid waste and loss of forest cover. Air, solid waste and water quality monitoring will be maintained to reduce human health hazards.

123 To achieve the desired growth in the agriculture sector, increased investments will be required from both private and public sectors. In parallel, public expenditure on key sub sectors and activities will be streamlined and refocused in line with the APP, to ensure adequate funding. Similarly, improved modalities of implementation will be adopted by emphasizing polycentric institutional arrangements to ensure greater participation of private sector and NGOs in activities such as input delivery, marketing, research and extension services. In this regard, the activities of inefficient public enterprises involved in these areas such as AIC, will be either restructured or phased out. Also, existing policies which inhibit agricultural growth, (such as those governing ground water development) will be reviewed, in order to make appropriate corrections.

124 The non-agriculture sector includes a number of important sub-sectors such as manufacturing, trade, tourism, transport, construction and financial and social services. Activity levels in most of these sub-sectors have been depressed in the last 2-3 years because of the present domestic social disorder, and weak export demand. It is reasonable to expect that the ceasefire declared in January 2003 would lead to a quick rebound in a number of subsectors, especially tourism, manufacturing, construction and services, where substantial under-utilized capacity exists. And, a pick up in development activity and rehabilitation and reconstruction efforts would also help provide a quick stimulus. Over the medium term, a revival of business confidence and private investment, increased domestic demand (associated with rural/agricultural growth), continued reasonably high growth in neighboring India, (trade with India has increased rapidly in the last few years), and the beneficial effects of ongoing structural reforms, (such as financial sector, trade and institutional reforms), would help to achieved a growth rate close to the level achieved over the past decade. 
125 However, the impending internal security issues and gloomy global economy will have implications for Nepal's private sector promotion. In the mean time, Nepal can do a number of things to promote private sector development, enhance competitiveness and boost the growth of the non-agricultural sector. The core objective of private sector development is to enhance the scope for private participation in economic activities through the creation of a private sector friendly environment, so that the private sector can make a meaningful contribution to poverty eradication. The major strategies to achieve this objective include: the acceleration of economic reforms; ensuring policy-wise consistency in order to create an investor friendly environment; simplifying entry and exit procedures for businesses; enhancing competitive environment by providing equal opportunities and facilities, and sectoral reforms. As per liberal economic policy, the government will gradually reduce its role in economic activities, while private involvement will be encouraged in a wide range of economic activities, such as investments in social and economic infrastructure and service delivery. As discussed elsewhere, policies have been already formulated and announced to facilitate private investment in power, roads, telecommunications and other infrastructure development. To create a level playing field, the privatization of public enterprises will be accelerated and those areas will be fully opened to the private sector. The Government intends to increase the involvement of the private sector in a number of public enterprises including Nepal Electricity Authority, Nepal Telecommunications Corporation and the Royal Nepal Airlines, among others. Efforts will be made to streamline the regulatory processes and to make them more transparent, for example by reducing complicated documentation requirements for exports; and improving tax administration so as to reduce discretionary power of tax officials. A fiscal reform commission (which is currently sitting) is expected to make important recommendations in this regard. Legal reforms will be initiated and new liquidation, merger and bankruptcy laws will be enacted. Finally, reforms currently under way in the financial sector (aimed at creating an efficient and competitive banking system and transferring state-owned banks to private management and ownership, among others), will help considerably in facilitating private sector development.

126 Nepal's trade, tourism and industrial regime is quite liberal. However, the size of the private sector is small and inefficient, and lacks competitiveness. The country needs to expand output capacity and improve the efficiency of the private sector through the adoption of appropriate measures. As Nepal is also seeking to join the World Trade Organization, it needs strong efforts to strengthen its international competitiveness. Therefore, in order to create a favorable environment to achieve private sector led growth, the government will focus on removing impediments to private sector development. In this regard, a strong promotional package especially for export-oriented industries, measures to increase incentives for investment, and an appropria te technology and information program will be introduced to enhance competitiveness. Concurrently, steps will be taken to reduce costs of exporting. For example, as noted earlier, initiatives are underway to reduce trade transport costs (through the multimodal transport strategy and developing internal container depots); while improving customs and tax administration and tax policy reforms also will help in this regard. In addition, programs in the trade sector aim to increase the number of private sector managed 
customs terminals, expand technical assistance programs for export commodities and revise existing Acts and regulations to make them compatible with WTO and SAPTA requirements.

127 In order to provide employers more flexibility to adjust their labour requirements with due compensation to those affected, the Tenth Plan will take a number of measures to reform existing labour laws. The major objective outlined in the Tenth Plan for the labour sector is to ensure a congenial industrial environment by maintaining a flexible labour market while safeguarding the basic rights of workers. The major strategies adopted in the Plan to achieve this objective are: the initiation of timely reforms in labour laws to promote private investment, promotion of better industrial relations, increasing productivity and elimination of child labour. The Government will also give even greater emphasis to its present policy of encouraging foreign employment. Similarly, to make Nepal free from child labour, legal measures would be adopted along with strict monitoring; and the ongoing programs for rehabilitation of child labour would be strengthened.

128 With the effective implementation of these policies and programs, it is hoped that both productivity and rights of labour would be enhanced and that industrial relations will improve. Existing child labour would be eliminated.

129 Infrastructure development has a major role to play in facilitating the development of the private sector. Despite significant progress in the expansion of road density, penetration of telephone and electricity is still low. The government will give priority to strategic road network, maintenance of major roads and highways and expansion of electricity and national communication infrastructure. The government, however, in the medium term, will gradually reduce its involvement, especially in the areas where private sector can increasingly take over, including telecommunications, hydroelectricity and roads, among others. Legislation has already been enacted for this purpose and encouraging progress has been made to date.

130 The main objectives of the Tenth Plan in the road sector are to develop and manage the road transport network to support the socio-economic development efforts and to promote private sector participation in the construction of new road networks and their maintenance. The major strategies to be adopted in this regard include increased participation of the private sector in road construction and maintenance, enhancing institutional capacities of both the roads department and the private sector to ensure cost effective sustainability of the road network, and transferring to DDCs the responsibility for rural roads. To encourage increased private involvement in the road sector, legislation will be enacted for the implementation of BOT and BOOT policies. A framework will be established for improved road maintenance, the Road Fund Board will be made fully operational and financed by a road levy. Measures to build capacities of the Department of Roads and the private sector will be undertaken. At the end of the Plan period, $1025 \mathrm{kms}$ of road will be added. An additional ten district headquarters will be connected by road, taking the number of HQs having road connections to 70. Private sector will actively participate in the construction and maintenance of roads.

131 The Tenth Plan's key objectives in the power sector include: expanding electricity coverage in a sustainable and environmental friendly manner by generating low-cost power; accelerating rural electrification to promote economic growth and improve living standards in 
rural areas and to develop hydro power as an important export item. The major strategies of the sector include promoting private sector participation in power generation and distribution, unbundling the activities of NEA and improving its financial viability, integrating rural electrification with rural economic development programs, and strengthening power infrastructure.

Major initiatives/activities to be undertaken to improve power sector development include the establishment of a Power Development Fund; the creation of an independent regulatory authority; initiation of an explicit subsidy policy for grid-based rural electrification; and promotion of small, medium and storage hydropower projects. The major expected outcomes are that the proportion of population having access to electricity will increase from 40 percent to 55 percent by the end of the Plan period, and adequate power will be supplied as needed to support economic growth.

132 In the information and communications sector, the Tenth Plan's main objective is to improve the access of people to information and telecommunication facilities, facilitating their participation in economic activities, as well as personal development. The major sector strategies are to enhance private sector participation in the expansion of information and communication network and facilities, and clarify the roles and responsibilities of private and public operators and to give them (as well as the postal service) functional autonomy. Regarding policies and activities, necessary steps for the promotion of private sector involvement in telecommunications will be taken. NTC will be converted into a public company under the Company Act, and general and rural telecom services will be opened up to the private sector. A policy of expanding broadcasting services will be adopted. A legal framework for functional autonomy of postal services will be finalized by FY 2004. With the effective implementation of these policies and activities, it is expected that the telecom market will be liberal and competitive. All VDCs will have access to telecom services with penetration rising to 40 lines per 1000 inhabitants. Broadcasting services will be available to all. Likewise, ICT services will be available in various urban areas.

133 Apart from its contribution to economic growth and the balance of payments, the tourism sector can be an important instrument of poverty reduction by increasing employment opportunities directly and indirectly in urban as well as rural areas, particularly in the hills and mountain areas along trekking trails and tourism sites. A major objective of the Tenth Plan is to increase the contribution of the tourism sector to the national economy through the expansion of tourism activities and generation of greater employment opportunities. Similarly, conservation and promotion of historic, cultural and religious sites, and the development of a safe reliable and easily accessible air transportation system are other objectives in the sector. The sector strategy aims to develop and market new tourism products, and to improve tourism facilities and services for promoting faster growth of the sector. Accordingly, the ongoing promotional activities will be further expanded, focussing on regional markets; developing and conserving national heritage/religious sites will be emphasized; and new areas will be opened up for rural tourism. Developing infrastructure and institutions particularly for eco-tourism, and solid-waste management will be given priority. Likewise, RNAC will be divested, measures will be taken to improve air safety, and the 
immigration system will be simplified. With the effective implementation of the policies and activities, it is expected that the total number of tourists coming into the country and the average length of stay will increase. Thus, the contribution of the tourism sector to the economy will rise. With effective promotion and the spread of tourism into rural areas, and resulting increases in incomes and employment generation, tourism will positively contribute to reducing rural poverty.

134 The core objectives of the Tenth Plan in the industrial sector is to accelerate the pace of industrialization through increased participation of private sector and to create additional employment in both rural and urban areas to reduce poverty. The main strategies to achieve these objectives are: improving policies to attract domestic and foreign investment, strengthening the role of SMEs in national production and improving the overall industrial environment. Tariffs will be further rationalized, and existing policies and Acts relating to foreign investment and industrial development will be revised. Up-gradation process of SMEs through technological improvements and policy of sub-contracting will be further accelerated. Incentives to improve backward linkages of industries will be continued; and information technology development will be given emphasis. The effective implementation of these policies and activities during the Tenth Plan will help improve industrial competitiveness, expand industrial production and employment generation, and raise the contribution of the industrial sector to GDP.

135 The major objective of supply sector in the Tenth Plan is to improve the supply and distribution of essential commodities throughout the country, to discourage illegal hoarding and black marketing, and to ensure food security for these purposes. The main strategies adopted are to improve food availability and supplies in remote areas and promote market based pricing mechanism for petroleum products. Accordingly, the government will rationalize the activities of Nepal Food Corporation and focus on enhancing food supply and distribution, particularly in food-deficit areas. Also, the management capacity of Nepal Oil Corporation (NOC) will be strengthened, and measures will be introduced to reduce leakages and to ensure private sector participation in the activities of NOC. The effective implementation of these policies and activities should help increase food security in deficit areas, ensure uninterrupted supplies of essential commodities and enable NOC to become financially viable.

136 Measures will also be taken to attract more foreign investment, along with appropriate technology, particularly in areas of comparative advantage in order to enhance competitiveness. As noted, policy and legal framework will be improved in line with the market economy; administrative mechanisms will be streamlined and made more efficient; and necessary physical infrastructure and human resource development will be undertaken. Ensuring macroeconomic stability (thereby assuring repatriatibility of capital and dividends) and a stable financial system will also help in this regard.

137 In parallel, similar reforms are also needed in corporate and financial governance. Nepal lacks sound accounting and reporting standards. Disclosure requirements for companies are inadequate and information available to lenders is incomplete, and sometimes 
inaccurate. Similarly, institutional capacity for regulation and supervision is weak. Improvements in these areas will help increase trust and confidence in the private sector and in turn reduce bureaucratic hassles.

138 Strengthening the financial system is of critical importance for private sector development, to ensure that national savings would be mobilized and intermediated at competitive interest rates to meet the private sector's financing needs, as its role in the economy progressively expands. Nepal's financial sector is in a critical stage. The main problems of the banking system are inefficiency, inadequate financial discipline, as well as political and other influences in lending decisions. These have resulted in poor loan quality, high spreads and high lending rates to borrowers, and increasing non-performing assets. To address these problems, a Financial Sector Strategy has been prepared and is being implemented. The reform agenda in the financial sector, currently underway, involves, among others: (i) restructuring and privatizing state owned banks, (ii) improving auditing and accounting standards, (iii) strengthening monitoring and regulatory functions and capacity of the NRB, (iv) strengthening legislative and institutional framework for effective loan recovery, and (v) improving loan quality and banking discipline. The reform program in the non-banking sector is expected to include the restructuring of the two government owned development banks, (Agricultural Development Bank and Nepal Industrial Development Bank), as well as ensuring healthy growth of the finance companies and the micro-finance sub-sector. They will be brought under a transparent and more accountable regulatory framework. And the Government will also reform the rural development banks with a view to minimizing its involvement in rural finance.

\section{Social Sector Development (including Human Development)}

139 The development of human resources is essential for reducing human poverty and improving the quality of life in rural areas. While human development has many dimensions, education, health, rural drinking water and sanitation are particularly important. In addition, basic infrastructure such as access to (even low-quality) roads, electricity and telephone communications (particularly in remote areas) can help improve living conditions for the poor in rural areas. As noted above, improvements in these areas are mutually reinforcing, and have benefits well beyond their direct impact. Ensuring equitable access to these services and facilities is especially important for mainstreaming the very poor, and deprived communities.

140 Recognizing the importance of ensuring the effective delivery of services (and basic infrastructure programs), the government has adopted in the Tenth Plan innovative approaches which cut across all the key social sectors: (i) The role of the government will continue to be particularly important in the social sectors because there are many programs where costs of providing services cannot be fully captured by private providers, even though the social returns from such programs and activities may be high, (for example, preventive programs). (ii) But, the government is committed to increasingly decentralizing to local governments the responsibilities for primary education and health care, and involving local communities in the management of primary schools and health centers. (iii) Greater involvement of the private sector, INGOs, NGOs and CBOs is being actively promoted in a 
variety of activities in these areas, both to supplement existing publicly managed activities and also to increase the outreach and effectiveness of these programs. In the case of rural drinking water, the implementation of this approach involving NGOs, CBOs and user groups is already well advanced and has shown good results; and it will be expanded and extended to other sectors. (iv) These approaches will be utilized for improving access of the very poor and deprived communities to social services (mainstreaming), together with better co-ordination, technical assistance, supervision and funding from the central government agencies to ensure satisfactory progress.

141 Guided by the objective of 'education for all', the education sector in the Tenth Plan aims at improving the access to and quality of primary education. The Plan also has among others, the objective of expanding literacy programs to improve the livelihoods of deprived groups, especially girls, dalits and disadvantaged children. The Plan objectives also include development and expansion of secondary education, production of middle-level technical manpower through the expansion of vocational and technical education and production of higher level skilled manpower through the development of higher education.

142 The major strategy adopted by the Tenth Plan to fulfill the education objectives is the decentralization of the management of local schools by handing it over to school management committees at the local level, and changing the role of district and central level agencies to that of facilitator, monitor and evaluator. Improving and expanding teacher training programs to uplift the quality of education and strengthening school monitoring and supervision system, in addition to mitigating social, cultural and financial barriers in order to ensure easy access to education are other major strategies. Similarly, promotion of vocational courses and private sector involvement in extending basic and middle level technical education also from a part of the Tenth Plan strategies. In higher education, cost recovery would be adopted as a guiding principle.

143 Transferring schools to school Management Committees has already been initiated under the $7^{\text {th }}$ Amendment to the Education Act; and this policy will be further accelerated and expanded. School Management Committees will be made responsible for the recruitment of new teachers. Teacher training at both primary and secondary education levels will be expanded. The government will also provide partial grants to community schools that do not receive government funding, and encourage the private sector to undertake production and distribution of textbooks to ensure adequate supply and timely distribution. The government will take steps to expand adult literacy by setting up Community Learning Centers with the increased participation of CBOs, NGOs and local bodies. It will also expand the policy of granting scholarships to first child or first girl of poor families from which none of the members have completed primary education. Effective system to provide middle level technical education for the poor will be introduced. With the effective implementation of proposed activities in the education sector, the net primary school enrolment is expected to increase to 90 percent from the existing 82 percent. Accessibility and the quality of education will improve signific antly; while the percentage of primary school repeaters will decline. The expanded literacy program is expected to increase the adult literacy rate to 63 percent. Enrolment of girls and disadvantaged children at primary level will increase significantly. 
Reforms in higher education with a view to enhance financial sustainability and market relevance will be supported.

144Education reforms announced by the government recently will help to expedite the implementation of this agenda. As noted, the handover of management responsibilities to School Management Committees together with adequate funding through District Development Councils has been started initially in selected districts. The government has also announced a new program to: (i) provide free education up to tenth grade for "oppressed, backward and below poverty line students"; (ii) providing education in mother languages (of communities) up to the primary level; (iii) regulating fees in private schools; (iv) providing basic facilities in private/boarding schools to students from "oppressed and backward communities" and (v) the setting up of a Rural Education Development Fund (financed by a levy of $1.5 \%$ of the income of private/boarding schools) which would be utilized for funding the education of marginalized communities.

145 The health sector is of critical importance for human development, improving living standards in rural areas and for mainstreaming marginalized groups and communities. Despite significant progress in recent years, service delivery in the health sector remains weak. Although an extensive network of primary healthcare centers has been constructed nationwide, it has not been functioning well in many rural areas due to lack of trained staff, drugs and medicines, etc. The sector's overall performance has suffered due to inadequate funding for essential recurrent expenditures, misallocation of resources and limited capacity for supervision and, for co-ordination of the activities of other agencies providing health care services.

146 To address the health sector needs, the government formulated a Health Sector Strategy in August 2002, which provides a coherent strategic framework to involve all the stakeholders. The key sector objectives are: (i) Extending essential health care services to all, with special emphasis on the poorer population living in rural areas; (ii) Management of the growing population by enhancing the accessibility of rural population to family planning services and expanding maternal and child health services; and (iii) Ensuring effective control of communicable diseases, such as Malaria, and Tuberculosis, as well as HIV/AIDS.

147 The Tenth Plan has adopted a number of strategies to achieve these objectives: (i) Expansion of primary health centers and district hospitals, and strengthening out-patient services in hospitals; (ii) Development and retention of trained health personnel in rural areas; (iii) Increased supply of essential drugs and vaccines; (iv) Improved delivery of health services, publicly, through decentralized management/delivery, through increased participation of the private sector, INGOs and NGOs, or through public-private partnerships; (v) Improved regulatory mechanisms to ensure the quality and accessibility of health services; and (vi) improving human resource development and management and health care financing.

148 The major policies and programs to implement these strategies include, among others, the following: As noted, primary health centers and outpatient facilities in hospitals will be expanded. In order to mainstream the marginalized groups and regions, efforts will be made to ensure access to a facility within one hour's walk to all, and to initiate special programs in 
the Mid and Far Western regions. Given the inadequate staffing and quality of health facilitie s in rural areas, the government will make recruitment and transfer process of health workers transparent; and adopt an incentive mechanism to encourage them to work in remote areas. The policy of transferring the management of sub-health posts and health posts to local communities will be further intensified; and recruitment of health workers and procurement of drugs will be done at the local level. The community drug program and human resources development program to produce trained health manpower will be further expanded. Focus programs particularly for immunization, safer motherhood and control and prevention of communicable diseases such as HIV/AIDS, as well as a Health Insurance Scheme will be initiated. Family planning and nutrition programs will be expanded and made more effective. $\mathrm{MOH}$ is also developing an annual work plan within the framework of the MTEF and the Tenth Plan that would help implement these key reform actions identified in the Health Sector Strategy as a part of a sector-wide approach to improve performance. It is expected that with effective implementation of these policies and programs, the existing infant mortality rate will come down to 45 and life expectancy will increase to 65 years from the current 61.9 years. All sub-health posts, some of the health posts, and some hospitals will be managed by local bodies/communities by the end of the Plan.

149 The new implementation modalities in the education and health sectors should be seen as

a logical extension of the decentralization process. Indeed, they represent the operationalization of the commitment the government made two years ago to transfer increased functions and responsibilities to local governments and communities, starting with education, health, rural roads and agricultural extension services. While the management of primary schools and primary health centers in specified areas are being transferred to community management committees, funding for them will be channelled through local governments-DDCs and VDCs. The community management committees will be answerable to, and be monitored by the DDCs/VDCs for ensuring effective use of and accountability for resources, while technical support for the management committees will be provided by the district offices of the line departments, since the DDCs and VDCs do not have sufficient capacity in this regard at present. Moreover, in both education and health, the pace of transferring management to the communities will be gradual, taking into account the management capacity and readiness of communities to take on such responsibilities, the degree of availability of support through NGOs and CBOs, and implementation constraints created by the domestic disorder. As conditions improve, particularly as peace and a degree of normalcy return to the affected areas, it would be possible and necessary to develop new implementation modalities involving local groups, NGOs and CBOs in order expand the community management approach to those areas also.

150 The core objectives of the Drinking Water supply and sanitation sector are to increase sustainable access to basic drinking water in rural areas and basic sanitation in both rural and urban areas. Similarly, upgrading basic drinking water services in urban and semi-urban areas through private sector involvement and checking water-induced diseases through the supply of safe drinking water are other major objectives. The main strategies of the sector are to encourage NGOs, CBOs and the private sector to actively participate in the planning, designing, implementing, operating and maintaining water supply and sanitation schemes 
with the support from NGOs and the private sector and to formulate and implement necessary legislative reforms and cost recovery policies, among others. Among the major policies and activities adopted by the Tenth Plan, the government will revise the 1998 rural sub-sector policy to specify clear roles and responsibilities for the various sector actors. It will also reform and consolidate the institutional mechanisms and approaches to facilitate the implementation of demand driven community managed programs and projects by making operational a sector monitoring and evaluation system within the line ministries. Likewise, the government will formulate an Act to ensure the autonomy of the RWSS Fund Development Board. With the completion of proposed activities, about 3.8 million people will have access to safe and sustainable drinking water services. Girls will have better opportunity to go to schools due to time saved in fetching water. Incidence of water borne diseases will be reduced considerably.

\section{Social Inclusion and Targeted Programs}

151 As discussed earlier, the Tenth Plan seeks to address gender and ethnic/caste-related disparities and facilitate social inclusion by mainstreaming such efforts, i.e. by taking actions under all four pillars of the poverty reduction strategy, instead of simply relying on targeted programs. Accordingly, in implementing key sectoral programs, attention will be paid to ensuring equity of access to such programs for all, with special attention (and monitoring of such actions) to assuring access of women and deprived communities, with the explicit objective of reducing the existing gaps between these groups and the rest of the population. The following paragraphs briefly summarize the Plan's expectations in this regard.

152 Gender mainstreaming will require a shift away from the traditional reliance on welfare measures to ensuring equal access for women and children to social and economic infrastructure and income and employment generating opportunities created by the broadbased growth process. In addition, to ensure equitable access, women will need to be empowered by removing the social, legal, economic and other constraints, which have traditionally hampered their access to and use of resources. How the Tenth Plan will try to achieve these goals is briefly discussed below.

153 The agricultural growth strategy will help landless women (as well as deprived community groups) through its emphasis on the production of high value crops (horticulture, bee keeping) and livestock, which require less land. Irrigation policies supporting shallow tube well development (complemented by strong support to the poor and women) will have similar effects. In forestry, community and leasehold forestry development based on the user group approach will help to significantly expand income generating opportunities for women, as well as for deprived groups. As discussed, the government also will explore the possibility of helping the poor to acquire land (through a land bank and/or low cost loans or grants), and improve their access to agricultural inputs and credit. Increased agricultural production and productivity would also help expand wage employment and improve wage levels in rural areas. Attention will also be given to reducing wage differentials between men and women through appropriate revisions in minimum wages. And, ongoing targeted programs for women (for example, entrepreneurship development and skills training, income generation 
programs, production loans and marketing programs) will be expanded, with priority given to women heads of households, all of which would help increase incomes of women.

154 Similar interventions will be undertaken in the social sectors. In education, literacy programs for women will be expanded, with the objective of raising female literacy to $55 \%$. As noted, scholarship programs for girls will be significantly expanded; and measures will be adopted to increase school attendance by girls and hiring of more female teachers; and the existing gender bias in the school curricula will be corrected. In the health sector, the major thrusts of the program - emphasis on $\mathrm{MCH}$ programs, family planning services, HIV/AIDS control,- - should all help women. Mobile clinics will also be used for this purpose. In drinking water, the community user group and demand based approach will significantly expand the role of women in this area, through increased voice (minimum $40 \%$ representation in user groups) and influence in decision-making. And the construction of rural roads and trails, (together with access to drinking water), would contribute significantly to improve quality of life and increased access to schools, health facilities and markets for women and girls.

155Other key areas where planned actions will significantly help women include: (i) Eliminating legal discrimination against women, by revising existing discriminatory laws; providing legal assistance to women to enforce the provisions of the newly revised Muluki Ain (inheritance laws); (ii) Affirmative action to increase women's role in public office, administration and community level participation and management, all of which will contribute to women's empowerment; and (iii) Introducing legal and other changes to prevent disorder against women, including a social education process, involving information campaigns and public discussions about the role of women and their rights. Women's development will be regarded as a cross cutting theme which runs across the four pillars; and each of the key ministries which will be responsible for program implementation will be required to specifically monitor the impact of their sectoral programs on women. In addition, the Ministry or Women, Children and Social Welfare, and the Poverty Monitoring Unit within the NPC will also monitor their progress (see below).

156 The approach to mainstreaming the deprived communities will be broadly similar: the emphasis will be on ensuring social inclusion through normal sectoral programs and activities, supplemented by targeted initiatives; for example, with regard to service delivery and infrastructure development, (such as primary schools, health facilities, drinking water etc.), the respective line ministries will be required to give equal attention to deprived communities to ensure that they are served as well as others. They will also be required to monitor and report progress achieved annually. Similarly, in targeted programs, equal opportunities will be provided for deprived communities (for example, in skills training, income generation activities, etc.). The Ministry of Local Development, together with Nepal Dalit Commission and the National Academy for the upliftment of indigenous people, which will be created, will monitor these activities. At the VDC level, VDCs will be required to include in their periodic Plans specific measures for meeting the needs of deprived communities, and report annually on their implementation. Affirmative action in a number of important areas (such education, health, participation in public service, administration, 
political life and at the community level) would be taken to help achieve progressive results in this regard, until such time as these communities become sufficiently empowered to stand on their own, and fight for their rights.

157 Targeted Programs. Broad-based economic growth human development and efforts to achieve social inclusion will benefit the poor. But, despite such efforts, there will be specific groups of people who may either be unable to escape the poverty trap or take an unacceptably long time to do so. Many of them lack education, knowledge, skills, and access to resources and opportunities to benefit from general development programs. These groups can be the hard-core poor, assetless, disadvantaged groups, indigenous communities, people living in remote areas, female-headed households and women.

158 In the past, several programs have been started under both Eighth and Ninth Plans to meet the needs of these diverse groups. However, despite some successes, the plans failed to achieve the desire results. Too many fragmented interventions, lack of co-ordination and follow-up, inadequate resources and commitment and lack of poor-targeted programs were the main deficiencies.

159 Along with efforts to mainstream the poor and deprived communities and areas, the Tenth Plan is bringing out a number of special programs to meet their needs. The basic objective of the targeted programs is to design and implement the programs in such a way so that they benefit the poor. The strategy underlying these programs will be to develop appropriate modalities for the selection or targeting of the beneficiary groups. The coverage and outreach will be increased in the case of successful projects. However, various income cut-off points, geographical targeting, group or self-targeting modalities will be used for various compensatory, market-based and facilitation programs. These measures will help in administering safety net and targeted programs fairly and equitably.

160 To improve their effectiveness, the Tenth Plan has adopted some new approaches: (i) Targeted programs of similar nature, (which were earlier implemented by different agencies with different modalities), will be merged and implementation modalities will be simplified. (ii) While central government agencies as Ministries of Local Development, Education, Health and Agriculture will continue to operate some of the programs, the government has initiated a Poverty Alleviation Fund (PAF), which will be used as an umbrella program in order to strengthen target-oriented programs. Proposed poverty interventions will be widely discussed with the grassroots organizations, local governments and the general public in order to strengthen ownership of the programs and ensure successful implementation. This will also help ensure that targeted programs will not undermine local governments and that they will correctly target the very poor. (iii) The PAF will increasingly utilize NGOs and CBOs as support groups for the target groups. (iv) Improved modalities will be put in place to ensure effective monitoring of the mainstreaming efforts by central government ministries, as well as of targeted programs. Poverty monitoring will be institutionalized; and a central monitoring unit under a Joint Secretary has been created in the National planning Commission (NPC) for this purpose. Also, poverty mapping will be initiated to provide a database for both mainstreaming by the line ministries and targeted programs in order to better identify 
beneficiary groups and targeting modalities. (v) Additional resources will be provided to the backward regions by the adoption of a population-based resource allocation formula, with possible additional funding to reduce existing disparities. This in turn should enable a number of programs (such as skills training, literacy etc) to be expanded, in consultation with local communities. And, (vi) actions will be taken to empower the poorer and deprived groups by increasing their representation/participation at various levels of public office and political process.

161 The targeted programs envisaged in the Tenth Plan include (a) multi dimensional/integrated area development programs for construction of infrastructures as drinking water, small irrigation, schools, health posts, and trails in backward areas with the support of training, credit and technical support activities; as well as (b) group programs, aimed at improving the access of target groups to resources, skills and opportunities for income generation. These include programs such as women's group formation and empowerment, income generation activities, non-formal education, skills training, technology adaptation and advisory services in agriculture and livestock, food for work in famine-hit areas, and occasionally cash grants for food and supplies, among others. Many of these programs already exist, sometimes overlapping and generally not efficiently run. As noted earlier, they will be streamlined and merged where possible. They will be supplemented by additional programs to ensure availability of food stuffs (food security) in remote areas, improved access to education for deprived groups, (through scholarship programs) and to rehabilitate people suffering from disorder in affected areas.

162 Targeted programs will also help to increase employment opportunities for the poor. For this purpose, the effectiveness of existing training and skill development programs will be improved, by making such programs more cost-effective and relevant for acquiring the skills needed for self-employment and for wage employment. For example, migrant workers who go abroad as unskilled labor from poor and deprived groups will be assisted to significantly increase their earning capacity through short duration training in appropriate skills. Other target groups would include youth, dropouts from schools and colleges and those affected by the disorder situation needing rehabilitation. Similarly, labor intensive public works and minimum needs programs using local labor will be utilized to help increase income generation in rural areas. Reconstruction and rehabilitation of damaged infrastructure and other structures will provide a major opportunity in this regard when the law and order situation improves. The Government will also explore the possibility of providing assistance to the landless poor to acquire land through arrangements such as a land bank or cash subsides.

163 Mainstreaming the very poor, deprived communities and backward regions through faster growth and social and infrastructure development are very essential. However, it will take time, if only because of limited capacity of central government agencies. Therefore, alternative ways must be explored to achieve quicker results. A possible approach would be to involve local governments and community groups in area development efforts and to channel the additional allocations for "infrastructure development in backward areas" through the DDCs/Village Committees themselves. This will be accompanied by mobilization of deprived 
(beneficiary) groups through NGOs and CBOs, earmarking funds for deprived groups, involving them and ensuring that they are adequately represented in the decision making process.

\section{Good Governance}

164 The government recognizes that good governance is one area where effective actions will help to make the Tenth Plan different from previous plans. Indeed, as noted earlier, without significant progress in this area, it will be virtually impossible to achieve the objectives outlined under the first three pillars of the poverty reduction strategy. It is worth noting that Nepal has made significant progress in creating institutional mechanisms and strengthening procedures to improve key governance aspects; for example, accounting and auditing functions within the government are clearly separated, an independent Auditor General's office and an active Public Accounts Committee exist, strong anti-corruption legislation and institutional mechanisms are in place, and considerable progress has been achieved in computerizing fiscal accounts and strengthening procurement procedure. Notwithstanding these improvements however, the effective enforcement of procedures and institutional arrangements remains weak, and governance problems abound. To achieve good progress in terms of poverty reduction and development, improvements are necessary over a broad spectrum of public actions, for ensuring the efficiency of the civil service, assuring accountability, reducing corruption and leakages, and accelerating decentralization as an important vehicle for better delivery of services, with greater accountability and beneficiary/community participation. The key elements of the Tenth Plan's strategies in these respects are discussed below.

165 Civil service reforms were started two years ago, but as noted, progress to date has been slow. The Tenth Plan seeks to accelerate reforms in this important area. Its main objectives in this regard are to: (i) in accordance with the overall strategy of streamlining the role of the government and transferring responsibilities to local levels, to "right-size" the government and to reduce the growth of financial administrative overheads; and (ii) to make the civil service efficient, accountable and transparent. (iii) Related to the last objective is the need to strengthen institutional capacity to combat corruption.

166 In regard to the first objective, a number of actions have already been taken in the last two years. On the basis of the recommendation of the Public Expenditure Review Commission (PERC), a number of offices of line ministries and departments have been merged or closed down, temporary staff have been eliminated or regularized, and several permanent posts have been abolished. A policy of utilizing surplus permanent staff in development activities conducted by other agencies of the government, as well as mot creating new posts (hiring freeze) have been adopted. A civil service census of existing staff to help update personnel records and to match them with the payroll, as well as computerization of personnel records by the Ministry of General Administration are under way, while a voluntary retirement scheme has been initiated. The completion of these activities, together with austerity measures introduced recently, would also help restrain the growth of current expenditures. 
167 The reform program to make the civil service efficient, accountable and transparent will involve actions on two fronts: (a) recruitment, transfers and promotions will be merit-based, with transparent criteria (to be finalized by the Ministry of General Administration), backed up by an annual performance evaluation system. (i) A long-term pay policy will be introduced together with appropriate decompression of the pay scales, together with additional economic incentives based on work performance in order to encourage the evolution of a motivated, honest and independent civil service cadre. The pay structure has already been increased by 50-80\% 1999 as a step in this direction. (ii) As a necessary complement to "right sizing", capacity and skill mix within the civil service will be improved, with a view to enhancing staff productivity; and adequate training and career development opportunities will be provided for this purpose. (iii) to ensure adequate representation of women and deprived groups, affirmative action will be introduced. (b) In parallel, to ensure accountability for work performance, (i) annual work plans and service standards (for delivery of services/work performance) will be set for central and local level administrative units, together with the publication of a Citizens' Charter. (ii) Accountability measures (discussed below) will be implemented in order to ensure service delivery, and strengthen supervision, monitoring and compliance with fiscal regulations and standards. (iii) The civil service Act will also be revised in order to insulate civil servants from political interference and hold them responsible for matters, which fall under their preview. (c) Finally, as an essential part of civil service reform, the institutional capacity in the government for effectively carrying out anticorruption programs will be significantly strengthened.

\section{Improving Financial Management and Accountability}

168 Nepal already has a good institutional framework for ensuring sound financial management and accountability, including well established regulations and administrative procedures, institutions for their enforcement, for independent auditing and reporting and for ultimate review/oversight by the parliament. However, as noted earlier, these arrangements have not worked well in practice, leading to considerable corruption, leakages and misuse of resources and poor development results. Correcting these weaknesses is critical to the effective implementation of the Tenth Plan.

169 Government has taken a number of steps over the last two years to address these issues, including the formulation of a comprehensive Financial Accountability Regulations Act in 1999, the adoption of the recommendations of the PERC, the Local Self Government Act and the recent Country Financial Administration Assessment (CFAA); and strict enforcement of these regulations. These collectively represent a systematic approach to significantly improve the budgeting, expenditure management and monitoring system. In this regard, some important measures have already been implemented, while the others are expected to be enforced over the next 1-3 years. The key reforms include the following: (i) The budgeting process is being strengthened. The development budget was prioritized in 2002, (as part of a three year MTEF), and the number of projects/programs was significantly reduced. Priority projects are required to prepare trimesterly work plans with detailed output/physical achievement targets and expected results. (ii) Fund releases by the FCGO are being linked directly to work programs and the provision of expenditure reports (on a trimesterly basis) for 
previous releases. Importantly, the discretion previously allowed to line ministries and agencies to transfer funds between programs and activities will now be restricted. The regular budget will be integrated with the development budget in 2004 and subjected to the same prioritization discipline, and the new expenditure reporting and fund release procedures linking them to performance will be extended to all projects/activities. (iii) Expenditure monitoring capacity within the government is being significantly strengthened; (iv) Together with the enhancement of the capacity of internal audit agency (Financial Comptroller General's Office-FCGO), external auditor (Office of the Auditor General-OAG) and the Public Accounts Committee. (v) The Government has agreed to the implementation of the Development Action Plan of the CFAA as per agreed time frame; (vi) Efforts are under way to reform the public procurement system through the enactment of a new procurement law and revision of procurement regulations along the lines suggested in the recent CPAR, and to enhance capacity building in this regard. (vii) Similarly, steps are being taken to ensure accountability of local governments for activities that will be transferred to them (see below). (viii) Similarly, to ensure transparency and accountability, information on budget allocations, expenditures and outputs will be published, and made available to the public. In this context, a web portal for $\mathrm{HMG} / \mathrm{N}$ has been created, with links to government departments forms information on programs and activities; (ix) a Political Party Law was enacted in 2002 requiring the Auditor General to audit the accounts of all political parties; and (x) to create increased public awareness, FM radio programming has been opened up to the private sector, while freedom of Information Legislation is expected to be enacted, and the National Vigilance Center is to be strengthened by mid 2004. Finally, a series of actions have already been taken to reduce corruption and misappropriation; and a comprehensive Anti-Corruption strategy have been approved and action plan for the implementation is being worked out.

170 Effective implementation of the government's Anti-Corruption Strategy is important to ensure good governance. In its drive against corruption, the Tenth Plan's main objective is to prevent corrupt practices and leakages in order to ensure proper use of public resources and improved service delivery. The major strategies being adopted for this purpose are to formulate and effectively implement an anti-corruption strategy, and strengthen the judicial system and institutional arrangements for prevention of corruption.

171 An important start has been made recently in taking effective actions in this area. Legislation to strengthen the Commission for Investigation of Abuse of Authority (CIAA) has been enacted, a special court for speedy handling of corruption cases has been established recently, and a Judicial Commission for investigating into holding of property and financial assets by politicians and senior government officials was established and the report has been submitted to the government. An Anti-money laundering Act will be enacted soon to discourage and control corruption. Similarly, National Vigilance Center will be activated and strengthened, while the Commission for Investigation of Abuse of Authority (CIAA) will be strengthened by increasing its budgetary, physical, human and technological resources, and the establishment of district/regional CIAA offices. With the effective implementation of these programs, corruption will be reduced considerably leading to efficiency in resource allocation and service delivery. Delivery of justice will become effective while the integrity of the public service will also improve. 


\section{Decentralization}

172 Decentralization is an important means of bringing development closer to the rural poor-by involving local communities in developing appropriate programs which are best suited to their needs and in implementing them, ensuring greater accountability for use of public resources, and mainstreaming the poor and deprived groups. The local Self Governance Act (LSGA, 1999) provides a framework for decentralization, which the government has agreed to implement in a phased manner. The Local Bodies Finance Commission (LBFC) has also recently made recommendations for fiscal devolution. A Decentralization Implementation and Monitoring Committee was also set up to oversee effective implementation. But progress so far has been hampered by institutional capacity and fiscal constraints, and more recently by the dissolution of elected local bodies.

173 The main objectives of the Tenth Plan in this area are to ensure greater participation of people in the governance process to accelerate the development process by implementing fiscal devolution in a phase-wise manner as envisaged in the LSGA; and creating necessary institutional mechanisms including the formation of a Local Service Commission. The main strategies being adopted to achieve these objectives include: the devolution of basic service delivery functions, capacity building of local bodies and decentralization of certain revenue mobilization functions to local bodies. The major activities being undertaken to carry out this strategy include the transfer of the management and operation of DIDO, schools, health posts, postal service, agriculture and small irrigation projects, as well as rural roads, to local bodies. The government will constitute local service cadres and enhance the planning, management and evaluation capacities of the local bodies by providing the necessary training and equipment. Revenue collection and fiscal management of local bodies will be improved and auditing and accounting system refined. As a result of these initiatives, it is expected that over the Plan period, 25,000 primary schools, all sub-health posts and agriculture extension services will be transferred to local bodies. The share of local revenue in the local bodies' budget will rise, transparency and accountability will increase and service delivery to communities at village levels will improve considerably. 


\section{Financing}

The Tenth Plan

\section{Introduction}

174 The formulation of a well-designed strategy through extensive nation-wide consultations is a major milestone in the drive to reduce poverty and mainstream the poor. The real test of this strategy, however, depends on: (a) whether it is credible and realistic in relation to the socio-political challenges and resource constraints facing the nation, and (b) whether it can be effectively implemented in order to deliver the expected results to the poor. This section briefly reviews the financing aspects of the Plan, while its implementation and monitoring aspects are discussed in Section VII.

175 In the present circumstances, it is possible to take different approaches to the (Tenth) Plan's development strategy and its macroeconomic framework. One could be a "business as usual" approach, setting higher targets and ambitious goals. However, this is very risky, because the Plan may not be implementable in the absence of domestic and external resources that are needed. A second approach would be to be very conservative, even err on the side of caution, and project the current gloom into the future in the belief that the situation will get worse before it begins to improve, and that donors' support would gradually erode. Such an approach based on "low case" projections however is equally undesirable and self-defeating; they could lead to a self-fulfilling downward spiral, in which poverty may only get worse. A third would be to chart a course in between: accept fully the current constraints for the short term, but take the difficult steps that are needed to move the economy on to a higher path as quickly as possible and win the support of stakeholders in that process. This would require limiting development activities to resource availabilities right now, but as the situation improves and more domestic and external resources become available through positive and pro-active actions, expand development/poverty reduction programs to higher, sustainable levels. This is what the Tenth Plan tries to do.

176 It is also important to keep the Plan's objectives in perspective. First, the Plan is expected to meet the needs of multiple audiences. The donor community-Nepal's important development partners - are a vital part of that audience. The Plan is also for domestic constituents. A Plan which offers only gloom and doom and continued sacrifices for the latter, without a ray of hope for the future is a recipe for social and political disaster. Second, the Plan has been under preparation for nearly two years now; and given the rapidity with which recent events have unfolded, the Plan drafts have already been revised several times. Taking more time again to revise the Plan in line with the latest developments as they unfold is a "nowin proposition", because it can be an un-ending process. Third, it is not necessary to do so. As indicated elsewhere in this report, the Tenth Plan should be seen as a flexible strategic 
document, not as an immutable Master Plan. It has built-in mechanisms to adjust its size, priorities in terms of projects/programs and activities, and resource allocations and expenditure levels to actual resource availability on an annual basis, (or even more frequently, if needed). If resource availability is less, budget allocations especially for lower priority activities can be reduced; and, if the resource situation improves, Plan expenditures can then be increased accordingly. As discussed below, the Government has already clearly demonstrated its willingness and ability to adjust the public expenditure program to resource availabilities and prioritize it to protect the PRSP's key poverty reduction priorities through the MTEF; and in actual implementation managed it even more tightly during the course of this fiscal year.

177 Accordingly, the rest of this section briefly reviews the Tenth Plan's strategy with regard to its financing. It starts with the "normal case"-what the government would like to do, if resources are available. Even here though, the program for the first year has been sharply reduced, (reflecting the present resource constraints), but picks up quickly thereafter. Recognizing that the resolution of the present fiscal and socio-political constraints may take more time and the Plan's targets and expenditure programs may have to be scaled down for a longer period, a "lower case" scenario, (which is really a base case) is then presented. The lower case scenario is indeed the operational basis at present, and will be adjusted every year through the MTEF as resource availabities and development needs change, (for example as may be required with the progress of the peace negotiation process). And, as and when resource availabilities improve, the Government will try to move up to the normal case scenario to the extent possible. The remainder of this section will discuss how future expenditure adjustments will be made in practice, (through the MTEF, expenditure prioritization etc); as well as the actual adjustments that have been made so far in this year's budget to firmly anchor the Tenth Plan to resource availability and to protect its poverty reduction priorities through the MTEF. A third "low case" scenario is not separately discussed, because these built-in mechanisms will help reduce the Plan expenditures further in a systematic way, if needed.

\section{Macro-economic Framework}

178 The macro-economic framework of the Tenth Plan has been set taking into account the economic growth target, the financial resources required to meet that target, and the incremental capital output ratio estimated at 4.3:1. Given the fact that resource availability, implementation capacity and Plan outcome will be heavily influenced by the law and order situation in the country, the macro economic framework has been designed on the basis of two scenarios for targeted economic growth. The first-Normal Case-assumes that restoration of peace within the first year of the Plan would provide room for a GDP growth of 6.2 percent per annum. The investment requirement to attain this growth, given the incremental capitaloutput ratio, would be about Rs. 610 billion for the entire Plan period. As private sector is expected to contribute about 72 percent of this investment, the required government investment for attaining the growth target would be Rs. 170 billion for the Plan period. The corresponding development outlay by the Government would be Rs. 234 billion. 
The annual decomposition of this development outlay is in line with the MTEF, which was formulated in FY 2003. Starting from Rs. 32.5 billion in the first year of the Plan, development expenditure would reach Rs. 51.5 billion in the third year of the Plan.

179 In case the restoration of sustainable peace takes a longer time, the 'normal' economic growth would be difficult to attain. A risky investment climate for the private sector, resource constraints in the public sector and constrained Plan implementation capacity would hamper the growth potential. Accordingly, economic growth in the constrained environment is expected to be confined to only 4.3 percent per annum under this alternative 'low case' scenario. The investment required to attain the lower growth target would be Rs. 457 billion. Of this, the investment to be made by the government would be Rs. 129 billion; and the corresponding development expenditure level would be Rs. 178 billion for the five year Plan period. Accordingly, from Rs. 29 billion in the first year, the development expenditure will rise to Rs. 40.5 billion in the third year of the Plan.

180 The key assumptions underlying these two scenarios are discussed in some detail below. However, it is worth noting that maintaining a sustainable macroeconomic framework and ensuring macroeconomic stability are built in as key imperatives under both scenarios. The major differences between the two scenarios are with regard to the scope for mobilization of government revenue and domestic/national savings, (both of which will be closely related to the levels of economic activity/growth), and the feasible levels of external assistance inflows. Under both scenarios, prudent monetary, fiscal and exchange rate policies designed to keep domestic inflation at around $4.5 \%$ p.a. and foreign exchange reserves at comfortable levels (nine months' imports equivalent) will be pursued; and the overall fiscal deficit (after grants) is expected to remain at a sustainable level of about 5 percent of GDP throughout the Plan period. Much of this deficit would be financed by concessional external loans; and domestic borrowing will average only about 2.0 percent of GDP per annum over the Plan period. Such a fiscal deficit would not pose any serious threat to price and balance of payments stability of the country. Financing this defic it through the planned level of domestic borrowing also will not lead to a substantial rise in the debt burden of the government. Debt servicing will remain within affordable limits.

\section{The Normal Case}

181 The Normal Case Scenario is based on a number of critical assumptions: (i) The security situation will improve beginning in the second half of 2002/03, helping to bring about a modest revival in tourism and domestic economic activities. (ii) The agriculture sector is expected to grow at a modest rate. These will help the economy to achieve a $3.3 \%$ growth rate in 2002/03. (iii) Global economic conditions will also improve in 2003/04, helping to achieve faster GDP growth from then on- $6.1 \%$ in $2003 / 04$, rising to $7.5 \%$ in $2006 / 07$. (iv) Lower revenue growth will initia lly constrain development spending in 2002/03 to only about Rs. 32.5 billion; but will recover strongly after that. (The revenue/GDP ratio will rise from $12.0 \%$ in FY 2002 to 14.0\% in FY 2007). (v) Savings and investment rates, after a slow start in $2002 / 03$, are expected to grow by $11 \%$ and $9 \%$ per annum respectively during the Plan period. (National savings will rise from $17.4 \%$ of GDP in FY 2002 to $23.1 \%$ in FY 2007). (vi) 
Prioritization of projects and improved monitoring will increase the effectiveness of public expenditure and bring positive results; and (vii) Accelerated reforms will help attract more foreign assistance and raise growth rates further, especially during the last 2 years of the Plan period.

182 Investment requirements of the Tenth Plan have been estimated by using the Input-Output methodology. A number of strategic choices made in the Plan, (for example, the need to focus on investments which can give quick results, the emphasis on agricultural and social development as the mainstay of the poverty reduction strategy, and the need to make the administration efficient and cost-effective), influence these estimates. Similarly, other crosscutting themes which run right through the Plan strategy, such as limiting public interventions and focusing them on critical areas where they can make the most beneficial impact, (such as social sector development), increasing the reliance on the private sector for the development of infrastructure etc., also have a significant impact on the pattern of investment. (These, as well as the prioritizing of activities to be included in the Tenth Plan are discussed in some detail in the sectoral chapters).

183 The investment requirements for the normal case derived on this basis and their broad sectoral composition are summarized in Table 12. A few comments help to clarify some of the numbers presented in that table: (i) The agriculture sector's share of total investment $(13.8 \%)$ includes its direct share only. There are additional investments which contribute to increasing agric ultural production and productivity, (such as agricultural and rural roads, rural electricity etc), which are included under the programs of those sectors. (ii) Similarly, apart from the social sector investment (of 31.5\% shown in Table 13), there are large expenditures of a recurrent nature in these sectors. (In education, for example, recurrent expenditures account for nearly $70 \%$ of total sectoral expenditures, and in health, about one-half). (iii) The construction sub-sector's share also represents only its direct investment, since capital expenditures on large projects (such as those for electricity generation and surface irrigation) are included under those sectors.

184 Subject to these caveats, Table 12 shows that: (i) total gross capital formation of about Rs. 610 billion would be required to implement the poverty reduction strategy and attain the targets and goals set under the normal case. (Gross investment, including stock changes, would be about Rs. 641 billion). This level of investment is equivalent to $25.9 \%$ of GDP projected under that scenario, about two percentage points above the somewhat disappointing investment/GDP ratio which was actually achieved during the Ninth Plan. (ii) The larger part of the investment (roughly 72\%) is expected to be undertaken by the private sector, with the public sector undertaking the remaining $28 \%$. This is higher than the past ratio of $63 \%$ during the Ninth Plan; but it reflects the Tenth Plan's strategy of reducing public interventions except in critical areas and the increased reliance on the private sector. (iii) The sectoral composition of proposed investment strongly reflects this structural shift. Public investment is expected to focus mainly on the social sectors and agriculture-related activities, transport and electricity and water, where there are still a number of large ongoing public sector projects, (such as Marsyangdi Hydropower and Melamchi). The private sector, on the other hand, is expected to contribute the dominant share of investment in finance, servic es, construction, manufacturing, 
trade, tourism, hotels and restaurants etc. Its share in agriculture, electricity and transport and communications (where the public sector role has traditionally been important) is also expected to grow rapidly.

Table 12: Investment requirements of The Tenth Plan (Normal Case) (Rs. billion, in 2001/02 prices)

\begin{tabular}{|c|c|c|c|c|c|c|}
\hline \multirow{3}{*}{ Sectors } & \multirow{3}{*}{$\begin{array}{c}\text { Gross } \\
\text { Fixed } \\
\text { Capital } \\
\text { Formation }\end{array}$} & \multirow{3}{*}{$\begin{array}{l}\text { Percent } \\
\text { of Total }\end{array}$} & \multicolumn{4}{|c|}{ Of Which } \\
\hline & & & \multicolumn{2}{|c|}{ Government } & \multicolumn{2}{|c|}{ Private Sector } \\
\hline & & & Amount & Percent & Amount & Percent \\
\hline Agriculture, Irrigation And Forestry & 84.4 & 13.8 & 31.8 & 18.7 & 52.6 & 12.0 \\
\hline Non-Agriculture & 525.4 & 86.2 & 137.9 & 81.2 & 387.5 & 88.0 \\
\hline Social Services & 131.3 & 21.5 & 64.1 & 37.8 & 67.2 & 15.3 \\
\hline - Industry and Mining & 36.7 & 6.0 & 1.4 & 0.8 & 35.3 & 8.0 \\
\hline - Electricity, gas and Water & 86.1 & 14.1 & 33.3 & 19.6 & 52.8 & 12.0 \\
\hline - Construction & 13.2 & 2.2 & 0.0 & 0.0 & 13.2 & 3.0 \\
\hline - Trade, Hotels and Restaurants & 44.6 & 7.3 & 2.0 & 1.2 & 42.6 & 9.7 \\
\hline - Transport and Communication & 122.3 & 20.1 & 34.4 & 20.3 & 87.9 & 20.0 \\
\hline - Finance, Real estate, Services & 91.3 & 15.0 & 2.7 & 1.6 & 88.6 & 20.1 \\
\hline Total Fixed Capital Formation & 609.8 & 100.0 & 169.7 & 100.0 & 440.1 & 100.0 \\
\hline
\end{tabular}

185 In accordance with the poverty reduction strategy, pubic sector development expenditures (Table 13) are expected to focus mainly on agriculture, irrigation and forestry (24\%), social sectors (39\%), transport and communications (16\%) and electricity and water (15\%). The combined share of agriculture and social services is expected to rise from $55 \%$ of development spending under the Ninth Plan to 63\% under the Tenth Plan.

Table 13: Sectoral Allocation of Development Expenditure- Normal Case (Rs billion in 2001/02 Prices)

\begin{tabular}{lcccccc}
\hline \multirow{2}{*}{ Sectors } & \multicolumn{3}{c}{ Ninth Plan Target } & \multicolumn{2}{c}{ Ninth Plan Estimate } & \multicolumn{2}{c}{ Tenth Plan Target } \\
\cline { 2 - 7 } & Amount & Percent & Amount & Percent & Amount & Percent \\
\hline Agriculture, Irrigation and & 67.4 & 27.1 & 32.7 & 19.2 & 56.2 & 24.0 \\
Forestry & & & & & & \\
Non-agriculture & 181.9 & 72.9 & 138.2 & 80.8 & 177.8 & 76.0 \\
Social Services & 83.0 & 33.3 & 61.1 & 36.0 & 90.4 & 38.6 \\
Industry and Mining & 2.1 & 0.8 & 2.7 & 1.6 & 2.3 & 1.0 \\
Electricity, Gas and Water & 46.6 & 18.7 & 30.8 & 18.1 & 36.0 & 15.4 \\
Trade, Hotel and Restaurant & 3.8 & 1.5 & 3.2 & 1.9 & 3.5 & 1.5 \\
Transport and Communication & 43.8 & 17.6 & 29.8 & 17.6 & 36.4 & 15.6 \\
Finance and Real Stateb & 0.3 & 0.1 & 6.6 & 3.9 & 2.7 & 1.2 \\
Miscellaneousc & 2.1 & 0.9 & 2.9 & 1.7 & 6.5 & 2.8 \\
Total & $\mathbf{2 4 9 . 3}$ & $\mathbf{1 0 0 . 0}$ & 169.8 & $\mathbf{1 0 0 . 0}$ & $\mathbf{2 3 4 . 0}$ & $\mathbf{1 0 0 . 0}$ \\
\hline
\end{tabular}

a Including targeted programs.

b Including financial sector reform program.

c Administration reform, plan, statistics, science and technology, labor and supplies are included.

186 Table 14 helps to explain how total investment in the economy and government development expenditures are expected to be financed under the normal case (Annex 3 provides the annual break-down of these numbers). While total investment is expected to rise by about four percentage points of GDP between 2001/02 and 2006/07, it is expected to be matched by a similar increase in domestic and national savings. Higher economic growth 
would enable significant increases in both per-capita consumption and domestic savings, while the continued growth of remittances by Nepali workers abroad would help to further augment national savings. And, the evolution of a more efficient and dynamic financial system (as a result of ongoing financial sector reforms) would help intermediate such savings for private investment. However, it is important to recognize that the assumed ICORs, and the associated investment and savings estimates, may be too high, if the potentialefficiency gains from the new emphasis on implementation and service delivery, public expenditure prioritization and greater private involvement are realized.

Table 14: The Tenth Plan Macroeconomic Projections- Normal Case Scenario (In 2001/02 Prices)

\begin{tabular}{lcccc}
\hline & $\begin{array}{c}\text { Ninth Plan } \\
\text { End 2001/02 }\end{array}$ & $\begin{array}{c}\text { Tenth Plan } \\
\text { End 2006/07 }\end{array}$ & $\begin{array}{c}\text { Tenth Plan } \\
\text { Average }\end{array}$ & $\begin{array}{c}\text { Change 2001/02- } \\
\text { 2006/07 (\% of GDP) }\end{array}$ \\
\hline Economic Growth & & & & \\
- GDP Growth (real) p.a. & -0.6 & 7.5 & 6.2 & +8.1 \\
- Per Capita GDP Growth (real) p.a. & -2.9 & 5.4 & 4.0 & +8.3 \\
Investment and Savings (\%of GDP) & & & & \\
- Total Investment & 24.4 & 29.0 & 25.9 & +4.6 \\
- Gross Fixed Capita formation & 23.2 & 27.7 & 24.6 & +4.5 \\
- Private & 13.2 & 19.9 & 16.7 & +6.7 \\
- Public & 10.0 & 7.9 & 8.0 & -2.1 \\
- Total Consumption & 88.4 & 83.8 & 86.1 & -4.6 \\
- Domestic Savings & 11.6 & 16.2 & 13.9 & +4.6 \\
- National Savings & 17.4 & 23.1 & 20.4 & +5.7 \\
Balance of Payments (\% of GDP) & & & & \\
- Exports of Goods \& NFS & 16.1 & 17.9 & 18.5 & +1.8 \\
- Imports of Goods \& NFS & 28.9 & 30.7 & 30.5 & 1.8 \\
- Factor Incomeb & 5.4 & 6.5 & 6.5 & +1.1 \\
- Current Account Balancec & -7.0 & -5.9 & -5.5 & +1.1 \\
Government finances (\%of GDP) & & & & \\
- Government Revenue & 12.0 & 14.0 & 13.0 & +2.0 \\
- Government Expenditure & 19.3 & 21.3 & 20.4 & +2.0 \\
- Regular & 11.7 & 9.7 & 11.0 & -2.0 \\
- Development & 7.6 & 11.5 & 9.5 & +3.9 \\
- Government Budget Balancec & -7.3 & -7.3 & -7.4 & - \\
Gross Foreign Aid & $\mathbf{4 . 7}$ & $\mathbf{5 . 9}$ & $\mathbf{5 . 4}$ & $\mathbf{+ 1 . 2}$ \\
- Grants & 2.1 & 2.0 & 2.2 & -0.1 \\
- Loans & 2.6 & 3.9 & 3.2 & +1.3 \\
Domestic Borrowing & $\mathbf{2 . 6}$ & 1.4 & $\mathbf{2 . 0}$ & $\mathbf{- 1 . 2}$ \\
Inflation (\% p.a.) & $\mathbf{2 . 9}$ & $\mathbf{4 . 0}$ & $\mathbf{4 . 5}$ & - \\
\hline
\end{tabular}

a Includes changes in stocks. b Includes net transfers. c Excluding grants.

187 The Plan strategy recognizes the importance of sound fiscal management for creating a sustainable basis for continued high economic growth and social development by maintaining macroeconomic stability and reducing the excessive dependence on foreign and domestic borrowing in order to mitigate the rising debt burden. To this end, it seeks to accelerate revenue growth, reduce the growth of current expenditures, and limit development expenditures to sustainable levels. 
Accordingly, under the Normal Case, an early resolution of the conflict, together with efforts to "right size" the administration and reduced administrative costs, would help to bring down the regular expenditure/GDP ratio from $12.7 \%$ this year (and $11.7 \%$ in 2001/02) to the preconflict level of around $10 \%$ by $2006 / 07$. Similarly, a recovery in economic activities and strong efforts to improve revenue collections (for example, by strengthening tax administration, and making it autonomous, revising and periodically updating customs valuation, reducing tax exemptions and rebates, widening the tax net etc.) would help raise the revenue ratio gradually (from 12.0 of GDP in 2001/02 to about $14 \%$ by 2006/07. The Plan also seeks to encourage the donor community to provide more grant funding, and in line with the government's Foreign Aid Policy (2002), to invite foreign loan assistance primarily to support poverty reducing priority activities. While a modest rise in the foreign aid/GDP ratio to $5.9 \%$ in $2006 / 07$ is projected, as a matter of policy, domestic borrowing will be reduced (from $2.6 \%$ of GDP in 2001/02) to about $1.4 \%$ of GDP by 2006/07. However, increased revenue surplus (higher revenues, lower current expenditures) and aid inflows would allow development spending as a percentage of GDP to rise from 7.6\% of GDP in 2001/02 to about $11.5 \%$ by $2006 / 07$ under this scenario. During the Tenth Plan period as a whole, foreign financing would be equivalent to $58 \%$ of the development budget - about the same ratio (56\%) under the Ninth Plan — while domestic borrowing would finance 21\%, and the revenue surplus the remaining 21\% (See Table 14).

188 The Tenth Plan recognizes that there are considerable uncertainties with regard to the key assumptions made in the normal case scenario, and that if these assumptions are not realized, it would be difficult to attain the poverty reduction targets. The major risks in this regard include the following: (i) The restoration of internal law and order will take more time. This will slowdown and prolong the recovery of the economy; and (ii) Resource constraints will continue to hamper development efforts for a longer period. Revenue growth will be lower (due to slower economic recovery) and current expenditures cannot be reduced quickly (due to continuation of the disorder); (iii) The recovery of the global economy may also take more time, so that external demand for commodity and labor exports from Nepal may remain weak; and this will lead to slower growth of domestic/national savings. The overall impact of such developments would be to significantly slow down economic growth, overall investment and government's development activities, and consequently development results in terms of poverty reduction. In such a situation, the government will need to pursue the economic reform agenda even more vigorously.

\section{The Alternative Case}

189 Recognizing that some of these risks outlined above may indeed materialize and constrain resource availability and the potential for economic recovery and growth, the Tenth Plan incorporates an alternative lower case scenario to indicate how the government will deal with such a situation (Table 15). The key assumptions of the lower case scenario include the following: (i) The security situation will improve late in (beginning in the last quarter of) 2002/03; (ii) The recovery in the domestic economy will be slower and take longer, with a slower rate of growth in exports and remittances reflecting slower recovery of the 
international economy also. (iii) Revenue growth will be slow, reflecting the continuing weakness in the economy. The revenue/GDP ratio, after an initial decline (from $12.0 \%$ in $2001 / 02$ ) to $11.8 \%$ in $2002 / 03$, will rise slowly to $13.0 \%$ by $2006 / 07$, averaging only $12.4 \%$ p.a. for the Tenth Plan period. (iv) Current expenditures will decline marginally from $11.7 \%$ in $2001 / 02$ and $12.6 \%$ in $2002 / 03$ (reflecting the need to sustain some security-related expenditure) to $11.1 \%$ of GDP by $2006 / 07$, and average $11.9 \%$ p.a. of the Tenth Plan period. (v) Gross aid inflows will increase only modestly (from $4.7 \%$ of GDP in 2001/02 to 5.7\% in 2006/07); (vi) but, the government will continue to limit domestic borrowing to limit the debt burden; and such borrowing will fall steadily from 3.2\% of GDP in 2002/03 to only $0.8 \%$ in 2006/07. (vii) The cumulative effects of these assumptions are that resource availability for financing development spending by the government will remain very tight. For example, in 2002/03 development spending is assumed to be only Rs. 29 billion (equivalent to 6.5\% of GDP) compared to a budget target of Rs. 38.3 billion and actual spending ratio of $7.6 \%$ in 2001/02. Moreover, development expenditure/GDP ratio will rise only gradually to $8.4 \%$ by 2006/07, averaging 7.6\% of GDP p.a. over the Plan period. (viii) Under this scenario domestic/ national savings and overall investment levels in the economy will decline below the 2001/02 levels, reflecting a sharp decline in these variables during the current year (2002/03), followed by a very modest recovery in the next few years. Thus, national savings are expected to reach only $16.1 \%$ of GDP by $2006 / 07$, and total investment in the economy only $21.8 \%$ by $2006 / 07$ (Table 15 ). Therefore, to attain a growth rate of $4.3 \%$ p.a. over the Plan period, a significant improvement in the efficiency of the use of resources will be required. This is of course what the Tenth Plan strategy tries to do by prioritizing expenditures, focusing on quick returns and results in terms of output and service delivery and improving accountability and monitoring.

190 Given these assumptions, the economy's performance in terms of GDP growth, social and infrastructure development and poverty reduction will be significantly lower under the Lower Case than under the Normal Case (Table 12, last column). For example, GDP growth will be only about $2.0 \%$ in $2002 / 03$, and rise slowly thereafter to $4.0 \%$ and $4.5 \%$ in the next two years, though picking up thereafter to $6.0 \%$ by 2006/07. For the Tenth Plan period as a whole, GDP growth will average $4.3 \%$ p.a., permitting per-capita income growth of about 2.0 $\%$ per annum. This is still better than the GDP and per capita income growth rates of $3.6 \%$ and $1.3 \%$ respectively achieved during the Ninth Plan, but not good enough from a macroeconomic perspective to achieve significant progress in poverty reduction. Not surprisingly, development programs, activities and results in virtually every area would be constrained.

However, qualitative improvements in the public expenditure program and supporting private sector investments can still make a significant difference in terms of development/poverty reduction results. For example, prioritizing the public expenditure program and directing limited public resources to the most important areas for poverty reduction, channelling donor aid and private initiatives to support the same objectives, and focusing intensively on the effective implementation of these programs to ensure better service delivery will help achieve better development results from the same resources and growth efforts. Accordingly, the government has initiated, and begun to vigorously implement, an extensive economic reform 
agenda (including the MTEF and related public resource management measures), which is summarized in the Immediate Action Plan.

Table 15: The Tenth Plan-Macroeconomic Projections-Alternative Scenario (In 2001/02 Prices)

\begin{tabular}{|c|c|c|c|c|}
\hline & $\begin{array}{l}\text { Ninth Plan } \\
\text { End 2001/02 }\end{array}$ & $\begin{array}{l}\text { Tenth Plan } \\
\text { End 2006/07 }\end{array}$ & $\begin{array}{l}\text { Tenth Plan } \\
\text { Average }\end{array}$ & $\begin{array}{l}\text { Change } 2001 / 02- \\
2006 / 07 \text { (\% of GDP) }\end{array}$ \\
\hline \multicolumn{5}{|l|}{ Economic Growth } \\
\hline - GDP Growth (real) p.a. & -0.6 & 6.0 & 4.3 & +4.9 \\
\hline $\begin{array}{l}\text { - Per Capita GDP Growth (real) p.a. } \\
\text { Investment and Savings (\%of GDP) }\end{array}$ & -2.9 & 3.9 & 2.1 & +4.9 \\
\hline - Total Investmenta & 24.4 & 21.8 & 20.8 & -2.6 \\
\hline - Gross Fixed capita formation & 23.2 & 20.5 & 19.5 & -2.7 \\
\hline - Private & 13.2 & 12.0 & 11.1 & -1.2 \\
\hline - Public & 10.0 & 8.6 & 8.4 & -1.4 \\
\hline - Total Consumption & 88.4 & 90.8 & 90.9 & +2.4 \\
\hline - Domestic Savings & 11.6 & 9.2 & 9.1 & -2.4 \\
\hline - National Savings & 17.4 & 16.1 & 15.7 & -1.3 \\
\hline \multicolumn{5}{|l|}{ Balance of Payments ( $\%$ of GDP) } \\
\hline - Exports of Goods \& NFS & 16.1 & 14.8 & 16.5 & -1.3 \\
\hline - Imports of Goods \& NFS & 28.9 & 27.4 & 28.2 & -1.6 \\
\hline - Factor Incomeb & 5.4 & 6.5 & 6.6 & +1.1 \\
\hline - Current Account Balancec & -7.0 & -5.7 & -5.1 & +1.3 \\
\hline \multicolumn{5}{|l|}{ Government finances (\%of GDP) } \\
\hline - Government Revenue & 12.0 & 13.0 & 12.4 & +1.0 \\
\hline - Government Expenditure & 19.3 & 19.5 & 19.5 & +0.2 \\
\hline - Regular & 11.7 & 11.1 & 11.9 & -0.6 \\
\hline - Development & 7.6 & 8.4 & 7.6 & +0.8 \\
\hline - Government Budget Balancec & -7.3 & -6.5 & -7.1 & +0.8 \\
\hline Gross Foreign Aid & 4.7 & 5.7 & 5.1 & +1.0 \\
\hline - Grants & 2.1 & 2.2 & 2.2 & +0.1 \\
\hline - Loans & 2.6 & 3.5 & 2.9 & +0.9 \\
\hline Domestic Borrowing & 2.6 & 0.8 & 1.9 & -1.8 \\
\hline Inflation (\% p.a.) & 2.9 & 4.6 & 4.5 & - \\
\hline
\end{tabular}

a Includes changes in stocks.

b Includes net transfers c Excluding grants

\section{Medium Term Expenditure Framework (MTEF)}

191 Recognizing the fiscal deterioration and the need to revise the Tenth Plan accordingly, the Government initiated the preparation in parallel of a Medium Term Expenditure Framework (MTEF) in late 2001. The key objective of the MTEF was to begin to implement the Tenth Plan from the beginning of the fiscal year 2002/03, without waiting for the formal finalization of the Plan. Accordingly, the key projects/programs and activities that are considered essential for achieving the Tenth Plan's poverty reduction goals and their resource requirements for the next three years were to be identified, and were to be given priority in terms of budget allocations in the 2002/03 budget. Additional considerations guiding the MTEF, in view of the fragility of the fiscal situation, were: (i) How to streamline the budget 
which was already overextended well beyond resource availability, with over 600 ongoing activities/budget lines? (ii) How to protect the Tenth Plan's key priorities in the event of further shortfalls in resource availability? and (iii) How to ensure that the resources allocated and released for priority activities would be effectively utilized? The MTEF was expected to be the principal instrument for operationalizing the Tenth Plan, by prioritizing the proposed Plan activities according to the changing resource situation, and firmly linking the annual budget process and the Plan.

192 Thus, a three year MTEF was prepared in early 2002 by virtually the same line ministry teams responsible for Tenth Plan preparation, using similar methodology for ranking and prioritizing activities, (but with a sharper focus on implementability, short term financing needs and results). On the basis of the MTEF, (i) the 2002/03 development budget was initially set at a significantly lower level-Rs. 38 billion, compared to Rs. 50 billion in the 2001/02 budget; and the number of budget lines were reduced from over 600 to 430. (ii) Even more importantly, all activities were classified into three groups according to their priority $\left(\mathrm{P}_{1}\right.$ being the highest priority and $\mathrm{P}_{3}$ being the lowest); and (iii) The principle was established that the priority classification would be strictly followed in releasing funds for development activities. Thus, $\mathrm{P}_{1} \mathrm{~s}$ will receive first priority in budget releases; and $\mathrm{P}_{2}$ and $\mathrm{P}_{3}$ will get funded only if funds are still available after providing for $\mathrm{P}_{1} \mathrm{~s}$. This has established clear criteria and methodology for adjusting resource allocations on the basis of Tenth Plan's priorities, in line with changes in the resource situation. (iv) Finally, resource allocation was linked to expenditure reporting and performance, in order to ensure satisfactory results. Thus, under the new system that has been evolved, activities which do not provide statements of expenditures (SOEs) for the preceding trimester will not be given additional funds, until they provide the SOE's. (Section VII discusses these in more detail).

193 The MTEF and the associated budget reforms now provide an effective mechanism to adjust the annual expenditure program to the changes in the government's resource position, while protecting the Tenth Plan's priorities. For example, the resource position appears to have become even more difficult during the months following the announcement of the 200203 budget; and accordingly, the MTEF and its macroeconomic scenarios have been further revised and updated to facilitate expenditure management. As noted above, the Lower Case scenario assumes development spending of Rs. 29 billion for this year, in line with this fiscal deterioration, compared with Rs. 32.5 billion assumed in the Normal Case scenario and the Rs.38 billion in he FY 2003 Budget which was announced last July. The prioritization classification (P1-P3) has been further sharpened to protect the poverty reduction priorities. This is summarized in Table 16 below, which shows the MTEF allocations for key priority sector activities under the revised Normal Case and Lower Case scenarios. Thus, (i) the budget allocations for the key sectors which are at the center of agricultural/rural development and human development/service delivery strategies (namely agriculture, irrigation, forestry, roads, electricity, education, health, drinking water and local development) have been increasingly protected; and their combined share is projected to rise from $65 \%$ of total expenditures in FY 2003 to 74\% in FY 2005 under the Normal case and from 71\% to 76\% under the Lower case (Table 16). (ii) Similarly, within these sectors themselves, the key poverty reducing activities are being increasingly emphasized. Thus, within the key sectors, $\mathrm{P} 1$ activities as a proportion of sectoral expenditures are projected to rise from $62 \%$ in $\mathrm{FY}$ 
2003 to $72 \%$ in FY 2005 under the Lower case, and from 64\% to 67\% under the Normal case. (iii) Similarly, all P1 activities as a proportion of total development expenditures would rise from 55\% in FY 2003 to 66\% in FY 2005 under the Lower case and from 52\% to 59\% under the Normal case. (iv) It is also important to note that the actual release of funds is being managed tightly, with funds being released so far only to P1 activities (186 out of 430 budget lines in the 2002/03 budget). Others will get funded, as noted, only if there are funds available after meeting the needs of $\mathrm{P}_{1} \mathrm{~s}$. This mechanism also provides upside flexibility to the government to expand the development program if the resource situation were to improve, for example by releasing such additional funds to the next sub-set of activities in terms of priorities. This has also obviated the need for another "Low Case" scenario, as discussed earlier, while considerably strengthening the government's capacity to control and manage the development/expenditure program in a difficult environment.

Table 16: MTEF-Budget Allocations for Priority Sectors and Activities, 2002/03-2004/05

\begin{tabular}{lccc}
\hline & $\mathbf{2 0 0 2 / 0 3}$ & $\mathbf{2 0 0 3 / 0 4}$ & $\mathbf{2 0 0 4 / 0 5}$ \\
\hline Normal Case & & & \\
- Total Development Exp (Rs. billion) & 32.5 & 40.9 & 51.4 \\
- Share of Key Sectors* in Dev. Exps.(\%) & 65.2 & 74.5 & 73.9 \\
- Share of P1s in Key Sectors (\%) & 64.2 & 62.5 & 67.2 \\
- Share of P1s in Total Dev. Exps.(\%) & 51.6 & 55.2 & 58.5 \\
Lower Case & & & \\
- Total Development Exp (Rs. billion) & 29.0 & 35.0 & 40.5 \\
- Share of Key Sectors* in Dev. Exps.(\%) & 71.4 & 73.5 & 75.5 \\
- Share of P1s in Key Sectors (\%) & 61.6 & 66.0 & 71.8 \\
- Share of P1s in Total Dev. Exps.(\%) & 54.9 & 59.4 & 66.2 \\
\hline
\end{tabular}

* Includes Agriculture, irrigation, forestry, roads, electricity, education, health, drinking water and local development.

Source: The Medium Term Expenditure Framework (MTEF).

194 Even though the Tenth Plan has been implemented in a difficult period and the MTEF has been prepared under a resource constraint, it is important that to meet the objective of poverty alleviation, pro-poor activities are protected and the poverty related expenses are increased. Table 17 shows the budget estimates of pro-poor activities identified in MTEF. Although, the given poverty related resource projections have to be reviewed and strengthened, allocation reflects the commitment of the government for pro-poor economic activities. The table shows that the percentage of prioritised poverty expenditure will increase from $67.6 \%$ in FY 2003 to $80.1 \%$ in FY 2005. Emphasis of the poverty focused expenditure has been mainly in enhancing agriculture focused economic growth, human development and targeted program for streamlining the deprived communities.

195 Thus, the MTEF represents a major step forward in operationalizing the PRSP/Tenth Plan. It is an extremely useful instrument for managing downside/upside risks, protecting the key poverty reduction priorities of the Plan and for ensuring tight fiscal management. Indeed, Nepal is currently the only country in the South Asia Region, which is rigorously utilizing the MTEF as an important operational instrument. Notwithstanding the progress, which has been achieved over the past year, however, there are a number of weaknesses in MTEF preparation, which need to be addressed: (i) The MTEF at present focuses only on development expenditures of the Government. To make it more useful, the Government intends to expand it to include regular expenditures also, and to improve the expenditure 
classification to conform with international norms, on the basis recurrent/capital (instead of regular/development) expenditures. (ii) Unit cost estimates which are used for costing programs and activities need to be improved. Unit costs can and do vary significantly for similar activities between urban and rural areas and between regions; but the information currently available within most sectors are not robust. The government intends to improve such estimates by undertaking field surveys and developing sector and activity-specific estimates in the future in order to improve expenditure estimates, as well as monitoring of progress. In this context, an important start has been already made towards improving personnel costs through the computerization of personnel records as noted earlier. (iii) The prioritization of activities needs to be significantly improved by consistent application of the ranking criteria, so that the MTEF accurately reflects the PRSP/Tenth Plan's poverty reduction priorities. MTEF developed and implemented in FY 2002/03 was a good start, more can and will be done on the next round of the MTEF to improve the prioritization/ranking process. (iv) Finally, to enhance its operational usefulness, the resource estimates underpinning the MTEF will need to be revised and updated regularly. While this is being done now, the estimates of aid inflows are still subject to considerable uncertainties; and these need to be forecasted and monitored better with the co-operation of external donors.

Table 17: Major Poverty Related Development Expenses (Rs. billion)

\begin{tabular}{|c|c|c|c|}
\hline \multirow[t]{2}{*}{ Sector } & \multirow{2}{*}{$\begin{array}{c}\text { Budget } \\
\text { FY 2002/03 }\end{array}$} & \multicolumn{2}{|c|}{ Projection } \\
\hline & & FY 2003/04 & FY 2004/05 \\
\hline Education & & & \\
\hline $\begin{array}{l}\text { - Basic and Primary Education, Scholarship and Women's } \\
\text { education }\end{array}$ & 2.34 & 2.57 & 2.83 \\
\hline \multicolumn{4}{|l|}{ Health } \\
\hline - Basic Health and Family Planning & 1.55 & 1.78 & 1.97 \\
\hline $\begin{array}{l}\text { Drinking Water Supply and Sanitation } \\
\text { Rural Electrification }\end{array}$ & 3.53 & 4.74 & 9.93 \\
\hline $\begin{array}{l}\text { - Rural Electrification and distribution alternate energy } \\
\text { Agriculture }\end{array}$ & 1.47 & 2.21 & 2.42 \\
\hline $\begin{array}{l}\text { - Programs for increasing agriculture productivity, crop } \\
\text { diversification, research, extension and training }\end{array}$ & 2.06 & 2.44 & 2.73 \\
\hline Irrigation & 2.58 & 2.35 & 2.98 \\
\hline Income generating forestry activities & 0.15 & 0.16 & 0.17 \\
\hline Rural Infrastructure Development & 5.20 & 5.64 & 6.53 \\
\hline Grant to local communities & 2.87 & 2.96 & 3.42 \\
\hline $\begin{array}{l}\text { Skill Development } \\
\text { (Only of Ministry of Education, Ministry of Industry and } \\
\text { Ministry of Labour) }\end{array}$ & 2.77 & 3.02 & 3.28 \\
\hline $\begin{array}{l}\text { Poverty Alleviation Fund } \\
\text { Micro Credit }\end{array}$ & $\begin{array}{l}0.17 \\
1.47\end{array}$ & $\begin{array}{l}0.5 \\
1.74\end{array}$ & $\begin{array}{l}1.0 \\
2.08\end{array}$ \\
\hline Total & 26.16 & 30.11 & 39.34 \\
\hline Total Development Budget & 38.68 & 43.07 & 49.1 \\
\hline (\% of Prioritized Poverty -Expenditure) & 67.6 & 69.9 & 80.1 \\
\hline
\end{tabular}

196 The potential fiscal stress emanating from the current as well as prospective external and domestic developments even under the Lower Case scenario underlines the need for continued revisions to and updating of the MTEF. A major potential impact of risk is the Iraq war, on the global economy and implications both directly and indirectly for Nepal's commodity and labor exports, remittances, tourism earnings, oil imports and transport costs, and economic growth, as well as for the mobilization of government revenues and domestic/national savings. Similarly, a continuation of the domestic conflict, associated high security spending and constraints on mobilizing adequate domestic revenue for financing development activities would be even more of a concern. The recent pause in hostilities and 
the initiation of peace negotiations however hold considerable promise in this regard; and over the past two months, there is evidence of some pick up in economic activity, tourism and revenue collections, as well as considerable optimism for a recovery in economic growth and development implementation. Nevertheless, there are also significant potential upside risks in this regard. Even as peace is restored, considerable additional resources than that envisaged in the initial MTEF would be required for undertaking rehabilitation, reconstruction and reconciliation activities. Such expenditures could be considerable and would need to be undertaken as a matter of priority in parallel with the prioritized development activities in key areas already identified (under P1s) in the MTEF. To finance such activities, considerable additional external assistance will be needed; and it is reasonable to expect that such assistance might be forthcoming in the event that the peace process is consolidated. Nevertheless, it is unlikely that such requirements will be fully covered by external aid alone, while there will also be uncertainties about the timing as well as the form of such assistance. More domestic resources will be needed to trigger additional external aid (through counterpart funding) as well as for undertaking urgent rehabilitation needs by the government itself. These risks call for continued review of the MTEF to make it a dynamic process whereby the spending needs coming out of the peace process could be incorporated into it. While revisiting the MTEF, as noted earlier, efforts will be made to make unit cost estimates of activities more robust; to build in recurrent expenditures into the MTEF to ensure better understanding of the expenditure demands and to make the budgetary system more predictable; and to improve the forecasting of resource availability for development works. The prioritization of development programs and projects will also be reviewed and low priority projects will be dropped as needed. For all these reasons, the MTEF process will be strengthened and institutionalized, and made an integral part of the planning and implementation process. 


\section{Implementation Modalities}

\section{Introduction}

197 As noted earlier, the effective implementation of the Tenth Plan's poverty reduction strategy in an environment of disorder and fiscal stringency is the biggest development challenge the government has faced in decades. The Tenth Plan will only be as good as its implementation; and its success or failure will be measured by the extent to which it will have succeeded in delivering basic services and infrastructure to the poor, enhancing their quality of life and promoting economic and social inclusion of backward communities and regions. Accordingly, the Tenth Plan lays strong emphasis on implementation, monitoring progress towards the attainment of key poverty reduction goals including those in the context of Millennium Development Goals, and ensuring that the feedback received from intended beneficiaries and target groups is effectively utilized for improving poverty interventions. This section discusses the arrangements that are being put in place for the effective implementation of the Plan's core activities, for monitoring progress and for evaluating their impact on beneficiaries; as well as the need for capacity building/technical assistance efforts at various levels. The key actions, (including institutional and policy reforms), which are required in all these areas, are summarized in the Policy Matrix (Annex 1) and the Immediate Action Plan (Annex 2), which should be viewed as the implementation strategy of the Tenth Plan.

198 The poverty reduction strategy will be implemented by many actors, including the central government and agencies, local bodies, community groups, the private sector, INGOs, NGOs, CBOs etc. Among these, the central government and its agencies will have primary responsibility for carrying out much of the development budget and reform measures. But the Tenth Plan will also rely on alternative mechanisms to improve service delivery. Major part of the reform agenda is aimed at facilitating private sector involvement in widening range of areas and activities. Accelerating the decentralization process by increasingly transferring additional functions and responsibilities to local governments is one approach. Utilizing the Fund Board approach (which has proved to be very successful in setting up drinking water facilities in rural areas), and expanding it to other areas wherever possible is another. Also, NGOs and CBOs will be enlisted for service delivery functions at the local level, (for example by contracting out specific tasks in such areas as health and drinking water), and for community mobilization. Even more important, the local communities themselves will be directly involved in the management of village level service delivery aspects in key areas (see below). With regard to the development budget, the major thrust of the implementation strategy is to, within a sustainable fiscal framework, (i) Identify the priority activities which are essential for poverty reduction; and (ii) Provide adequate funding for them to ensure their 
early completion. (iii) A mid year budget review will be institutionalized so that a sound fiscal framework will be adhered to; (iv) The MTEF would be annually revised and updated for the purpose of ranking and prioritizing all budget-financed activities and for ensuring that priority activities would be protected from funding shortfalls. The scope of the MTEF would be expanded in 2004/05 to cover both recurrent and capital budgets, so that the resource needs for service delivery as well as for operation and maintenance can be fully provided for. (v) Also a project screening system will be introduced to ensure that only those activities with acceptable rates of return will be included in the development program. (vii) To ensure better utilization of funds, accountability and development results, procurement system and fund release procedures have already been changed (see below).

199 The Tenth Plan emphasizes the increased involvement of local bodies - DDCs and VDCs - and communities in the planning, implementation and management of local level activities for ensuring that public money is spent properly to meet the people's needs, and for improving service delivery and accountability. Accordingly, more functions, responsibilities and resources will be transferred to local bodies. Agricultural extension and rural roads programs will be handed over to local bodies in 2003/04. In addition, each ministry will be required over the next five months to review their activities, and develop a detailed work plan, indicating what activities could be transferred to local bodies and when, and what resources and technical support would be needed to ensure a reasonably smooth transition. Similarly, a poverty-based formula will be adopted for providing development grants to DDCs and VDCs, and additional "catch up" grants would be provided to the Mid-Western and Far-Western regions from 2003/04 onwards. Within these allocations, separate amounts will be earmarked for deprived communities to ensure that they will have equal access to public resources; and their representation/participation in community management committees will be assured through affirmative action. To provide a greater degree of self reliance for local bodies, the recommendations of the Local Bodies Finance Commission's report will be implemented in a phased manner, starting with the stronger DDCs in terms of tax potential and management capacity.

200 A major recent innovation in this regard is directly involving the communities themselves in the management of primary schools and health facilities. Community management of primary schools and primary health centers was started in a few districts this year, by setting up village level management committees, giving them the responsibility for their operation and management, and providing funds for them through the DDCs and VDCs and technical support and supervision through the district offices of the concerned ministries. This approach will be expanded into other areas and other activities. Programs are underway to transfer all public primary schools to the communities during the plan period.

201 Related to this issue is the need to similarly co-ordinate the activities of INGOs and NGOs. Undoubtedly, they play a very useful role in many areas in the rural economy; and the Tenth Plan, as discussed, intends to involve them even more in service delivery and social mobilization functions. However, the activities of many such organizations are not transparent, particularly in terms of their sources of funding and the use of such funds; nor are they accountable to local communities. They will need to be subject to similar standards of 
transparency and accountability as the central and local government agencies and communities they work with, as indicated in the recent Foreign Aid Policy (2002) of the Government.

202 Although the main objective of the Tenth Plan is to set the overall framework, principles and main strategies for poverty reduction, the Policy Matrix presented in Annex 1, provides a more detail view of major strategies activities and outcome. The Matrix also clarifies the relations between public strategies and actions and poverty reduction. The structure will be useful in the implementation of poverty reduction strategy of the country.

203 The implementation of the Tenth Plan is not a separate exercise, but will be carried out primarily through actions in each sector, MTEF and the annual budgeting exercise. An exercise to develop prioritized through the detailed annual plans within each sector will be carried out by individual line ministries. The exercise will also refine and sharpen the output indicators which are indicated in the Policy Matrix. This work of designing the detail action plans and refinement of output indicators will be completed by December 2003. This action plan will help to set a good track record on implementation.

204 In order to ensure, good implementation expedite reform programs and improve public service delivery, $\mathrm{HMG} / \mathrm{N}$ has started an intermediate implementation modality called Immediate Action Plan (IAP). The first IAP (Annex 2), which was initiated and implemented in the FY 2002/03, was well-anchored in the Tenth Plan. The IAP was successfully implemented and the result was encouraging. The second IAP is being developed to further strengthen the implementation of the Tenth Plan. Implementation progress is being monitored by a committee - the Reform and Development Group (RDG) - comprising representatives of NPC, MOF and donor agencies. The IAP, in addition to specific actions, sets out the time frame over which the actions are to be implemented, immediate indicators and expected outcomes. The IAP has proved to be an unique tool in the effective implementation of the Tenth Plan.

205 The prevailing disorder situation in the country presents special challenges in terms of implementation. However, a ceasefire has recently taken place, and peace process is in progress. There is considerable optimism that a return to a more normal situation will enable the government to deliver services better and undertake reform measures. Though it seems unlikely, if the peace process is to be in jeopardy, the government will adopt a multi-pronged approach to implementation in the disturbed areas: (i) Where important development projects will need to go on, the government will carry out such activities within "shield and support" programs, for example, sealing off large project construction sites and carrying out the work. (ii) A similar approach will be adopted for critical road construction work, (for example, where explosives will need to be provided and used for rock-blasting purposes). The use of mobile teams for service delivery and for undertaking repairs are some other examples. (iii) Where it is possible to carry out development activities in a larger area with security presence, Integrated Security and Development Programs (ISDP) will be carried out; for example, the Gorkha district has been selected initially for significant ISDP activities. (iv) In areas where government agencies will have difficulty in actively engaging in service delivery, but it is 
possible to use NGOs and local CBOs to carry out essential development activities (for example, providing food and medicines to avoid starvation and epidemics), the government will utilize such channels. (v) In other areas, where there is less problem of security, the government will make serious efforts to implement programs to deliver quick results, in order to prevent further alienation and to win public support. In these areas government interventions will seek to provide employment and income generating activities for the poor, for example through rehabilitation programs, road construction and work for food programs. Such interventions will add extra costs to the normal development activities; but they will have to be accepted (within reasonable limits) to maintain government presence and to prevent further erosion of public sympathy and confidence.

\section{Monitoring and Evaluation Arrangements}

206 Traditionally, monitoring of development activities in Nepal has focused largely on expenditure monitoring only. Although there have been attempts to monitor physical progress and results, this has not been consistently done. This deficiency inevitably le d to leakages and misuse of public resources and poor development results. Although budget allocations and releases were spent on activities, their results in terms of outputs and service delivery were not commensurate with expectations. Ministerial Development Action Committee at the ministry level and National Development Action Committee at the Prime Ministerial level are responsible for rectifying development policies and programs based on the monitoring reports from respective ministries and for some national level core projects from National Planning Commission. However, due to the absence of effective management information system, monitoring, the actions from these Action Committees have still to be fruitful. There is a need for strengthening management information system, and define an integrated frame for monitoring progress of development programs, link them with resources spent, and evaluating them for their effectiveness in reducing income poverty and promoting human development.

207 Monitoring capacity within the government has been weak up to now, in part because of the lack of interest on the part of political leadership in the past and the consequent disuse of even the existing institutional arrangements. Strong efforts will be made to revitalize and strengthen monitoring capacity. Rather than creating new institutions for this purpose, existing arrangements will be reinforced, as necessary, by new initiatives: (i) the primary responsibility for supervision and monitoring is with the line ministries. The existing Project Implementation Units (PIUs) within the line ministries will be significantly strengthened for this purpose. As noted, the line ministries have already been made responsible for monitoring and certifying both financial and implementation (work program) progress of agencies under them. (ii) The NPC has an overview supervisory role, if only to carry out crosschecks on the accuracy of progress certifications by line ministries in order to ensure proper accountability. More importantly, monitoring progress towards poverty reduction will remain a NPC mandate. The Central Monitoring Division and recently established Poverty Monitoring Section of the NPC need to be significantly strengthened to carry out this role and to function as the servicing body for the higher (national) level supervisory institutions. Members of the NPC, who are responsible for various sectors, will be given additional responsibility of 
monitoring and supervision in one of the Development Regions of the country, (iii) The sector level and national level review committees will be reinvigorated. Thus the Ministerial Development Action Committee (MDAC), chaired by concerned Ministers will review sector progress every two months; while the National Development Action Committee (NDAC), chaired by the Prime Minister, will review both sector implementation and progress towards poverty reduction and key human development goals every four months. Key data and information for poverty monitoring will be derived from surveys to be conducted by Central Bureau of Statistics for which institutional structure and human resources of the CBS will be significantly improved.

208 To improve the effectiveness of the existing set-up and new initiatives as noted earlier, considerable capacity building will be required at all levels of the government-line ministries, starting with the NPC, FCGO, as well as the statutory bodies involved in ensuring public accountability, such as the Auditor General's Office and the Public Accounts Committee. This is because the nature of proposed implementation arrangements will be significantly different from current practice and the scale of monitoring efforts envisaged is far larger than the existing capacity of the government. Additional staffing, training and resources therefore will need to be devoted to these activities. Apart from traditional project/program monitoring, skills will need to be developed in the key ministries for poverty monitoring. In addition, the co-ordination of sector activities and programs involving the private sector, NGOs, CBOs etc. in such areas as health, education and drinking water will demand new management skills from the government staff. An assessment will be undertaken of the capacity building needs at various levels of the government as an essential part of the monitoring framework that would be developed by December, 2003 (see below). And, substantial donor assistance (in the form of technical assistance) as well as the government's own resources will need to be provided for this purpose, once such a framework is developed.

209 The government has introduced monitoring of both financial and physical progress from the beginning of fiscal year 2002/03. Fiscal reforms announced in this year's budget require the implementing agencies, for all priority activities (classified as P1), to (i) prepare detailed work programs on a trimesterly basis and, on that basis, formulate monitoring/output indicators for each activity. (ii) Fund releases for priority projects by the Financial Comptroller General's Office (FCGO) will be directly tied to the submission of statements of expenditures by the implementing agency, and certification of satisfactory performance of the agreed work program by the supervising line ministry. This system, though a bit cumbersome initially, is expected to ensure that actual expenditures on priority activities are matched reasonably closely with physical progress, or output/service delivery performance. Apart from providing greater financial discipline, it will also facilitate the preparation of reimbursement claims to donor agencies and help improve aid disbursements. Eventually, as the monitoring capacity within the government ministries improves, these monitoring requirements will be extended to all budgetary activities.

$\mathbf{2 1 0}$ For activities undertaken by local governments, similar monitoring arrangements will be adopted. The Local Self Government (Administration) Rules 1999 provide guidelines in this regard. The reporting requirements will be simplified and strictly enforced, with the Ministry 
of Local Development (MOLD) responsible for overall supervision. The same trimesterly reporting procedures with regard to expenditure reporting and work programs will be initiated and applied, with MOLD providing the certification on satisfactory performance to FCGO before the release of funds can take place. Similarly, for primary schools and health centers that have been transferred by Ministries of Education and Health respectively to village communities, the District Offices of these ministries could provide the supervision and monitoring and the certification that is needed for the trimesterly release of funds by FCGO.

211 Accelerating the decentralization process and ensuring its success will be an important challenge for both the central government and local bodies. To make the decentralization process effective, it is necessary not only to transfer functions and responsibilities to local governments, but also to enhance their capacity building to carry out the delegated functions, including the provision of requisite technical, management supervision, monitoring, as well as accounting and reporting skills. Until these capacities are built up at the local levels, technical support and supervision from central and district level agencies will be essential. While considerable progress has been made in several districts in building the capacities of DDCs and VDCs through donor-supported programs, these efforts will need to be deepened and extended to other districts. This overall capacity building effort in the Government (both central and local) is one area where donor assistance will be needed to ensure the success of the Tenth Plan, perhaps even more than traditional project support. Since various technical assistance programs already constitute a significant proportion of donor aid to Nepal, these programs will be reassessed in order to re-direct such assistance to the national priorities for development, as suggested above.

$\mathbf{2 1 2}$ Given the record so far with regard to capacity and accountability of some local government bodies, additional measures will be adopted to ensure greater accountability and transparency: (i) Access of the public to information is critical for ensuring better service delivery and accountability. Accordingly, information on resources made available to VDCs, for what purposes, planned activities, and how the money has been spent so far will be posted outside each VDC. Also, access of the public to the reports made by VDCs and DDCs on their trimesterly work programs, SOEs and outputs/service delivery performance will be made available, so that the communities themselves can act as watchdogs over VDC performance. (ii) This will be backed by periodic surveys aimed at assessing customer satisfaction with the functioning of local, as well as, central government agencies (see below). (iii) To ensure participation of the poorer and deprived groups in decision-making and management processes at the village level, affirmative action will be taken to ensure their participation. Citizens' charters will be posted. Budget and expenditure status will be put in the web to encourage citizens' direct involvement in the progress monitoring.

213 Considerable data is being collected at present by various agencies and development partners for poverty monitoring purposes (including the assessment of income poverty and human development trends); but there has been no effort to integrate them into a systematic framework/database for poverty monitoring on a regular basis. Accordingly, efforts will now be made to develop such a framework for systematically monitoring and evaluating progress towards the overall goals set for poverty reduction, human development and mainstreaming 
the poor and deprived communities. Poverty monitoring will be closely integrated with the monitoring of the PRSP's implementation and assessing the country's progress towards achieving Millennium Development Goals. Several actions are being taken in this regard: (a) Establishing a special poverty monitoring system within the government, as distinct from normal project/program monitoring. For this purpose, a Poverty Monitoring Section has already been created in the NPC, with the mandate of monitoring and analyzing poverty trends, progress towards key human development indicators and the implementation of measures to ensure social inclusion, and undertaking periodic reviews. (b) Efforts are under way to develop intermediate indicators, with assistance from the line ministries. Indeed, as noted above, work programs and output targets/ intermediate indicators have been developed in many areas, to which both fund releases and actual expenditures will be linked. While this will enable evaluation of short term implementation progress and financial accountability, (c) considerable work remains to be done to develop a framework for assessing the outcomes and impacts of development actions over the medium to longer term on the incomes and livelihoods of people, human development and social progress, among others. This will require significant efforts to evaluate existing data sources, to collect additional data that will be needed for poverty monitoring, to decide on institutional responsibilities and the frequency of collecting such data, and to strengthen institutional capacity, as well as to assess funding needs for such efforts. As indicated in Table 18, apart from data that will be routinely collected for MIS purposes, it would be necessary to conduct detailed NLSS surveys every 56 years. These will be supplemented in the intervening periods by household surveys carried out every 2-3 years. In addition, additional sector surveys (such as those conducted by the Department of Health Services) will be undertaken from time to ascertain progress in critical areas, especially the social sectors. Annual surveys will be carried out focusing particularly on backward regions and deprived communities, to assess year-to-year progress. While these would help evaluate progress over time in reducing poverty reduction and reaching social development goals, other efforts will be launched in parallel to improve the effectiveness of public (and private) programs and activities, for example, through participatory monitoring exercises, expenditure tracking, and client satisfaction surveys in specific sectors and areas. It is expected that such a framework for poverty monitoring and tracking PRSP's progress would be finalized by December 2003.

214 As an initial step, the NPC will undertake a Poverty Mapping exercise, to identify the poor and marginalized groups, to provide a good basis for locating basic social sector infrastructure facilities in backward areas. A new round of the Nepal Living Standards Survey will be carried out in 2003, and its coverage will be broadened to provide additional information required for poverty monitoring. To ensure the effective dissemination of poverty reporting, an annual report on progress on poverty reduction and mainstreaming will be prepared (drawing also on regular monitoring reports by line ministries), by the Poverty Monitoring Unit, under the direction of the Vice-Chairman, NPC, for review by the National Development Action Committee (NDAC). This Annual report will be evolved as a Country Report on the Progress on Millennium Development Goals. Utilizing available information on various dimensions of income and human poverty, the first issue of such a report has already been brought out. 
215 Table 18 below summarizes the indicators/key actions that are presently envisaged for monitoring both PRSP implementation and progress in poverty reduction. The Table focuses on key areas where progress in effective implementation of the PRSP is critical, but it should be regarded as preliminary. A more detailed set of indicators to track progress in PRSP implementation and poverty reduction will be formulated when the work program for setting up a monitoring framework is completed in December.

\section{Conclusion}

216 Recognizing the importance of effective implementation and monitoring of the poverty reduction strategy, His Majesty's Government is developing a comprehensive participatory implementation, monitoring and evaluation strategy, with technical support and assistance from the development partners. The current work program has focussed on the initial requirements for monitoring the implementation of key work programs and activities and the intermediate indicators of outputs from such activities, together with specification of institutional responsibilities and formats and time schedules for reporting. This phase of the work program including necessary budgeting, planning and procedural changes; the establishment of a central poverty monitoring unit; and supervisory arrangements at the national and highest political levels to oversee progress has been largely completed and made operational. Work is now under way to develop comprehensive institutional arrangements for measuring and evaluating the impact and outcomes of poverty reduction efforts over the medium to longer term, to put in place effective arrangements to collect relevant data and information on a sustainable and regular basis, to analyse and effectively utilize them for policy purposes, for institutionalizing dissemination and feedback mechanisms and for developing and strengthening the necessary institutional capacity at all levels to carry out these tasks. Developing such a comprehensive framework, with donor support, is a major undertaking; and it is expected that the exercise would be completed by December 2003. 
Table 18: Key Output/Outcome/Impact and Process Indicators

\begin{tabular}{|c|c|c|c|c|c|}
\hline Strategy/sector & Indicators/Key Actions & $\begin{array}{l}\text { Levels of } \\
\text { Analysis/ } \\
\text { Desegregation }\end{array}$ & $\begin{array}{l}\text { Frequency of } \\
\text { Collection }\end{array}$ & Sources & $\begin{array}{l}\text { Responsible } \\
\text { Agency }\end{array}$ \\
\hline \multirow[t]{4}{*}{$\begin{array}{l}\text { Poverty Incidence } \\
\text { and Employment }\end{array}$} & $\begin{array}{l}\text { Poverty Incidence, Intensity and Severity (poverty threshold,\$'day, } \\
\text { consumption basket etc.) }\end{array}$ & NERUS & $5-6$ years & NLSS & CBS \\
\hline & $\begin{array}{l}\text { Household Distribution by Consumption Deciles and Share of } \\
\text { Poorest Quintile }\end{array}$ & NUR & $2-3$ years & Household Survey & CBS \\
\hline & Gini Coefficient of Income & NERUR & $5-6$ years & NLSS & CBS \\
\hline & Labor Participation Rates & NERG & $5-6$ years & Labor Force Survey & CBS \\
\hline Broad-based (pro- & GDP and Per Capita Income Growth & NERS & 2-4 years/Annual & NLSS/HH Survey & CBS \\
\hline poor) Economic & Agriculture GDP and Per Capita Agricultural Income Growth & NERS & 2-4 years/Annual & NLSS/HH Survey & CBS \\
\hline \multirow{5}{*}{ Growth } & Provision of Key Inputs for Agriculture (fertilizer, extension, irrigation) & NER & Annual & MIS & $\mathrm{DOA} / \mathrm{DOI}$ \\
\hline & Access to Institutional/Micro Credit & NERUS & 2-4 years/Annual & HH Survey/MIS & $\mathrm{CBS} / \mathrm{NRB}$ \\
\hline & Tourists' Arrivals & National & Annual & MIS & $\mathrm{DOI}$ \\
\hline & Gross/Net Nepali Workers Going Abroad & National Sector & Annual & National Accounts & CBS \\
\hline & Employment- Number of Jobs Created & National Sector & Annual & National Accounts & CBS \\
\hline Human & Human Development Indicator & NER & 2 years & Survey & UNDP \\
\hline \multirow[t]{17}{*}{ Infrastructure } & Net Enrollment Rates (primary/secondary) & NERUGS & $2-4$ years Annual & NLSS/HH Survey & CBS/DoE \\
\hline & Repetition/Failure Rates in Primary and secondary Levels & NERUGS & 2-4 years Annual & NLSS/HH Survey & CBS/DoE \\
\hline & Time Taken to Reach a Primary School & NERU & $2-4$ years & NLSS/HH Survey & CBS \\
\hline & Student Teacher Ratio & NER & Annual & MIS & CBS \\
\hline & Proportion of Trained Teachers in Primary School & NERU & Annual & MIS & CBS \\
\hline & Proportion of Students in Primary school Getting Scholarship & NERUGS & Annual & MIS & CBS \\
\hline & Life Expectancy at Birth & NEUG & 5 years & NLSS & CBS \\
\hline & Mortality Rates (infant, child, under 5 and maternal & NERUGS & $5-6$ years & HH Survey/MIS & DoHS/CBS \\
\hline & Time Taken to Reach the Nearest Health Facility & NERU & $2-4$ years & NLSS/HH Survey & CBS \\
\hline & One Year Olds (\%) fully Immunized Against Target Diseases & NERU & $2-4$ years Annual & NLSS/DHS/HH Survey & $\mathrm{CBS} / \mathrm{MoHS}$ \\
\hline & Diseases Incidence (TB, malaria, HIVIAIDS) & NERUGS & $5-6$ years & HH Survey & DoHS/CBS \\
\hline & Births (\%) Attended by Skilled Health Personnel & NERUS & 2-4 years/Annual & HH Survey & $\mathrm{CBS} / \mathrm{MoHS}$ \\
\hline & Access to Antenatal Care During Pregnancy & HERUS & 2-4 years/Annual & HH Survey & $\mathrm{CBS} / \mathrm{MoHS}$ \\
\hline & Contraceptive Prevalence Rate & NERUS & $2-4$ years/Annual & HH Survey & CBS \\
\hline & Access to Improved Drinking Water Sources & NERUS & $2-4$ years/Annual & NLSS/HH Survey/MIS & CBS/DWSS \\
\hline & Access to Adequate Sanitation Facilities & NERUS & 2-4 years/Annual & NLSS/HH Survey/MIS & CBS/DWSS \\
\hline & Access to Motorable All Weather Roads & NER & 2-4 years/Annual & HH Survey/MIS & CBS/DoR \\
\hline
\end{tabular}




\begin{tabular}{|c|c|c|c|c|c|}
\hline Strategy/sector & Indicators/Key Actions & $\begin{array}{l}\text { Levels of } \\
\text { Analysis/ } \\
\text { Desegregation }\end{array}$ & $\begin{array}{l}\text { Frequency of } \\
\text { Collection }\end{array}$ & Sources & $\begin{array}{l}\text { Responsible } \\
\text { Agency }\end{array}$ \\
\hline \multirow{9}{*}{$\begin{array}{l}\text { Social Inclusion } \\
\text { And Targeted } \\
\text { Programs }\end{array}$} & Rural Roads Constructed-Kms & NER & $2-4$ years/Annual & HH Survey/MIS & CBS/DoR \\
\hline & Percentage Served by Electricity & NERUS & 2-4 years/Annual & HH Survey/MIS & CBS/NEA \\
\hline & Ratio of Female Literacy to Male Literacy Rate & NERUS & $2-4$ years & NLSS/HH Survey & CBS \\
\hline & $\begin{array}{l}\text { Ratio of Girls' Enrollment to Boys' Enrollment Rate (primary and } \\
\text { secondary) }\end{array}$ & NERUS & 2-4 years/Annual & NLSS/HH Survey/MIS & $\mathrm{CBS} / \mathrm{DoE}$ \\
\hline & Proportion of Female School Teachers & NER & Annual & MIS & DoE \\
\hline & Percentage of Women in political Positions & National Local & $2-4$ years & MIS & $\begin{array}{l}\text { Mo } \\
\text { Parliamentary } \\
\text { Affairs/MoLD }\end{array}$ \\
\hline & Number of Community/Leasehold Forestry UG's formed & NERS & 2-4 years/Annual & HH Survey/MIS & $\mathrm{CBS} / \mathrm{MoF}$ \\
\hline & Expenditure and Number of People Receiving Skill Training & NERUGS & 2-4 years/Annual & HH Survey/MIS & CBS/MoL \\
\hline & $\begin{array}{l}\text { Proportion and budget of Students From Disadvantaged Groups } \\
\text { Awarded Scholarships }\end{array}$ & NERGS & Annual & MIS & $\mathrm{MoE}$ \\
\hline \multirow{3}{*}{ Governance } & Number of Mobile Health Camps in Disadvantaged Groups/Areas & NERS & Annual & MIS & $\mathrm{MoH}$ \\
\hline & $\begin{array}{l}\text { Implementation of Decentralization (education, health, agri. } \\
\text { extension, rural roads, fiscal devolution) }\end{array}$ & National & Annual & MIS & MoLD, NPC \\
\hline & Implementation of Anti-Corruption Agenda & National & Annual & MIS & $\begin{array}{l}\text { MoF, NPC, } \\
\text { MoGA }\end{array}$ \\
\hline \multirow{5}{*}{$\begin{array}{l}\text { Civil Service } \\
\text { Reform } \\
\text { Environmental } \\
\text { Management }\end{array}$} & Improvement in recruitment and promotion system & National & $2-4$ years & MIS & MGA,PSC \\
\hline & Reduce political interference in civil service functioning & National & Annual & MIS & MOGA, PMO \\
\hline & Proportion of Land Area Covered by Forest & National Regional & Annual & MIS & MOF \\
\hline & Land Area Protected for Biodiversity & National & Annual & MIS & DNPWC \\
\hline & Carbon dioxide Emission Per Capita & National & Annual & MIS & DoHM \\
\hline \multirow{6}{*}{$\begin{array}{l}\text { Macroeconomic } \\
\text { Stability }\end{array}$} & Gross national Savings and Investment (percent of GDP) & National & Annual & National Accounts & CBS \\
\hline & $\begin{array}{l}\text { Government Expenditure (regular/dev, current/capital) Percent of } \\
\text { GDP }\end{array}$ & National & Annual & Economic Survey & MoF \\
\hline & Revenue (percent of GDP) & National & Annual & Economic Survey & $\mathrm{CBS} / \mathrm{MoF}$ \\
\hline & Fiscal Deficit as Percent of GDP & National & Annual & Economic Survey & $\mathrm{CBS} / \mathrm{MoF}$ \\
\hline & Domestic Borrowing as Percent of GDP & National & Annual & Economic Survey & CBS/NRB \\
\hline & External Assistance as Percent of GDP & National & Annual & Economic Survey & $\mathrm{CBS} / \mathrm{MoF}$ \\
\hline
\end{tabular}




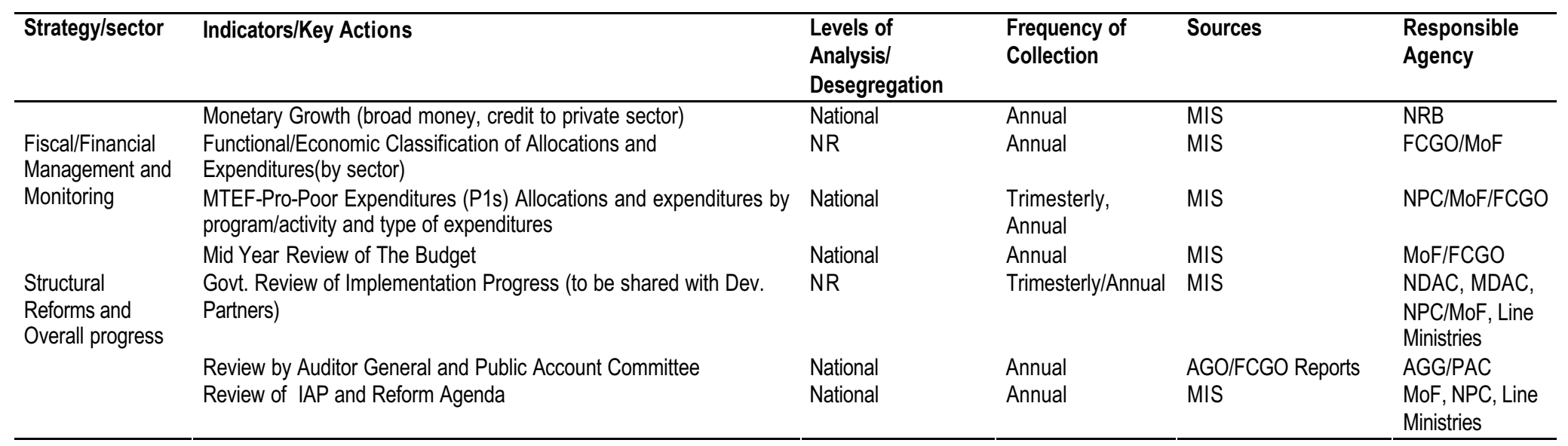

Note NERUS: National/Ecological/Regional/urban/Rural/Social Groups

NERS: National/Ecological/Regional/Social Groups

NER: National/Ecological/Regional

NERUGS: National/Ecological/Regional/Urban/Rural/Gender and Social Groups

NERUR: National/Ecological/Regional/Urban/Rural

NERGS: National/Ecological/Regional/Gender/Social Groups 
Macro Economic Stability

Annex 1

\begin{tabular}{|c|c|c|c|c|c|}
\hline Objective & Strategies & Activities & Intermediate indicators & Outcome & $\begin{array}{l}\text { Responsible } \\
\text { Agency }\end{array}$ \\
\hline \multirow[t]{9}{*}{$\begin{array}{l}\text { Maintain fiscal } \\
\text { discipline }\end{array}$} & \multirow[t]{3}{*}{$\begin{array}{l}\text { - Pursue prudent expenditure } \\
\text { management }\end{array}$} & \multirow{2}{*}{$\begin{array}{l}\text { - Medium Term Expenditure } \\
\text { Framework (MTEF) strengthened } \\
\text { by consolidating regular and } \\
\text { development expenditure and } \\
\text { classifying into recurrent and } \\
\text { capital expenditures ( } 2005 \\
\text { ongoing). }\end{array}$} & $\begin{array}{l}\text { - Fiscal deficit remaining } \\
\text { around } 5 \% \text { of GDP. }\end{array}$ & $\begin{array}{l}\text { - Revenue GDP ratio } \\
\text { increased to } 14 \text { percent } \\
\text { by } 2007 \text {. }\end{array}$ & - NPC,MOF \\
\hline & & & $\begin{array}{l}\text { - Regular expenditure as } \\
\text { percent of GDP declining. }\end{array}$ & $\begin{array}{l}\text { - Decrease tax arrears by } \\
50 \text { percent by } 2007 \text {. }\end{array}$ & \\
\hline & & $\begin{array}{l}\text { - Development expenditure in all } \\
\text { sectors widened and deepened } \\
\text { through MTEF (ongoing). }\end{array}$ & $\begin{array}{l}\text { - Revenue surplus to finance } \\
\text { development spending } \\
\text { improves over years. }\end{array}$ & $\begin{array}{l}\text { - Revenue surplus to } \\
\text { contribute at least } 18 \\
\text { percent of development }\end{array}$ & $\begin{array}{l}\text { - NPC, MOF, } \\
\text { Line } \\
\text { ministries }\end{array}$ \\
\hline & \multirow[t]{6}{*}{$\begin{array}{l}\text { - Improve domestic resource } \\
\text { mobilization }\end{array}$} & $\begin{array}{l}\text { - Actions taken to clear government } \\
\text { arrears to/from the public utilities } \\
(2003 / 04) \text {. }\end{array}$ & $\begin{array}{l}\text { - Annual revenue to grow by } \\
0.4 \% \text { of GDP. }\end{array}$ & expenditure by 2007. & - MOF, FCGO \\
\hline & & - Settle tax arrears (ongoing). & - Number of tax payers with & & - MOF \\
\hline & & $\begin{array}{l}\text { - Recommendations of the fiscal } \\
\text { taskforce for tax reform } \\
\text { implemented (FY } 2004 \text { onwards). }\end{array}$ & $\begin{array}{l}\text { PAN increased to } 300,000 \\
\text { by } 2007 \text {. }\end{array}$ & & - MOF \\
\hline & & $\begin{array}{l}\text { - Tax exemptions and tax rebates } \\
\text { narrowed downed and tax net } \\
\text { widened (ongoing). }\end{array}$ & & & - MOF \\
\hline & & $\begin{array}{l}\text { - Tax administration strengthened } \\
\text { through a move towards an } \\
\text { autonomous tax administration } \\
\text { (ongoing). }\end{array}$ & & & - MOF \\
\hline & & $\begin{array}{l}\text { - Customs valuations revised every } \\
\text { six months based on ASYCUDA } \\
\text { and product (ongoing). }\end{array}$ & & & - MOF \\
\hline \multirow[t]{2}{*}{$\begin{array}{l}\text { Ensure efficiency } \\
\text { of public } \\
\text { resources }\end{array}$} & $\begin{array}{l}\text { - Widen and deepen MTEF to cover } \\
\text { all sectors }\end{array}$ & $\begin{array}{l}\text { - MTEF extended to all Ministries } \\
(2002 / 03) \text {. }\end{array}$ & $\begin{array}{l}\text { - All priority projects/ } \\
\text { programs published in the } \\
\text { Red Book. }\end{array}$ & $\begin{array}{l}\text { - Improved pro poor } \\
\text { budget allocation. }\end{array}$ & - NPC, MOF \\
\hline & $\begin{array}{l}\text { - Increase the share of priority } \\
\text { projects }(\mathrm{P} 1) \text { in the budget. }\end{array}$ & $\begin{array}{l}\text { - Performance based fund release } \\
\text { institutionalized (2003 onwards) }\end{array}$ & $\begin{array}{l}\text { - Project completion period } \\
\text { reduced. }\end{array}$ & $\begin{array}{l}\text { - Improved efficiency of } \\
\text { public spending. }\end{array}$ & - MOF \\
\hline
\end{tabular}




\begin{tabular}{|c|c|c|c|c|c|}
\hline Objective & Strategies & Activities & Intermediate indicators & Outcome & $\begin{array}{l}\text { Responsible } \\
\text { Agency }\end{array}$ \\
\hline & & $\begin{array}{l}\text { - Monitoring and evaluation unit } \\
\text { strengthened ( } 2003 \text { onwards) } \\
\text { - Performance of all } \\
\text { projects/programs made available } \\
\text { in the web site ( } 2003 \text { onwards) }\end{array}$ & $\begin{array}{l}\text { - Time and cost over run } \\
\text { reduced. } \\
\text { - Total share of P1 project } \\
\text { budget in sector ceiling } \\
\text { increased. }\end{array}$ & & $\begin{array}{l}\text { - NPC, MOF } \\
\text { - NPC }\end{array}$ \\
\hline & & $\begin{array}{l}\text { - The new procurement law } \\
\text { implemented (2004). }\end{array}$ & & & MOF, MOPPW \\
\hline \multirow[t]{4}{*}{$\begin{array}{l}\text { Maintenance of } \\
\text { monetary stability }\end{array}$} & $\begin{array}{l}\text { - Pursue Prudent monetary policy to } \\
\text { (i) contain inflation and (ii) attain } \\
\text { favorable balance of payments }\end{array}$ & $\begin{array}{l}\text { - Money supply (M2) contained to a } \\
\text { desirable level (ongoing). }\end{array}$ & $\begin{array}{l}\text { - Money supply (M2) growing } \\
\text { at the rate of } 14.5 \text { percent. }\end{array}$ & $\begin{array}{l}\text { - Average inflation rate } \\
\text { contained at } 5 \% \text { per } \\
\text { annum. }\end{array}$ & - NRB \\
\hline & position & $\begin{array}{l}\text { - Limit central bank borrowing as } \\
\text { per financial regulation (2003/04). }\end{array}$ & $\begin{array}{l}\text { - Share of private sector } \\
\text { credit at } 76 \text { percent of the }\end{array}$ & $\begin{array}{l}\text { - Favorable balance of } \\
\text { payment }\end{array}$ & - MOF \\
\hline & & $\begin{array}{l}\text { - Limit the growth of bank finance to } \\
\text { the government (ongoing). }\end{array}$ & total. & & - NRB/MOF \\
\hline & & $\begin{array}{l}\text { - Widen the instruments of open } \\
\text { market operations (ongoing). }\end{array}$ & & & - NRB \\
\hline \multirow[t]{5}{*}{$\begin{array}{l}\text { Ensure external } \\
\text { sector stability }\end{array}$} & - Diversification of exports. & $\begin{array}{l}\text { - Promote and divers exportable } \\
\text { commodities (commodity -wise and } \\
\text { country-wise) (ongoing). }\end{array}$ & $\begin{array}{l}\text { - Current account deficit } \\
\text { contained at less than } 4 \\
\text { percent of GDP. }\end{array}$ & $\begin{array}{l}\text { - Balance of payment } \\
\text { favorable. }\end{array}$ & - MOICS \\
\hline & $\begin{array}{l}\text { - Promotion of foreign direct } \\
\text { investment. }\end{array}$ & - Alignment of real exchange rate. & & $\begin{array}{l}\text { - International reserves } \\
\text { remains to a }\end{array}$ & - NRB \\
\hline & $\begin{array}{l}\text { - Implementation of prudent foreign } \\
\text { exchange rate policy. }\end{array}$ & $\begin{array}{l}\text { - Act, regulation, tariff structure } \\
\text { amended/revised and procedural } \\
\text { simplification initiated. }\end{array}$ & & comfortable position. & - MOICS, MOF \\
\hline & & $\begin{array}{l}\text { - Increase remittance (from } \\
\text { Nepalese working abroad) by } \\
\text { increasing access/quality of } \\
\text { workers into foreign labor markets } \\
\text { (ongoing). }\end{array}$ & & & - DOL, NRB \\
\hline & & $\begin{array}{l}\text { - Foreign exchange regime } \\
\text { rationalized (ongoing). }\end{array}$ & $\begin{array}{l}\text { - Foreign exchange reserve } \\
\text { to cover minimum of } 6 \\
\text { months of imports. }\end{array}$ & & - NRB \\
\hline
\end{tabular}




\begin{tabular}{|c|c|c|c|c|c|}
\hline Objective & Strategies & Activities & Intermediate indicators & Outcome & $\begin{array}{l}\text { Responsible } \\
\text { Agency }\end{array}$ \\
\hline \multirow[t]{8}{*}{$\begin{array}{l}\text { Strengthen } \\
\text { financial system }\end{array}$} & $\begin{array}{l}\text { - Strengthen Central Bank's } \\
\text { regulatory and supervisory } \\
\text { capability. }\end{array}$ & $\begin{array}{l}\text { - Implement re-engineering plan of } \\
\text { Nepal Rastra Bank (2005). }\end{array}$ & $\begin{array}{l}\text { - Reduced NPA of the } \\
\text { banking system. }\end{array}$ & $\begin{array}{l}\text { - Central Bank's } \\
\text { supervisory and } \\
\text { regulatory capacity } \\
\text { improved. }\end{array}$ & - NRB, MOF \\
\hline & $\begin{array}{l}\text { - Reform state owned commercial } \\
\text { bank. }\end{array}$ & $\begin{array}{l}\text { - Initiate privatization process of } \\
\text { Rastriya Banijya Bank and Nepal } \\
\text { Bank Limited (2005). } \\
\text { - Establish asset Reconstruction } \\
\text { Company (2003/04). }\end{array}$ & $\begin{array}{l}\text { - Improved capital adequacy } \\
\text { ratio. }\end{array}$ & $\begin{array}{l}\text { - Confidence in the } \\
\text { financial system } \\
\text { strengthened. }\end{array}$ & - NRB/MOF \\
\hline & $\begin{array}{l}\text { - Strengthen banking and non- } \\
\text { banking financial institutions. }\end{array}$ & $\begin{array}{l}\text { - Strengthen legislative and } \\
\text { institutional framework for } \\
\text { effective loan recovery (2003/04). }\end{array}$ & $\begin{array}{l}\text { - Interest rate spread } \\
\text { between deposit and } \\
\text { lending narrowed. }\end{array}$ & $\begin{array}{l}\text { - Efficiency of the } \\
\text { financial system service } \\
\text { delivery improved. }\end{array}$ & - NRB/MOF \\
\hline & $\begin{array}{l}\text { - Widen and deepen the activities of } \\
\text { the stock market. }\end{array}$ & $\begin{array}{l}\text { - Enact necessary acts for } \\
\text { regulation of local co-operatives } \\
\text { (2004). }\end{array}$ & $\begin{array}{l}\text { - Number of listed } \\
\text { companies and transaction } \\
\text { volume in the stock }\end{array}$ & & - NRB/MOF \\
\hline & & $\begin{array}{l}\text { Complete audits of two main } \\
\text { development banks ( ADB/N and } \\
\text { NIDC) and develop restructuring } \\
\text { strategy for them (2004). }\end{array}$ & exchange increased. & & - NRB/MOF \\
\hline & & $\begin{array}{l}\text { - Reform rural development banks } \\
\text { (2004). }\end{array}$ & & & - MOF \\
\hline & & $\begin{array}{l}\text { - Strengthen rural financing system } \\
\text { (ongoing). }\end{array}$ & & & - MOF, NRB \\
\hline & & $\begin{array}{l}\text { - Improve the regulatory framework } \\
\text { and operational efficiency of the } \\
\text { stock market (ongoing). }\end{array}$ & & & - MOF, SEBI \\
\hline \multirow{3}{*}{$\begin{array}{l}\text { Enhanced role of } \\
\text { private sector in } \\
\text { economic } \\
\text { activities } \\
\text { enhanced }\end{array}$} & $\begin{array}{l}\text { - Create conducive and competitive } \\
\text { environment for private sector } \\
\text { investment. }\end{array}$ & $\begin{array}{l}\text { - Review labor act and enact } \\
\text { necessary laws for easy entry and } \\
\text { exit (2004). }\end{array}$ & $\begin{array}{l}\text { - Increased share of private } \\
\text { sector in total investment. }\end{array}$ & $\begin{array}{l}\text { - Private sector } \\
\text { investment reached } \\
16.7 \% \text { of GDP. }\end{array}$ & - MOLTM \\
\hline & & $\begin{array}{l}\text { - Mechanism for improving } \\
\text { accounting, auditing and reporting } \\
\text { system strengthened. }\end{array}$ & $\begin{array}{l}\text { - Privatize at least three } \\
\text { SOEs annually. }\end{array}$ & $\begin{array}{l}\text { - Foreign Direct } \\
\text { Investment increased. }\end{array}$ & - MOF, AGO \\
\hline & \multicolumn{5}{|c|}{90} \\
\hline
\end{tabular}




\begin{tabular}{|c|c|c|c|c|}
\hline Objective & Strategies & Activities & $\begin{array}{ll}\text { Intermediate indicators } & \text { Outcome }\end{array}$ & $\begin{array}{l}\text { Responsible } \\
\text { Agency }\end{array}$ \\
\hline & & $\begin{array}{l}\text { - Procedural simplification } \\
\text { especially for investment and } \\
\text { exports. }\end{array}$ & $\begin{array}{l}\text { - Unbundling of NEA and } \\
\text { corporatization of NTC. }\end{array}$ & - MOF, MOICS \\
\hline & $\begin{array}{l}\text { - Continue economic reform to } \\
\text { ensure macroeconomic stability to } \\
\text { increase private sector } \\
\text { investment. }\end{array}$ & $\begin{array}{l}\text { - Continue reform in fiscal, } \\
\text { monetary and financial sectors } \\
\text { (ongoing). }\end{array}$ & & - NRB, MOF \\
\hline & $\begin{array}{l}\text { - Restructure/privatize state owned } \\
\text { enterprises. }\end{array}$ & $\begin{array}{l}\text { - Privatize/corporatize Nepal } \\
\text { Electricity Authority, Nepal } \\
\text { Telecommunication Corporation, } \\
\text { Royal Nepal Airlines. }\end{array}$ & & $\begin{array}{l}\text { - MOF, Line } \\
\text { Ministries }\end{array}$ \\
\hline & & $\begin{array}{l}\text { - Accelerate the privatization of } \\
\text { state owned enterprises and } \\
\text { complete audits of all state owned } \\
\text { enterprises (2004). }\end{array}$ & & $\begin{array}{l}\text { MOF, Line } \\
\text { Ministries }\end{array}$ \\
\hline & & $\begin{array}{l}\text { - Enact liquidation, merger, } \\
\text { bankruptcy acts (2004). }\end{array}$ & & - MOF, MOICS \\
\hline
\end{tabular}




\section{Agriculture}

\begin{tabular}{|c|c|c|c|c|c|}
\hline Objective & Strategies & Activities & Intermediate indicators & Outcome & $\begin{array}{l}\text { Responsible } \\
\text { Agency }\end{array}$ \\
\hline $\begin{array}{l}\text { Increase } \\
\text { agricultural } \\
\text { production } \\
\text { productivity and } \\
\text { income for food } \\
\text { security and }\end{array}$ & $\begin{array}{l}\text { - Expand the use of available } \\
\text { modern technology }\end{array}$ & $\begin{array}{l}\text { Enhanced farmer's group based } \\
\text { technology dissemination system } \\
\text { and capability enhancement of } \\
\text { staff and farmers groups } \\
\text { (continued). }\end{array}$ & $\begin{array}{l}\text { Increased number of } \\
\text { effective farmers groups. }\end{array}$ & $\begin{array}{l}\text { - Need based location } \\
\text { specific technology } \\
\text { recommendations } \\
\text { available and } \\
\text { dissemination system in } \\
\text { place. }\end{array}$ & - MOAC \\
\hline \multirow[t]{6}{*}{ poverty reduction. } & & $\begin{array}{l}\text { Promote research, development } \\
\text { and extension for food security in } \\
\text { severely food deficit districts } \\
\text { (continued). }\end{array}$ & $\begin{array}{l}\text { - Co-ordinated need based } \\
\text { research and extension } \\
\text { programs for severely food } \\
\text { deficit areas (specially } \\
\text { remote) in operation. }\end{array}$ & $\begin{array}{l}\text { - More diversified } \\
\text { production system and } \\
\text { enhanced } \\
\text { commercialization }\end{array}$ & - MOAC \\
\hline & & $\begin{array}{l}\text { - Enhance balanced use of agro- } \\
\text { chemicals (continued). }\end{array}$ & $\begin{array}{l}\text { Increase number of } \\
\text { Integrated Pest } \\
\text { Management (IPM) and } \\
\text { other farmers field schools. }\end{array}$ & $\begin{array}{l}\text { - Overall agricultural } \\
\text { growth by } 4.1 \text { percent }\end{array}$ & - MOAC \\
\hline & $\begin{array}{l}\text { - Increase farmers access to } \\
\text { modern agricultural input and } \\
\text { credit }\end{array}$ & $\begin{array}{l}\text { Enhance market based } \\
\text { environment for increasing } \\
\text { fertilizer supply and uses } \\
\text { (continued). }\end{array}$ & $\begin{array}{l}\text { - Increased supply and uses } \\
\text { of fertilizer. }\end{array}$ & $\begin{array}{l}\text { - Crops production } \\
\text { increased by } 4.1 \\
\text { percent. }\end{array}$ & - MOAC \\
\hline & & $\begin{array}{l}\text { - Enhance rural banking activities } \\
\text { (ADBN/ Rural Banks) for effective } \\
\text { credit delivery (continued). }\end{array}$ & - Increased flow of credits. & $\begin{array}{l}\text { - Livestock production } \\
\text { increased by } 4.9 \\
\text { percent. }\end{array}$ & $\begin{array}{l}\text { - } \text { ADBN,NRB, } \\
\text { MOF }\end{array}$ \\
\hline & & $\begin{array}{l}\text { - Strengthen regional research } \\
\text { farms stations and private sectors } \\
\text { resources for ensured quality } \\
\text { seeds/ breeds / planting materials } \\
\text { production and supply to the local } \\
\text { multipliers/ nurseries (continued). }\end{array}$ & $\begin{array}{l}\text { - Increased supply of quality } \\
\text { seeds/breeds/planting } \\
\text { materials to local } \\
\text { multipliers. }\end{array}$ & $\begin{array}{l}\text { - Enhanced agricultural } \\
\text { productivity. }\end{array}$ & $\begin{array}{l}\text { NARC, } \\
\text { MOAC }\end{array}$ \\
\hline & $\begin{array}{l}\text { - Promote diversification and } \\
\text { commercialization in crops/ } \\
\text { livestock production system. }\end{array}$ & $\begin{array}{l}\text { - Implement intensive agriculture } \\
\text { program in year round irrigated } \\
\text { areas (continued). }\end{array}$ & $\begin{array}{l}\text { - Increased number and } \\
\text { coverage of intensive } \\
\text { pockets in year round } \\
\text { irrigated areas. }\end{array}$ & $\begin{array}{l}\text { - Reduced food insecurity } \\
\text { and significant } \\
\text { contribution to income } \\
\text { increases and reduction } \\
\text { in malnutrition and } \\
\text { poverty in rural areas. }\end{array}$ & - MOAC, DOI \\
\hline
\end{tabular}




\begin{tabular}{|c|c|c|c|c|c|}
\hline Objective & Strategies & Activities & Intermediate indicators & Outcome & $\begin{array}{l}\text { Responsible } \\
\text { Agency }\end{array}$ \\
\hline & & $\begin{array}{l}\text { - Provide Incentive and appropriate } \\
\text { support package for expansion of } \\
\text { ground water irrigation and on } \\
\text { farm water management } \\
\text { (continued). }\end{array}$ & $\begin{array}{l}\text { - Increased no of shallow } \\
\text { tubewell and Improved } \\
\text { efficiency of on farm water } \\
\text { uses. }\end{array}$ & $\begin{array}{l}\text { - Increased marketed } \\
\text { volumes of agricultural } \\
\text { products and diversified } \\
\text { agricultural export. }\end{array}$ & - MOAC, DOI \\
\hline & & $\begin{array}{l}\text { - Intensify production of high value } \\
\text { crops /livestock commodities in } \\
\text { potential pockets (continued). }\end{array}$ & $\begin{array}{l}\text { - Increased areas and } \\
\text { coverage of High value } \\
\text { crops/ commodities. }\end{array}$ & & - MOAC \\
\hline & $\begin{array}{l}\text { - Include NGOs / private sector } \\
\text { involvement in partnership and } \\
\text { contract in agricultural service } \\
\text { delivery system. }\end{array}$ & $\begin{array}{l}\text { Ensure involvement of private } \\
\text { sector/ NGOs /CBOs and local } \\
\text { bodies in extension service } \\
\text { delivery (continued). }\end{array}$ & $\begin{array}{l}\text { - Increased involvement of } \\
\text { NGOs/ CBOs / private } \\
\text { sector in service devilry. }\end{array}$ & & - MOAC \\
\hline & $\begin{array}{l}\text { - Improve effectiveness of Planning, } \\
\text { Monitoring and Evaluation (PME) }\end{array}$ & $\begin{array}{l}\text { - Enhance PME capabilities at all } \\
\text { levels (continued). }\end{array}$ & $\begin{array}{l}\text { - Improved database and } \\
\text { regularized reporting and } \\
\text { review system in place. }\end{array}$ & & - MOAC, DOA \\
\hline & & $\begin{array}{l}\text { - Ensure effective, transparent and } \\
\text { timely reporting and review } \\
\text { system (continued). }\end{array}$ & $\begin{array}{l}\text { - Printed monitoring reports } \\
\text { in regular basis. }\end{array}$ & & - MOAC, DOA \\
\hline & $\begin{array}{l}\text { - Decentralize research and } \\
\text { extension. }\end{array}$ & $\begin{array}{l}\text { Devolve DOA/ DLS extension } \\
\text { activities to local bodies and } \\
\text { ensure operational effectiveness } \\
\text { and technical backstopping to } \\
\text { them (continued). }\end{array}$ & $\begin{array}{l}\text { - Decentralized extensions } \\
\text { are fully functional by } 2004 \text {. }\end{array}$ & & - MOAC \\
\hline & & $\begin{array}{l}\text { - Decentralize NARC's adaptive and } \\
\text { on farms research activities to } \\
\text { Regional Agricultural Research } \\
\text { Centers (RARCS) (2005). }\end{array}$ & $\begin{array}{l}\text { - Decentralized NARC's } \\
\text { research to RARCS in } \\
\text { place by } 2004 .\end{array}$ & & - MOAC \\
\hline \multirow[t]{2}{*}{$\begin{array}{l}\text { Develop local and } \\
\text { export market } \\
\text { opportunities }\end{array}$} & $\begin{array}{l}\text { - Encourage private and co- } \\
\text { operative sectors involvement for } \\
\text { market promotion and } \\
\text { infrastructure development. }\end{array}$ & $\begin{array}{l}\text { Co-ordinate the expansion of } \\
\text { agricultural roads and rural } \\
\text { electrification (continued). }\end{array}$ & $\begin{array}{l}\text { - Increased investment in } \\
\text { agricultural road and } \\
\text { electrification. }\end{array}$ & & $\begin{array}{l}\text { - MOAC, DOR, } \\
\text { NEA }\end{array}$ \\
\hline & & $\begin{array}{l}\text { - Develop commodity policies for } \\
\text { congenial environment for private } \\
\text { sector investment. (continued). }\end{array}$ & $\begin{array}{l}\text { - Commodity policies } \\
\text { developed for major } \\
\text { commodities by } 2004 \text {. }\end{array}$ & & $\begin{array}{l}\text { MOAC, } \\
\text { MOICS }\end{array}$ \\
\hline
\end{tabular}




\begin{tabular}{|c|c|c|c|c|}
\hline Objective & Strategies & Activities & Intermediate indicators & $\begin{array}{l}\text { Responsible } \\
\text { Agency }\end{array}$ \\
\hline & & $\begin{array}{l}\text { - Emphasize on marketing } \\
\text { research, flow of market } \\
\text { information and development of } \\
\text { market infrastructure (Agro } \\
\text { industry, collection center, whole- } \\
\text { sale and retail outlets) (continued). } \\
\text { - Promote conductive tariff rate for } \\
\text { agricultural export and import } \\
\text { (continued). }\end{array}$ & $\begin{array}{l}\text { - Increased number of } \\
\text { market infrastructures and } \\
\text { continuity in market } \\
\text { research and information } \\
\text { flow. } \\
\text { - Conducive tariff policies in } \\
\text { place. }\end{array}$ & $\begin{array}{l}\text { - MOAC, } \\
\text { MOICS } \\
\text { - MOAC, MOF, } \\
\text { MOICS }\end{array}$ \\
\hline & & $\begin{array}{l}\text { - Regulate/facilitate agro- } \\
\text { processing and standardization } \\
\text { (ongoing). }\end{array}$ & $\begin{array}{l}\text { - Regulatory services in } \\
\text { place. }\end{array}$ & $\begin{array}{l}\text { - MOAC, FP } \\
\text { Laboratory }\end{array}$ \\
\hline & $\begin{array}{l}\text { - Promote co-operative and } \\
\text { contractual farming. }\end{array}$ & $\begin{array}{l}\text { - Facilitate legal arrangements for } \\
\text { cooperative and contractual } \\
\text { farming }(2004 / 05) \text {. }\end{array}$ & $\begin{array}{l}\text { - Legal arrangement for } \\
\text { contractual farming in place } \\
\text { by } 2004 \text {. } \\
\text { - Cases of cooperative and } \\
\text { contractual farming in place } \\
\text { after } 2004 \text {. }\end{array}$ & - MOAC \\
\hline
\end{tabular}




\begin{tabular}{|c|c|c|c|c|c|}
\hline Objective & Strategies & Activities & Intermediate indicators & Outcome & $\begin{array}{l}\text { Responsible } \\
\text { Agency }\end{array}$ \\
\hline $\begin{array}{l}\text { Promote year } \\
\text { round irrigation } \\
\text { in the irrigable } \\
\text { land. }\end{array}$ & $\begin{array}{l}\text { Establish coordination in } \\
\text { intensive agriculture } \\
\text { program formulation and } \\
\text { implementation in year } \\
\text { round irrigated areas at all } \\
\text { level. }\end{array}$ & $\begin{array}{l}\text { - Enhance maintenance and } \\
\text { rehabilitation of existing farmer } \\
\text { managed and public irrigation } \\
\text { systems (continued). } \\
\text { - Revise irrigation policy and } \\
\text { regulations to give WUAs legal power } \\
\text { to collect irrigation charges (2004/05). } \\
\text { - Initiate private sector management of } \\
\text { large/ medium scale of HMG } \\
\text { managed irrigation system (2004/05). } \\
\text { - Develop and implement small surface } \\
\text { irrigation facilities in the hill and } \\
\text { surface and ground water irrigation } \\
\text { facilities in the Terai (continued). } \\
\text { - Increase involvement of NGO's and } \\
\text { private sector in the irrigation } \\
\text { development and management } \\
\text { (2004/05). } \\
\text { - Adopt co-ordinate approach for timely } \\
\text { supply of irrigation water in intensive } \\
\text { packet areas (continued). } \\
\text { - Scale up On Farm Water } \\
\text { Management Program (continued). } \\
\text { - Ensure irrigation support component } \\
\text { in intensive agriculture program of } \\
\text { MOA (continued). }\end{array}$ & $\begin{array}{l}\text { - Increased number of } \\
\text { rehabilitated and handed } \\
\text { over schemes. } \\
\text { - Increased and strengthened } \\
\text { water users' committees } \\
\text { (WUAS) in place. } \\
\text { - Revised irrigation policy and } \\
\text { regulation in place by } 2004 \text {. } \\
\text { - Increase number and } \\
\text { hecterage of private sector } \\
\text { managed government owned } \\
\text { large/medium schemes. } \\
\text { - Increased number of STW, } \\
\text { DTW and other irrigation } \\
\text { schemes. } \\
\text { - Increased number and } \\
\text { hecterage of new schemes } \\
\text { developed and managed by } \\
\text { NGO's and private sector. } \\
\text { - Timely supply of irrigation } \\
\text { water in pocket areas. } \\
\text { - Strengthen technical support } \\
\text { to farmers. } \\
\text { - Coordinated intensive } \\
\text { agriculture pocket program in } \\
\text { place. }\end{array}$ & $\begin{array}{l}\text { - Year round irrigation } \\
\text { increased to } 50 \% \text { of the } \\
\text { irrigated land by } 2005 . \\
\text { - Additional irrigation } \\
\text { facilities developed in } \\
177,600 \text { ha. from new } \\
\text { schemes and } \\
\text { rehabilitation of } 64,000 \text { ha. } \\
\text { - Management transfer to } \\
\text { WUAs in } 37,000 \text { ha. } \\
\text { - Farmers/WUAs become } \\
\text { capable to own and } \\
\text { manage irrigation systems } \\
\text { up to the size of } 500 \text { ha by } \\
2005 . \\
\text { - Increased irrigation } \\
\text { charge collection by } \\
\text { WUAs significantly. } \\
\text { - Private sector and NGO } \\
\text { participation in irrigation } \\
\text { management increased. }\end{array}$ & 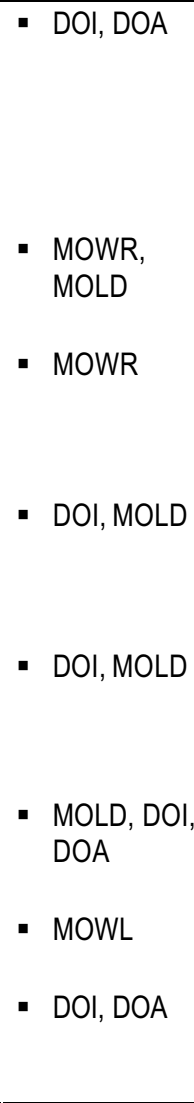 \\
\hline
\end{tabular}




\section{Trade}

\begin{tabular}{|c|c|c|c|c|c|}
\hline Objective & Strategies & Activities & Intermediate indicators & Outcome & $\begin{array}{l}\text { Responsible } \\
\text { Agency }\end{array}$ \\
\hline \multirow[t]{5}{*}{$\begin{array}{l}\text { Increase the } \\
\text { contribution of } \\
\text { trade in the } \\
\text { economy }\end{array}$} & $\begin{array}{l}\text { - Trade policy to be made } \\
\text { compatible with regional / } \\
\text { international agreements. }\end{array}$ & $\begin{array}{l}\text { - Acts/rules compatible with } \\
\text { WTO/SAPTA. (2004 onwards). }\end{array}$ & $\begin{array}{l}\text { - Accession to WTO/SAFTA. } \\
\text { - Trade diversification } \\
\text { enhanced product wise and } \\
\text { country wise. }\end{array}$ & $\begin{array}{l}\text { - Export GDP ratio increased. } \\
\text { - Market/product } \\
\text { diversification. }\end{array}$ & - MOICS \\
\hline & $\begin{array}{l}\text { - Enhance } \\
\text { competitiveness. }\end{array}$ & $\begin{array}{l}\text { - Operationalization of ICD, Birgunj. } \\
(03 / 04) \text {. }\end{array}$ & - ICD Birgunj operationalized. & & - MOICS \\
\hline & & $\begin{array}{l}\text { - Technical support service to } \\
\text { enhance competitiveness of exports } \\
\text { (ongoing). }\end{array}$ & $\begin{array}{l}\text { - Exports of supported } \\
\text { commodities increased. }\end{array}$ & & $\begin{array}{l}\text { - MOICS, } \\
\text { TPC }\end{array}$ \\
\hline & & $\begin{array}{l}\text { - Emphasis on quality improvement } \\
\text { (ongoing) }\end{array}$ & $\begin{array}{l}\text { - Quality certification } \\
\text { expanded. }\end{array}$ & & - MOICS \\
\hline & $\begin{array}{l}\text { - Involve private sector for } \\
\text { export promotion. }\end{array}$ & $\begin{array}{l}\text { - Introduce selected services in the } \\
\text { management of private sector in } \\
\text { major customs terminal (by 2004). }\end{array}$ & $\begin{array}{l}\text { - Involvement of private sector } \\
\text { in providing services in } \\
\text { customs terminals. }\end{array}$ & & - DOC \\
\hline
\end{tabular}




\begin{tabular}{|c|c|c|c|c|c|}
\hline Objective & Strategies & Activities & Intermediate indicators & Outcome & $\begin{array}{l}\text { Responsible } \\
\text { Agency }\end{array}$ \\
\hline \multirow[t]{6}{*}{$\begin{array}{l}\text { Increase } \\
\text { employment to } \\
\text { reduce poverty }\end{array}$} & $\begin{array}{l}\text { - Make employment } \\
\text { intensive growth } \\
\text { objectives }\end{array}$ & $\begin{array}{l}\text { - Reorient public expenditure to make it more } \\
\text { employment intensive. } \\
\text { - Incentives and policies improvement for } \\
\text { private sector to generate employment } \\
\text { growth. }\end{array}$ & $\begin{array}{l}\text { - Employment } \\
\text { opportunities } \\
\text { expanded. }\end{array}$ & $\begin{array}{l}\text { - Underemployment/ } \\
\text { Unemployment rates decline. } \\
\text { - Industrial relations improved. } \\
\text { - Labor productivity enhanced } \\
\text { - Rights of labor protected }\end{array}$ & $\begin{array}{l}\text { - MOLTM, } \\
\text { MOF, NPC } \\
\text { Line } \\
\text { Ministries }\end{array}$ \\
\hline & $\begin{array}{l}\text { - Reform vocational } \\
\text { training program to link } \\
\text { with employment policy } \\
\text { objectives and labor } \\
\text { demand. }\end{array}$ & $\begin{array}{l}\text { - Streamline present training programs based } \\
\text { on market and demand for such training } \\
\text { identified by CBOs at district level } \\
\text { - Consultative process strengthened and } \\
\text { cooperation initiated and institutionalized } \\
\text { with the private sector in making the training } \\
\text { program more demand driven and effective. }\end{array}$ & $\begin{array}{l}\text { - Efficiency of labor } \\
\text { enhanced. }\end{array}$ & $\begin{array}{l}\text { - Worst form of Child labor } \\
\text { reduced significantly. } \\
\text { - Remittance income } \\
\text { increased. }\end{array}$ & $\begin{array}{l}\text { - MOLTM, } \\
\text { CTEVT, } \\
\text { MOICS etc. } \\
\text { - MOLTM, } \\
\text { CTEVT }\end{array}$ \\
\hline & $\begin{array}{l}\text { - Make labor laws } \\
\text { flexible. }\end{array}$ & - Reform labor laws by (2004) & - Labor law amended. & & $\begin{array}{l}\text { - DOL, } \\
\text { MOLTM }\end{array}$ \\
\hline & $\begin{array}{l}\text { - Enhance foreign } \\
\text { employment. }\end{array}$ & $\begin{array}{l}\text { - Agreements with labor importing countries } \\
\text { increased/strengthened (continued). }\end{array}$ & $\begin{array}{l}\text { - Number of laborers } \\
\text { employed oversees } \\
\text { increases. }\end{array}$ & & $\begin{array}{l}\text { - DOS, DOL, } \\
\text { CTEVT }\end{array}$ \\
\hline & & $\begin{array}{l}\text { - Skill development program encouraged for } \\
\text { outward migrants workers (continued). }\end{array}$ & $\begin{array}{l}\text { - Number of disputes } \\
\text { decreased. }\end{array}$ & & $\begin{array}{l}\text { - DOI, DOC, } \\
\text { CTEVT }\end{array}$ \\
\hline & & $\begin{array}{l}\text { - Support services for overseas laborers } \\
\text { enhanced (continued). }\end{array}$ & & & - DOL \\
\hline $\begin{array}{l}\text { Ensure congenial } \\
\text { environment for } \\
\text { better industrial } \\
\text { relation. }\end{array}$ & $\begin{array}{l}\text { - Promote industrial } \\
\text { relationship for } \\
\text { increasing the labor } \\
\text { productivity. }\end{array}$ & $\begin{array}{l}\text { - Orientation/training on industrial relations } \\
\text { increased and guidelines/regulation } \\
\text { strengthened (continued). }\end{array}$ & & & $\begin{array}{l}\text { - MOICS, } \\
\text { MOLTM }\end{array}$ \\
\hline $\begin{array}{l}\text { Protect children } \\
\text { from exploitation }\end{array}$ & - Eliminate child labour. & $\begin{array}{l}\text { - Legal measures and strict monitoring for } \\
\text { eliminating child labour and their } \\
\text { rehabilitation (ongoing) }\end{array}$ & $\begin{array}{l}\text { - Number of child } \\
\text { labour rescued and } \\
\text { rehabilitated. }\end{array}$ & & $\begin{array}{l}\text { - MOLTM, } \\
\text { MOWSW }\end{array}$ \\
\hline
\end{tabular}




\section{Infrastructure Development}

\section{Road}

\begin{tabular}{|c|c|c|c|c|c|}
\hline Objective & Strategies & Activities & Intermediate indicators & Outcome & $\begin{array}{l}\text { Responsible } \\
\text { Agency }\end{array}$ \\
\hline $\begin{array}{l}\text { Develop \& } \\
\text { manage road } \\
\text { transport network } \\
\text { in cost effective } \\
\text { way to support } \\
\text { socio economic } \\
\text { development } \\
\text { effort }\end{array}$ & $\begin{array}{l}\text { - Expansion of road } \\
\text { network to link the } \\
\text { districts without road. } \\
\text { - Encourage private sector } \\
\text { participation } \\
\text { - Maintain the road network } \\
\text { in serviceable condition. } \\
\text { - Enhance the institutional } \\
\text { capacity in the context of } \\
\text { liberal economy and } \\
\text { decentralization. }\end{array}$ & $\begin{array}{l}\text { - } 10 \text { Additional District } \\
\text { headquarters connected by } \\
\text { road (by FY 07). } \\
\text { - Act developed for BOT projects } \\
\text { (FY 04). } \\
\text { - Rural roads management } \\
\text { responsibility transferred to } \\
\text { DDCs (FY } 04 \text { onwards) } \\
\text { - Road Board operational (FY } \\
\text { 04). } \\
\text { - Framework planned for road } \\
\text { maintenance system (FY 04). } \\
\text { - Capacity building of } \\
\text { Department of Roads in the } \\
\text { context of liberal economy and } \\
\text { decentralization (FY } 03 \\
\text { onwards). }\end{array}$ & $\begin{array}{l}\text { - Additional } 1025 \mathrm{~km} \text {. to be } \\
\text { constructed by MOPPW. } \\
\text { - Detail plan approved enough } \\
\text { and budget allocation. } \\
\text { - Rural Roads responsibilities } \\
\text { transferred to DDCs. } \\
\text { - Full levy collected. } \\
\text { - } 90 \text { percent of SRN in good / fair } \\
\text { condition. } \\
\text { - Act implemented. } \\
\text { - Annual maintenance plan for } \\
2003 / 04 \text { received and } \\
\text { approved (2003 April) } \\
\text { - Technical auditing agency } \\
\text { operational. }\end{array}$ & $\begin{array}{l}\text { - Sustainable Road maintenance } \\
\text { fund available in a accordance } \\
\text { with annual maintenances plan } \\
\text { - Management efficiency } \\
\text { improved in planning, } \\
\text { procurement, and } \\
\text { implementation. } \\
\text { - } \text { BOT legal frame finalization. } \\
\text { - } 90 \text { percent of SRN in good/fair } \\
\text { condition. }\end{array}$ & $\begin{array}{l}\text { - DOR, MOLD } \\
\text { - MOPPW }\end{array}$ \\
\hline
\end{tabular}




\section{Power Sector}

\begin{tabular}{|c|c|c|c|c|c|}
\hline Objective & Strategies & Activities & Intermediate indicators & Outcome & $\begin{array}{l}\text { Responsible } \\
\text { Agency }\end{array}$ \\
\hline \multirow{8}{*}{$\begin{array}{l}\text { Expand electricity } \\
\text { coverage in a } \\
\text { reliable, } \\
\text { financially and } \\
\text { environmentally } \\
\text { sustainable } \\
\text { manner. }\end{array}$} & $\begin{array}{l}\text { - Promote private sector } \\
\text { participation in power } \\
\text { sector }\end{array}$ & $\begin{array}{l}\text { - Establish power } \\
\text { development fund (FY } \\
\text { 2004). } \\
\text { - Establish an independent } \\
\text { regulatory body (FY 2004). }\end{array}$ & $\begin{array}{l}\text { - Power Development Fund established. } \\
\text { - Regulatory Body established. }\end{array}$ & $\begin{array}{l}\text { - Increase in percentage } \\
\text { of population with } \\
\text { access to electricity from } \\
40 \text { to } 55 \text { percent. }\end{array}$ & - MOWR \\
\hline & $\begin{array}{l}\text { - Improve financial viability } \\
\text { of NEA }\end{array}$ & $\begin{array}{l}\text { - "Develop" profitmaking } \\
\text { centers within NEA (FY } 2003 \\
\text { onwards). }\end{array}$ & $\begin{array}{l}\text { - Reduce system losses } 1 \% \text { a year from } \\
23 \% \text { at the beginning of Tenth Plan. }\end{array}$ & & - NEA \\
\hline & & $\begin{array}{l}\text { - Internal unbundling of NEA } \\
\text { into generation, } \\
\text { transmission, and } \\
\text { distribution units (FY 04). }\end{array}$ & $\begin{array}{l}\text { - Complete internal unbundling of NEA by } \\
\text { FY } 2004 \text {. }\end{array}$ & & - MOWR \\
\hline & & $\begin{array}{l}\text { - Initiate explicit subsidy policy } \\
\text { for grid-based rural } \\
\text { electrification (FY 2004). }\end{array}$ & $\begin{array}{l}\text { - Adopt a subsidy policy for grid-based } \\
\text { rural electrification by FY } 2004 \text {. }\end{array}$ & & - MOWR, MOF \\
\hline & $\begin{array}{l}\text { - Integrate rural } \\
\text { electrification with rural } \\
\text { economic development }\end{array}$ & $\begin{array}{l}\text { - Promote productive end- } \\
\text { uses (continued). }\end{array}$ & $\begin{array}{l}\text { - Adopt a framework for cooperative } \\
\text { based rural electrification. }\end{array}$ & & - NEA \\
\hline & $\begin{array}{l}\text { - Promote cooperative } \\
\text { based grid-based rural } \\
\text { electrification. }\end{array}$ & $\begin{array}{l}\text { - Capacity building of } \\
\text { cooperatives (continued). }\end{array}$ & - Training programs to cooperatives. & & - MOWR \\
\hline & $\begin{array}{l}\text { - Expand and reinforce } \\
\text { power infrastructure }\end{array}$ & $\begin{array}{l}\text { - Expand and reinforce } \\
\text { generation, transmission and } \\
\text { distribution (on-going). }\end{array}$ & $\begin{array}{l}\text { - Increase installed capacity from } 527 \mathrm{MW} \\
\text { to } 830 \mathrm{MW}\end{array}$ & & - NEA \\
\hline & & $\begin{array}{l}\text { Promote small-, medium- } \\
\text { scale and storage } \\
\text { hydropower projects (on- } \\
\text { going). }\end{array}$ & $\begin{array}{l}\text { - Increase length of transmission lines } \\
(66,132 \text { and } 220 \mathrm{kV}) \text { from } 1962 \mathrm{~km} \text { to } \\
2392 \mathrm{~km} \\
\text { - Initiate construction of a storage project. }\end{array}$ & & $\begin{array}{l}\text { - MOWR, } \\
\text { WECS }\end{array}$ \\
\hline
\end{tabular}




\section{Information and Communication}

\begin{tabular}{|c|c|c|c|c|c|}
\hline Objective & Strategies & Activities & Intermediate indicators & Outcome & $\begin{array}{l}\text { Responsible } \\
\text { Agency }\end{array}$ \\
\hline $\begin{array}{l}\text { Improve access of } \\
\text { information and } \\
\text { communication. }\end{array}$ & $\begin{array}{l}\text { - Clarity on role and } \\
\text { responsibility of public } \\
\text { and private operators } \\
\text { - Functional autonomy }\end{array}$ & $\begin{array}{l}\text { - Expansion of broadcasting } \\
\text { services (continued). } \\
\text { - Creation of legal frame for } \\
\text { functional autonomy of postal } \\
\text { service (2003/04). }\end{array}$ & $\begin{array}{l}\text { - Convert NTC to a Company } \\
\text { under Company Act by 2003/04. } \\
\text { - Private GSM operator in place. } \\
\text { - Private RTS operator in place in } \\
\text { Eastern Region. } \\
\text { - Radio and Television service } \\
\text { extension to the whole country } \\
\text { initiated. } \\
\text { - Approval of Rules and } \\
\text { Regulation for functional } \\
\text { autonomy of postal service by } \\
2003 / 04\end{array}$ & $\begin{array}{l}\text { - Competitive and liberalized } \\
\text { market of Telecom service. } \\
\text { - Access of Telecom service } \\
\text { to all VDCs. } \\
\text { - Telephone penetration } 40 \\
\text { lines per } 1000 \text { inhabitants. } \\
\text { - Radio and Television } \\
\text { service available to all } \\
\text { people. } \\
\text { - Effective function of postal } \\
\text { service. } \\
\text { - At least two telephone lines } \\
\text { in all VDCs. }\end{array}$ & $\begin{array}{l}\text { - MOIC, TCA } \\
\text { - MOIC, TCA }\end{array}$ \\
\hline
\end{tabular}


Tourism, Infrastructure, Services and Promotion

\begin{tabular}{|c|c|c|c|c|c|}
\hline Objective & Strategies & Activities & Intermediate indicators & Outcome & $\begin{array}{l}\text { Responsible } \\
\text { Agency }\end{array}$ \\
\hline \multirow[t]{6}{*}{$\begin{array}{l}\text { Expand tourism } \\
\text { activities }\end{array}$} & $\begin{array}{l}\text { - Tourism promotion/ } \\
\text { marketing and } \\
\text { product } \\
\text { development }\end{array}$ & $\begin{array}{l}\text { - Promotional activities focused in } \\
\text { regional markets (on-going). } \\
\text { - Development and conservation of } \\
\text { national heritage/religious sites (on- } \\
\text { going). } \\
\text { - Promote eco-tourism (on-going). }\end{array}$ & $\begin{array}{l}\text { - Number of promotional activities } \\
\text { increase. } \\
\text { - World heritage guidelines followed. } \\
\text { - National heritages developed and } \\
\text { conserved. } \\
\text { - Infrastructure and physical structure } \\
\text { improved. } \\
\text { - New destination opened. } \\
\text { - Increase tourist activities in National } \\
\text { Parks and Nature conservation areas. }\end{array}$ & $\begin{array}{l}\text { - Increase in the number } \\
\text { of tourists to } 516,000 \text {. } \\
\text { - Length of stay of tourist } \\
\text { increases to } 13 \text { days. } \\
\text { - Tourism earnings } \\
\text { distributed widely to } \\
\text { rural areas also. } \\
\text { - Domestic tourism } \\
\text { enhanced. } \\
\text { - Contribution of tourism }\end{array}$ & $\begin{array}{l}\text { - MOCTCA, NTB } \\
\text { - MOCTCA, DOA }\end{array}$ \\
\hline & $\begin{array}{l}\text { - Infrastructure } \\
\text { development }\end{array}$ & $\begin{array}{l}\text { - Develop Infrastructure and } \\
\text { institutions particularly for eco } \\
\text { tourism (on-going). }\end{array}$ & $\begin{array}{l}\text { - Air services at eco-tourism areas } \\
\text { enhanced. } \\
\text { - Infrastructure and institution for eco- } \\
\text { tourism developed. }\end{array}$ & $\begin{array}{l}\text { in the economy } \\
\text { enhanced to } 3 \% \text {. }\end{array}$ & $\begin{array}{l}\text { MOCTCA, } \\
\text { NTB, MOLD }\end{array}$ \\
\hline & & - Manage air-safety (by 2004/05). & $\begin{array}{l}\text { - Air safety standard strengthened are } \\
\text { executed. }\end{array}$ & & - CAAN \\
\hline & - Tourism facilitation & $\begin{array}{l}\text { - Simplify Immigration system (on- } \\
\text { going) }\end{array}$ & - Visa issuing simplifiied. & & - $\mathrm{MOH}$ \\
\hline & & $\begin{array}{l}\text { - Expand transportation facilities for } \\
\text { tourism industry (on-going). } \\
\text { - Accessibility of information. }\end{array}$ & $\begin{array}{l}\text { - Domestic air services enhanced. } \\
\text { - Number international connection and } \\
\text { briers increased. }\end{array}$ & & $\begin{array}{l}\text { - MOCTCA, } \\
\text { MOPPW }\end{array}$ \\
\hline & & $\begin{array}{l}\text { - Promote quality of tourism services } \\
\text { (on-going). }\end{array}$ & $\begin{array}{l}\text { - Tourism service standard } \\
\text { strengthened and monitored. }\end{array}$ & & - NTB \\
\hline
\end{tabular}




\section{Industry}

\begin{tabular}{|c|c|c|c|c|c|}
\hline Objective & Strategies & Activities & Intermediate indicators & Outcome & $\begin{array}{l}\text { Responsible } \\
\text { Agency }\end{array}$ \\
\hline \multirow[t]{7}{*}{$\begin{array}{l}\text { Expand } \\
\text { Industrialization }\end{array}$} & $\begin{array}{l}\text { - Strengthened } \\
\text { market oriented } \\
\text { policies. }\end{array}$ & $\begin{array}{l}\text { - Tariff rationalization (on-going). } \\
\text { - Foreign investment policy reform } \\
\text { (by 2004). } \\
\text { - Industrial acts \& policies reform (by } \\
\text { 2004). }\end{array}$ & $\begin{array}{l}\text { - Industrial competitiveness improved. } \\
\text { - Foreign investment increased. } \\
\text { - Labour/company law amended. } \\
\text { - Exit policy introduced. } \\
\text { - Acts amended according to } \\
\text { WTO/SAFTA. } \\
\text { - Action plan developed according to } \\
\text { Industrial Perspective Plan. }\end{array}$ & $\begin{array}{l}\text { - } \text { Contribution of GDP } \\
\text { enhanced. } \\
\text { - Employment } \\
\text { generation. } \\
\text { - Product expansion. } \\
\text { - Information } \\
\text { institutionalization. } \\
\text { - Harmonious industrial } \\
\text { relation. } \\
\text { - Industrial production } \\
\text { expanded in average }\end{array}$ & $\begin{array}{l}\text { - MOICS, MOF } \\
\text { - MOICS } \\
\text { - MOICS }\end{array}$ \\
\hline & $\begin{array}{l}\text { - Strengthening } \\
\text { SMEs }\end{array}$ & $\begin{array}{l}\text { - Incentive and programs for } \\
\text { technological improvement and } \\
\text { upgrading SMEs. (on-going). }\end{array}$ & $\begin{array}{l}\text { - Production and productivity } \\
\text { increased. }\end{array}$ & $\begin{array}{l}7.8 \text { percent/annum. } \\
\text { - SME Additional } \\
\text { employment generated }\end{array}$ & - DOI, MOST \\
\hline & & $\begin{array}{l}\text { - Institutional mechanism/acts sub- } \\
\text { contracting to SMEs (2005). }\end{array}$ & - Number of trainings/trainees. & to 250,000 & - DOI, DOSCl \\
\hline & & $\begin{array}{l}\text { - Entrepreneurship training, skill } \\
\text { development (on-going). } \\
\text { - Promotional activities. }\end{array}$ & & & - DOSCS, ETDC \\
\hline & & $\begin{array}{l}\text { - Incentive for backward linkages to } \\
\text { industries (ongoing). }\end{array}$ & - Industrial production expanded. & & - DOI, DOSCl \\
\hline & & $\begin{array}{l}\text { - Information technology } \\
\text { development (ongoing). }\end{array}$ & - Access to information improved. & & - MOICS, MOST \\
\hline & $\begin{array}{l}\text { - Improved Industrial } \\
\text { environment }\end{array}$ & $\begin{array}{l}\text { - Tripartite industrial relati onship } \\
\text { improved (on-going). }\end{array}$ & - Smooth industrial operation. & & - MOICS, MOLT \\
\hline
\end{tabular}




\section{Supply}

\begin{tabular}{|c|c|c|c|c|c|}
\hline Objective & Strategies & Activities & Intermediate indicators & Outcome & $\begin{array}{l}\text { Responsible } \\
\text { Agency }\end{array}$ \\
\hline \multirow{4}{*}{$\begin{array}{l}\text { Improve the } \\
\text { supply and } \\
\text { distribution of } \\
\text { essential } \\
\text { commodities. }\end{array}$} & $\begin{array}{l}\text { - Strengthen food } \\
\text { supplies in remote } \\
\text { areas. }\end{array}$ & $\begin{array}{l}\text { - Rationalization NFC activities and } \\
\text { strengthen supply system (on- } \\
\text { going). }\end{array}$ & $\begin{array}{l}\text { - Focus distribution in districts and } \\
\text { strengthened networks. }\end{array}$ & $\begin{array}{l}\text { - Food security will be } \\
\text { improved. }\end{array}$ & - MOICS, NFC \\
\hline & & $\begin{array}{l}\text { - Enhance food supply and } \\
\text { distribution in food deficit areas (on- } \\
\text { going). }\end{array}$ & $\begin{array}{l}\text { - Supply and distribution of } 35000 \mathrm{MT} \\
\text { food per annum mainly in remote } \\
\text { districts. }\end{array}$ & $\begin{array}{l}\text { - Price of petroleum } \\
\text { products competitive. }\end{array}$ & - NFC \\
\hline & $\begin{array}{l}\text { - Market based } \\
\text { petroleum price. }\end{array}$ & $\begin{array}{l}\text { Management of NOC improved, } \\
\text { leakage reduced and private } \\
\text { sector's involvement in NOC } \\
\text { activities initiated (by 2004). }\end{array}$ & $\begin{array}{l}\text { - Loss of NOC reduced. } \\
\text { - Storage capacity of petroleum product } \\
\text { will be increased. }\end{array}$ & & - MOICS, NOC \\
\hline & & $\begin{array}{l}\text { - Rationalization of petroleum } \\
\text { product prices (by 2003). }\end{array}$ & $\begin{array}{l}\text { - Private sector involvement increased. } \\
\text { - Petroleum price will be market based. }\end{array}$ & & - MOICS, NOC \\
\hline
\end{tabular}




\section{Education}

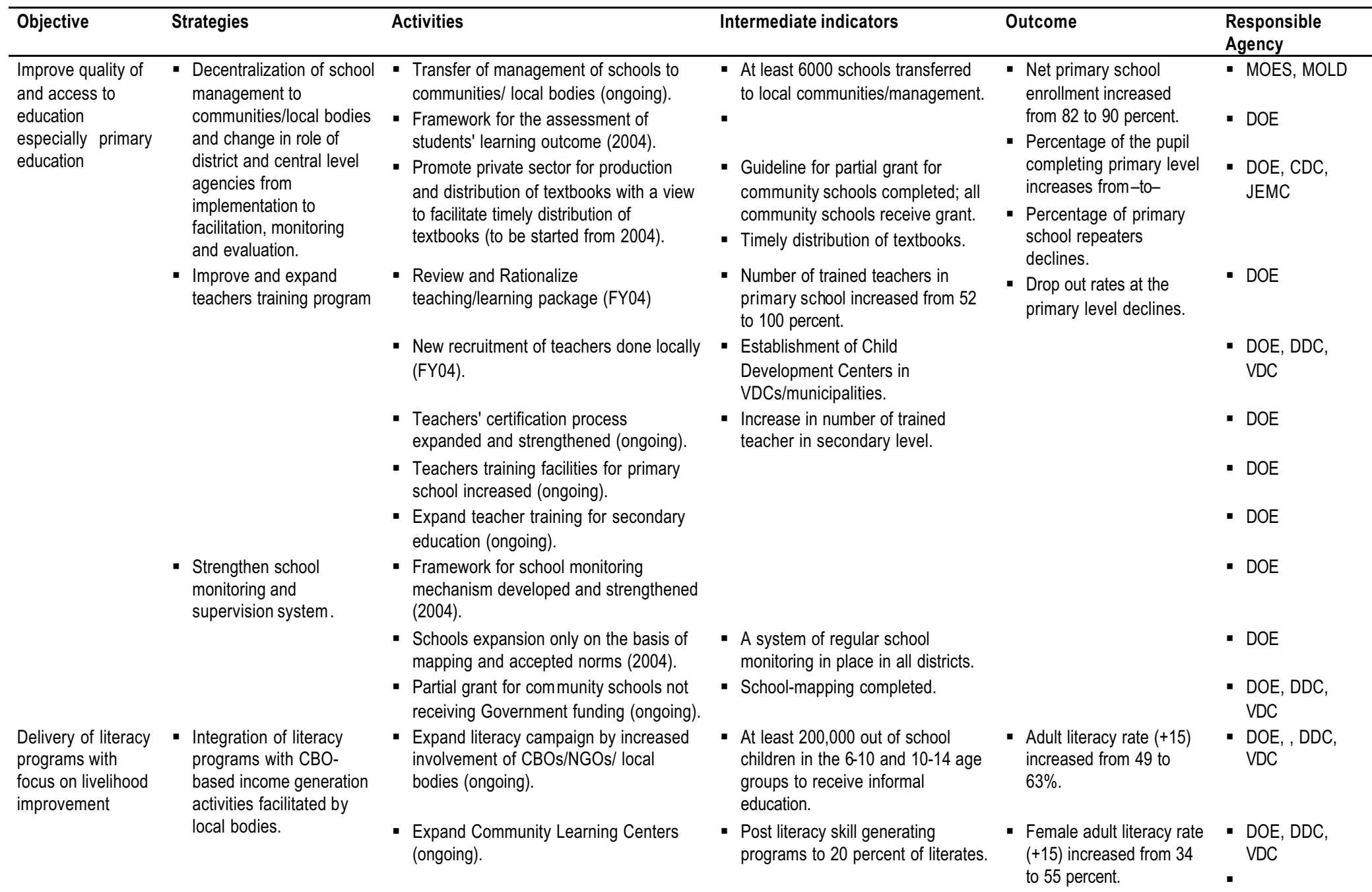




\begin{tabular}{|c|c|c|c|c|c|}
\hline Objective & Strategies & Activities & Intermediate indicators & Outcome & $\begin{array}{l}\text { Responsible } \\
\text { Agency }\end{array}$ \\
\hline \multirow{5}{*}{$\begin{array}{l}\text { Improve access of } \\
\text { girls, Dalits and } \\
\text { disadvantaged } \\
\text { children to } \\
\text { education }\end{array}$} & $\begin{array}{l}\text { Mitigate social, cultural } \\
\text { and financial barriers for } \\
\text { access to education }\end{array}$ & $\begin{array}{l}\text { - Enhanced scholarship for children of } \\
\text { poor families (on-going). }\end{array}$ & $\begin{array}{l}\text { - Enroll all of age } 6 \text { children to } \\
\text { primary education. }\end{array}$ & $\begin{array}{l}\text { Enrolment rate of girls } \\
\text { and disadvantaged } \\
\text { children increase. }\end{array}$ & $\begin{array}{l}\text { - DOE, DDC, } \\
\text { VDC }\end{array}$ \\
\hline & $\begin{array}{l}\text { - Social contracts for } \\
\text { access improvement }\end{array}$ & $\begin{array}{l}\text { - Expand school feeding program in } \\
\text { deprived areas (on-going). }\end{array}$ & $\begin{array}{l}\text { - Number of students for } \\
\text { disadvantaged receiving } \\
\text { scholarship increased. }\end{array}$ & $\begin{array}{l}\text { - Improvement in the ratio } \\
\text { of girls enrollment rate to } \\
\text { that of boys. }\end{array}$ & $\begin{array}{l}\text { - DOE, DDC, } \\
\text { VDC }\end{array}$ \\
\hline & & $\begin{array}{l}\text { Expand secondary scholarships for } \\
\text { children, girl and Dalit/disadvantaged } \\
\text { from poor families (on-going). }\end{array}$ & $\begin{array}{l}\text { - Increased share of female } \\
\text { teachers in primary schools from } \\
26 \text { to } 30 \text { percent. }\end{array}$ & & $\begin{array}{l}\text { - DOE, DDC, } \\
\text { VDC }\end{array}$ \\
\hline & & - Separate latrines for girls (on-going). & $\begin{array}{l}\text { - Share of girls and disadvantaged } \\
\text { children in primary and secondary }\end{array}$ & & $\begin{array}{l}\text { - DOE, DDC, } \\
\text { VDC }\end{array}$ \\
\hline & & $\begin{array}{l}\text { - Incentive grant for schools employing } \\
\text { female teachers (on-going). }\end{array}$ & levels increase. & & $\begin{array}{l}\text { - DOE, DDC, } \\
\text { VDC }\end{array}$ \\
\hline \multirow{2}{*}{$\begin{array}{l}\text { Meet national } \\
\text { demand for basic } \\
\text { and middle level } \\
\text { technical human } \\
\text { resources }\end{array}$} & $\begin{array}{l}\text { Vocational courses } \\
\text { attached to existing } \\
\text { secondary school. }\end{array}$ & $\begin{array}{l}\text { - Initiate and strengthen the program in } 25 \\
\text { schools as an annex program (to start } \\
\text { from 2004). }\end{array}$ & $\begin{array}{l}\text { - Short and medium term technical } \\
\text { training to more than } 30,000 \\
\text { people. }\end{array}$ & $\begin{array}{l}\text { - Increase share of semi- } \\
\text { skilled and skilled labour } \\
\text { in the labour force from. }\end{array}$ & $\begin{array}{l}\text { - DOE, DDC, } \\
\text { VDC }\end{array}$ \\
\hline & $\begin{array}{l}\text { - Promote private provision } \\
\text { of basic and middle level } \\
\text { technical training. }\end{array}$ & $\begin{array}{l}\text { - Introduction of voucher system targeted } \\
\text { to poor for basic and middle level } \\
\text { technical training (to start from 2004). }\end{array}$ & & & - DOE, CTEVT \\
\hline
\end{tabular}




\begin{tabular}{|c|c|c|c|c|c|}
\hline Objective & Strategies & Activities & Intermediate indicators & Outcome & $\begin{array}{l}\text { Responsible } \\
\text { Agency }\end{array}$ \\
\hline \multirow[t]{7}{*}{$\begin{array}{l}\text { Increase essential } \\
\text { health care } \\
\text { services to all with } \\
\text { special emphasis } \\
\text { to rural/remote/ } \\
\text { poor population. }\end{array}$} & $\begin{array}{l}\text { - Development and } \\
\text { retenti on of trained } \\
\text { staff especially in rural } \\
\text { areas. }\end{array}$ & $\begin{array}{l}\text { - Terms and conditions of recruitment } \\
\text { and transfer made transparent (end } \\
\text { 2003). } \\
\text { - Incentive mechanism devised to } \\
\text { encourage health workers to work in } \\
\text { remote and rural areas (FY 2003/04). } \\
\text { - Fulfill vacant positions (on-going). }\end{array}$ & $\begin{array}{l}\text { - Sick individuals (\%) who visited } \\
\text { rural health centers (during the } \\
\text { past month). } \\
\text { - Number of absentee health } \\
\text { workers. }\end{array}$ & $\begin{array}{l}\text { - Reduction in infant } \\
\text { mortality rate from } 64 \text { to } \\
45 . \\
\text { - Reduction in child } \\
\text { (U5MR) mortality rate } \\
\text { from } 91 \text { to } 72 \text {. } \\
\text { - Reduction in maternal } \\
\text { mortality from } 415 \text { to }\end{array}$ & - $\mathrm{MOH}$ \\
\hline & $\begin{array}{l}\text { - Training and } \\
\text { upgrading of health } \\
\text { personnel. }\end{array}$ & $\begin{array}{l}\text { - Increased availability of Auxiliary } \\
\text { Health Midwife/ nurse in the health } \\
\text { posts especially to address } \mathrm{MCH} \\
\text { problems (FY } 04 \text { to 08) }\end{array}$ & $\begin{array}{l}\text { - Women receiving at least } 4 \\
\text { alternated visit increased from } 14 \\
\text { to } 40 \% \text {. }\end{array}$ & $\begin{array}{l}300 . \\
\text { - Life expectancy } \\
\text { increased from } 61.9 \\
\text { years to } 65 \text { years. }\end{array}$ & - $\mathrm{MOH}, \mathrm{DOH}$ \\
\hline & & $\begin{array}{l}\text { - Training programmes strengthen and } \\
\text { manpower production enhanced (on } \\
\text { going). }\end{array}$ & $\begin{array}{l}\text { - Births (\%) attended by skilled } \\
\text { health personnel increased from } \\
13 \text { to } 40 \% \text {. }\end{array}$ & & $\begin{array}{l}\text { - } \mathrm{MOH}, \mathrm{DOH} \\
\mathrm{DDC}, \mathrm{VDC}\end{array}$ \\
\hline & $\begin{array}{l}\text { - Increased supply of } \\
\text { essential drugs, } \\
\text { vaccines. }\end{array}$ & $\begin{array}{l}\text { - Procurement of drugs and equipment } \\
\text { based on program priorities (on } \\
\text { going). }\end{array}$ & $\begin{array}{l}\text { Number of drug outlets where } 15 \\
\text { of the most essential drugs } \\
\text { available. }\end{array}$ & & - $\mathrm{MOH}$ \\
\hline & & $\begin{array}{l}\text { Expansion of community drug } \\
\text { program (on going). }\end{array}$ & $\begin{array}{l}\text { Number of sub/health posts with } \\
\text { community drug program } \\
\text { increases. }\end{array}$ & & - MOH, SAJHA \\
\hline & & & $\begin{array}{l}\text { Availability of essential and } \\
\text { priority drugs increased to } 90 \% \\
\text { places. }\end{array}$ & & $\begin{array}{l}\text { - } \mathrm{MOH}, \mathrm{DDC} \\
\mathrm{VDC}\end{array}$ \\
\hline & $\begin{array}{l}\text { - Expand } \\
\text { accessibility/facilities }\end{array}$ & $\begin{array}{l}\text { - Initiation of health insurance scheme } \\
\text { (FY04 onwards). }\end{array}$ & $\begin{array}{l}\text { - Population under health } \\
\text { insurance. } \\
\text { - One year olds (\%) fully } \\
\text { immunized against target } \\
\text { diseases. }\end{array}$ & & - $\mathrm{MOH}$ \\
\hline
\end{tabular}




\begin{tabular}{|c|c|c|c|c|}
\hline Objective & Strategies & Activities & Intermediate indicators & $\begin{array}{l}\text { Responsible } \\
\text { Agency }\end{array}$ \\
\hline & & $\begin{array}{l}\text { Focus of the program in immunization, } \\
\text { safer motherhood, control and } \\
\text { prevention of communicable diseases, } \\
\text { malaria control, JE, TB and leprosy, } \\
\text { HIVIAIDS and CDP Programmes (on } \\
\text { going) }\end{array}$ & $\begin{array}{l}\text { Proportion of } \\
\text { TB/malaria/JE/leprosy/HIVIAIDS } \\
\text { etc. cases detected and } \\
\text { prevention and treatment } \\
\text { measures. Condom use by } \\
14-35 \text { years old men increased } \\
\text { to } 35 \text { percent. }\end{array}$ & - $\mathrm{MOH}, \mathrm{DOH}$ \\
\hline & & $\begin{array}{l}\text { - Effective family planning program (on } \\
\text { going). }\end{array}$ & $\begin{array}{l}\text { - Contraceptive prevalence rate } \\
\text { increase from } 40 \text { to } 55 \text { percent. }\end{array}$ & - $\mathrm{MOH}, \mathrm{FPAN}$ \\
\hline & & $\begin{array}{l}\text { - Reorientation/refocus of programmes } \\
\text { based on mapping of HDI index } \\
\text { (initiation from FY04). }\end{array}$ & $\begin{array}{l}\text { - Condom use by } 14-35 \text { years old } \\
\text { men increased to } 35 \text { percent. }\end{array}$ & $\begin{array}{l}\text { - } \mathrm{MOH}, \mathrm{DDC} \\
\mathrm{VDC}\end{array}$ \\
\hline & & - Expand nutritional program (on going). & & $\begin{array}{l}\text { - } \mathrm{MOH}, \mathrm{DDC} \\
\text { VDC }\end{array}$ \\
\hline & & - Education/awareness (ongoing). & & - $\mathrm{MOH}, \mathrm{MOES}$ \\
\hline & $\begin{array}{l}\text { - Up-gradation of } \\
\text { primary health centers } \\
\text { and hospitals. }\end{array}$ & $\begin{array}{l}\text { Up-gradation of hospitals/health } \\
\text { centres to manage the increasing } \\
\text { problem of accidents and injuries a } \\
\text { phased manner (FY04 onwards). }\end{array}$ & $\begin{array}{l}\text { - Number of health centers and } \\
\text { hospitals upgraded. }\end{array}$ & - $\mathrm{MOH}$ \\
\hline & $\begin{array}{l}\text { - Decentralized } \\
\text { operation and } \\
\text { management }\end{array}$ & $\begin{array}{l}\text { Transfer of sub health post, health } \\
\text { post etc. to local management } \\
\text { committees (on going). }\end{array}$ & $\begin{array}{l}\text { - All sub health post and more } \\
\text { than } 50 \% \text { of health posts and a } \\
25 \text { hospitals handed over to local } \\
\text { bodies/management. }\end{array}$ & $\begin{array}{l}\text { - } \mathrm{MOH}, \mathrm{DDC} \\
\text { VDC }\end{array}$ \\
\hline & & $\begin{array}{l}\text { - Recruitment of health workers at the } \\
\text { local level ((FY04 and onwards). }\end{array}$ & $\begin{array}{l}\text { - Guidelines/frameworks local } \\
\text { recruitment developed. }\end{array}$ & $\begin{array}{l}\text { - } \mathrm{MOH}, \mathrm{DDC} \\
\mathrm{VDC}\end{array}$ \\
\hline & & $\begin{array}{l}\text { - Procurement of drugs at the local level } \\
\text { (FY 2003/04 onwards). }\end{array}$ & $\begin{array}{l}\text { Number of health centers } \\
\text { authorized for procurement. }\end{array}$ & $\begin{array}{l}\text { - } \mathrm{MOH}, \mathrm{DDC} \\
\mathrm{VDC}\end{array}$ \\
\hline & $\begin{array}{l}\text { - Promotion and } \\
\text { coordination with } \\
\text { NGO/INGOs and }\end{array}$ & $\begin{array}{l}\text { - Avoid duplication with private sectors } \\
\text { and NGOs. }\end{array}$ & $\begin{array}{l}\text { Coordination guideline } \\
\text { developed. }\end{array}$ & $\begin{array}{l}\text { - } \mathrm{MOH}, \mathrm{DDC} \\
\text { VDC }\end{array}$ \\
\hline
\end{tabular}




\begin{tabular}{|c|c|c|c|c|}
\hline Objective & Strategies & Activities & Intermediate indicators & $\begin{array}{l}\text { Responsible } \\
\text { Agency }\end{array}$ \\
\hline & private Sectors & $\begin{array}{l}\text { Environmental and occupational } \\
\text { health care and sanitation facilities } \\
\text { provided with inter-sectoral } \\
\text { collaboration (on going) }\end{array}$ & - Level of collaboration improved. & $\begin{array}{l}\text { - } \mathrm{MOH}, \\
\text { Municipalities }\end{array}$ \\
\hline & $\begin{array}{l}\text { - Improved regulatory } \\
\text { mechanism }\end{array}$ & $\begin{array}{l}\text { - Strong supervision and monitoring } \\
\text { mechanism devised and implemented } \\
\text { for the availability, quality and } \\
\text { accessibility of health services (private } \\
\text { nursing home/hospitals/colleges). }\end{array}$ & $\begin{array}{l}\text { - Strong supervision and } \\
\text { monitoring mechanism devised } \\
\text { and implemented for the } \\
\text { availability, quality and } \\
\text { accessibility of health services. }\end{array}$ & - $\mathrm{MOH}$ \\
\hline
\end{tabular}

\section{Drinking Water and Sanitation}

\begin{tabular}{|c|c|c|c|c|c|}
\hline Objective & Strategies & Activities & Intermediate indicators & Outcome & $\begin{array}{l}\text { Responsible } \\
\text { Agency }\end{array}$ \\
\hline \multirow{4}{*}{$\begin{array}{l}\text { Increased/improv } \\
\text { ed access to } \\
\text { sustainable basic } \\
\text { drinking water } \\
\text { services in rural } \\
\text { areas. }\end{array}$} & \multirow{4}{*}{$\begin{array}{l}\text { Scale up the demand } \\
\text { driven and participatory } \\
\text { approach to rural water } \\
\text { supply and sanitation } \\
\text { schemes. This approach } \\
\text { involves NGOs, CBOs, } \\
\text { local private sector to } \\
\text { assist communities to plan, } \\
\text { design and implement and } \\
\text { operate and maintain their } \\
\text { own schemes. }\end{array}$} & $\begin{array}{l}\text { - Revise the } 1998 \text { rural sub-sector } \\
\text { policy to include clear roles \& } \\
\text { responsibilities of sector actors } \\
\text { by } 2003 \text {. }\end{array}$ & $\begin{array}{l}\text { - A consistent sector policy in } \\
\text { place and implemented }\end{array}$ & $\begin{array}{l}\text { - Consistent community } \\
\text { driven approach } \\
\text { operational sector wide }\end{array}$ & - DDWSS \\
\hline & & $\begin{array}{l}\text { - Reform/consolidate the } \\
\text { institutional mechanisms and } \\
\text { approaches to service delivery to } \\
\text { facilitate implementation by } 2003\end{array}$ & $\begin{array}{l}\text { Community driven approach } \\
\text { adopted to provide sustainable } \\
\text { water systems to benefit some } \\
2.0 \text { million additional people. }\end{array}$ & $\begin{array}{l}\text { - About } 3.8 \text { million people } \\
\text { have access to safe } \\
\text { and sustainable } \\
\text { drinking water services. }\end{array}$ & $\begin{array}{l}\text { - DDWSS, DDC, } \\
\text { VDC }\end{array}$ \\
\hline & & $\begin{array}{l}\text { - Strengthen autonomy of the } \\
\text { RWSS Fund Development Board } \\
\text { through an Act by } 2003\end{array}$ & $\begin{array}{l}\text { - Fund Board operational as a } \\
\text { regular sector agency. }\end{array}$ & $\begin{array}{l}\text { Increased opportunity } \\
\text { for enrolment of girl } \\
\text { child in schools due to } \\
\text { time saved in fetching } \\
\text { water }\end{array}$ & $\begin{array}{l}\text { - DDWSS, DDC, } \\
\text { VDC }\end{array}$ \\
\hline & & $\begin{array}{l}\text { - Rehabilitate rural water supply } \\
\text { schemes for community } \\
\text { management (continued). }\end{array}$ & $\begin{array}{l}\text { Sector monitoring system } \\
\text { established; the sector monitored } \\
\text { effectively and regularly and } \\
\text { budget allocations to sector } \\
\text { agencies are performance } \\
\text { based. }\end{array}$ & $\begin{array}{l}\text { - Reduced water borne } \\
\text { and water washed } \\
\text { diseases }\end{array}$ & - DDWSS \\
\hline
\end{tabular}




\begin{tabular}{|c|c|c|c|c|c|}
\hline Objective & Strategies & Activities & Intermediate indicators & Outcome & $\begin{array}{l}\text { Responsible } \\
\text { Agency }\end{array}$ \\
\hline & & $\begin{array}{l}\text { Districts develop/update district } \\
\text { water development plans regular } \\
\text { to improve planning starting } 2003 \\
\text { and continuous. }\end{array}$ & $\begin{array}{l}\text { - About } 150 \text { schemes rehabilitated } \\
\text { and community managed. }\end{array}$ & & $\begin{array}{l}\text { - DDWSS, DDC, } \\
\text { VDC }\end{array}$ \\
\hline \multirow[t]{3}{*}{$\begin{array}{l}\text { Improve and } \\
\text { expand basic } \\
\text { sanitation facilities } \\
\text { in rural and urban } \\
\text { areas }\end{array}$} & \multirow{3}{*}{$\begin{array}{l}\text { - Promote sanitation as an } \\
\text { integral part of water } \\
\text { supply projects through } \\
\text { public education and } \\
\text { awareness campaigns by } \\
\text { mobilizing NGOs, CBOs, } \\
\text { local bodies and the private } \\
\text { sector }\end{array}$} & $\begin{array}{l}\text { Every new water supply scheme } \\
\text { should include sanitation as a } \\
\text { component of the project and } \\
\text { provide for promotional activities } \\
\text { (continued). }\end{array}$ & $\begin{array}{l}\text { - About 4,50,000 households build } \\
\text { and use latrines in rural areas }\end{array}$ & $\begin{array}{l}\text { - Health and hygiene } \\
\text { improved }\end{array}$ & $\begin{array}{l}\text { - DDWSS, DDC, } \\
\text { VDC }\end{array}$ \\
\hline & & $\begin{array}{l}\text { Promote sanitation activities in } \\
\text { areas that already have water } \\
\text { supply services but no sanitation } \\
\text { facilities (continued). }\end{array}$ & $\begin{array}{l}\text { - About } 150,000 \text { households with } \\
\text { appropriate sanitation services in } \\
\text { urban area }\end{array}$ & $\begin{array}{l}\text { - Reduction in diarrhoeal } \\
\text { diseases }\end{array}$ & $\begin{array}{l}\text { - DDWSS, DDC, } \\
\text { VDC }\end{array}$ \\
\hline & & $\begin{array}{l}\text { Promote appropriate sanitation } \\
\text { facilities in urban and semi-urban } \\
\text { areas through users' participation } \\
\text { (continued). }\end{array}$ & & & $\begin{array}{l}\text { - DDWSS, DDC, } \\
\text { VDC }\end{array}$ \\
\hline \multirow{4}{*}{$\begin{array}{l}\text { Improv ed access } \\
\text { to and up- } \\
\text { gradation of basic } \\
\text { drinking water } \\
\text { services in urban } \\
\text { and semi-urban } \\
\text { areas through } \\
\text { involvement of } \\
\text { private sector } \\
\text { and/or local } \\
\text { bodies. }\end{array}$} & \multirow{3}{*}{$\begin{array}{l}\text { - Create a conducive } \\
\text { environment for private } \\
\text { sector participation \& local } \\
\text { bodies involvement in } \\
\text { urban and semi-urban } \\
\text { water supply services by } \\
\text { legislative reforms, cost } \\
\text { recovery policy \& a } \\
\text { national water quality } \\
\text { standards/guideline. }\end{array}$} & $\begin{array}{l}\text { - Implement cost recovery policies } \\
\text { starting } 2003\end{array}$ & $\begin{array}{l}\text { - A private operator in place by } \\
2004 \text { in Kathmandu Valley towns }\end{array}$ & $\begin{array}{l}\text { - Arrangements and } \\
\text { regulatory framework } \\
\text { for PSP in urban WSS } \\
\text { services established }\end{array}$ & - MDPP, MOLD \\
\hline & & $\begin{array}{l}\text { Develop national water quality } \\
\text { standard/guidelines and } \\
\text { strengthen water quality } \\
\text { monitoring by } 2004\end{array}$ & $\begin{array}{l}\text { - Carry out a study to develop a } \\
\text { strategy for PSP and local body } \\
\text { involvement in the other urban } \\
\text { and semi-urban areas by } 2004\end{array}$ & $\begin{array}{l}\text { - More efficient and cost } \\
\text { effective services } \\
\text { available to urban and } \\
\text { semi-urban areas }\end{array}$ & $\begin{array}{l}\text { - MOPP, DDC, } \\
\text { VDC }\end{array}$ \\
\hline & & $\begin{array}{l}\text { - Frame legislation, establish and } \\
\text { make operational a regulatory } \\
\text { body by } 2003\end{array}$ & & & $\begin{array}{l}\text { - MOPP, } \\
\text { DDWSS }\end{array}$ \\
\hline & $\begin{array}{l}\text { - Increased supply in the } \\
\text { valley by reducing } \\
\text { unaccounted for water. }\end{array}$ & $\begin{array}{l}\text { - Reduce unaccounted-for water in } \\
\text { Kathmandu Valley towns by } 4 \% \\
\text { annually. }\end{array}$ & $\begin{array}{l}\text { - Unaccounted for water reduced } \\
\text { by } 4 \% \text { annually. }\end{array}$ & $\begin{array}{l}\text { - Reduction in water } \\
\text { borne and water } \\
\text { washed diseases. }\end{array}$ & - NWSSC \\
\hline
\end{tabular}




\begin{tabular}{|c|c|c|c|c|c|}
\hline Objective & Strategies & Activities & Intermediate indicators & Outcome & $\begin{array}{l}\text { Responsible } \\
\text { Agency }\end{array}$ \\
\hline \multirow[t]{10}{*}{$\begin{array}{l}\text { Bring poor/socially } \\
\text { excluded/disadvant } \\
\text { aged groups out of } \\
\text { poverty trap }\end{array}$} & $\begin{array}{l}\text { Reorient sectoral } \\
\text { programmes to focus on } \\
\text { targeted groups/areas. }\end{array}$ & $\begin{array}{l}\text { - Initiate the system of } \\
\text { expanding/developing sectoral } \\
\text { activities based on poverty mapping } \\
\text { (FY04 onwards). } \\
\text { - Framework for addressing the } \\
\text { problem of deprived } \\
\text { communities/regions developed and } \\
\text { implemented (FY } 04 \text { onwards) }\end{array}$ & $\begin{array}{l}\text { - Budget allocation for deprived } \\
\text { communities/areas increased. }\end{array}$ & $\begin{array}{l}\text { - HDI index of Far-western } \\
\text { and Midwestern increase } \\
\text { by } 8 \% \text { per annum. } \\
\text { - Literacy rate of dalits and } \\
\text { indigenous people } \\
\text { increases significantly. } \\
\text { - Life expectancy of } \\
\text { deprived }\end{array}$ & - MOLD \\
\hline & $\begin{array}{l}\text { - Make local bodies more } \\
\text { responsible for designing }\end{array}$ & $\begin{array}{l}\text { - Use decentralize mechanism for } \\
\text { implementation (ongoing). }\end{array}$ & $\begin{array}{l}\text { - DIDO and service delivery agencies } \\
\text { transferred to local level. }\end{array}$ & $\begin{array}{l}\text { communities/region } \\
\text { increases. }\end{array}$ & - MOLD \\
\hline & $\begin{array}{l}\text { and implementing local } \\
\text { poverty programmes }\end{array}$ & $\begin{array}{l}\text { - Increase grant to local bodies on } \\
\text { the basis of poverty index (FY04 } \\
\text { onwards). }\end{array}$ & $\begin{array}{l}\text { - Allocation to district with low HDI } \\
\text { increased. }\end{array}$ & $\begin{array}{l}\text { - Mean years of schooling } \\
\text { of deprived communities } \\
\text { and regions increase. }\end{array}$ & - MOLD/MoF \\
\hline & & & $\begin{array}{l}\text { - Number of training program under } \\
\text { LGDP/LGFC/PAF increased. }\end{array}$ & & $\begin{array}{l}\text { - MOLD, DDC, } \\
\text { VDC }\end{array}$ \\
\hline & $\begin{array}{l}\text { - Supplement the targeted } \\
\text { programmes of local } \\
\text { bodies and the } \\
\text { government with the } \\
\text { participation of } \\
\text { NGOs/CBOs. }\end{array}$ & $\begin{array}{l}\text { Train local bodies and make them } \\
\text { accountable for the poverty } \\
\text { reduction program at the local level } \\
\text { (FY04 onwards). }\end{array}$ & $\begin{array}{l}\text { - PAF guidelines approved. Program } \\
\text { implemented for targeted groups. }\end{array}$ & & - NPC, MOLD \\
\hline & & $\begin{array}{l}\text { - Strengthen social mobilization } \\
\text { (continued) }\end{array}$ & - PAF office established (FY 2003). & & \\
\hline & & $\begin{array}{l}\text { - Use PAF to supplement targeted } \\
\text { programmes, to be carried out } \\
\text { mainly by NGOs/CBOs (FY } 2004 \\
\text { onwards). }\end{array}$ & & & - NPC, MOLD \\
\hline & $\begin{array}{l}\text { - Reorient and coordinate } \\
\text { NGO/INGOs activities } \\
\text { towards targeted groups. }\end{array}$ & $\begin{array}{l}\text { Encourage coordination and } \\
\text { develop partnership with } \\
\text { NGO/CBOs and the private sector } \\
\text { to work in the poorer areas. }\end{array}$ & $\begin{array}{l}\text { - Mapping of INGOs activities done } \\
\text { and INGOs encouraged to work for } \\
\text { deprived areas/communities }\end{array}$ & & $\begin{array}{l}\text { - MOLD, DDC, } \\
\text { VDC }\end{array}$ \\
\hline & $\begin{array}{l}\text { - Initiate and implement } \\
\text { effective mechanism for } \\
\text { poverty monitoring. }\end{array}$ & $\begin{array}{l}\text { - Design special mechanism to } \\
\text { monitor outcome and input } \\
\text { indicators for targeted group (FY04 } \\
\text { onwards). }\end{array}$ & $\begin{array}{l}\text { - Poverty monitoring disaggregated } \\
\text { by gender/social groups/regions. }\end{array}$ & & - NPC, MOLD \\
\hline & & & 110 & & \\
\hline
\end{tabular}




\begin{tabular}{|c|c|c|c|c|c|}
\hline Objective & Strategies & Activities & Intermediate indicators & Outcome & $\begin{array}{l}\text { Responsible } \\
\text { Agency }\end{array}$ \\
\hline & & $\begin{array}{l}\text { - Initiate and support district level } \\
\text { poverty monitoring mechanism } \\
\text { (FY04 onwards). }\end{array}$ & $\begin{array}{l}\text { - Districtpoverty monitoring } \\
\text { mechanism assessed and system } \\
\text { strengthened. }\end{array}$ & & - NPC, MOLD \\
\hline & $\begin{array}{l}\text { Encourage philanthropic } \\
\text { organization in expanding } \\
\text { poverty reduction strategy. }\end{array}$ & $\begin{array}{l}\text { Enhance public awareness } \\
\text { campaign for voluntary work, } \\
\text { welfare activities and pov erty } \\
\text { reduction programmes to be } \\
\text { generated by philanthropic } \\
\text { organizations and private sector } \\
\text { (FY04 onwards). }\end{array}$ & $\begin{array}{l}\text { - More resources mobilized by local } \\
\text { NGOs locally. }\end{array}$ & & - NPC, NVSD \\
\hline & $\begin{array}{l}\text { - Special programs from } \\
\text { Far-west and Mid-west } \\
\text { regions' poor districts. }\end{array}$ & $\begin{array}{l}\text { - Assistance for overseas } \\
\text { employment (FY04-05) }\end{array}$ & $\begin{array}{l}\text { - Assistant to poor people for foreign } \\
\text { employment. }\end{array}$ & & - DOL, MOFA \\
\hline & & $\begin{array}{l}\text { Micro credit/micro-enterprises } \\
\text { training/education etc and or } \\
\text { strengthened. }\end{array}$ & - Asset creating activities increases. & & $\begin{array}{l}\text { - ADBN, Rural } \\
\text { Dev. Bank, } \\
\text { CTEVT }\end{array}$ \\
\hline \multirow[t]{6}{*}{$\begin{array}{l}\text { Mainstreaming } \\
\text { gender in } \\
\text { development } \\
\text { activities }\end{array}$} & \multirow{6}{*}{$\begin{array}{l}\text { - Women empowered by } \\
\text { removing the social, legal, } \\
\text { economic and other } \\
\text { constraints. }\end{array}$} & $\begin{array}{l}\text { - Production loan and social } \\
\text { mobilization (ongoing). }\end{array}$ & $\begin{array}{l}\text { - Number and volume of loan } \\
\text { awarded. }\end{array}$ & \multirow{6}{*}{$\begin{array}{l}\text { Economic status of } \\
\text { women improved. } \\
\text { Proportion of women in } \\
\text { socio-economic political } \\
\text { activities and public } \\
\text { positions improved. } \\
\text { Status of women } \\
\text { enhanced. }\end{array}$} & - RDBs \\
\hline & & $\begin{array}{l}\text { - Incentives to increase proportion of } \\
\text { girls in education ( } 2003 \text { onwards). }\end{array}$ & - Scholarship to girls. & & - MOES \\
\hline & & $\begin{array}{l}\text { - Special health care system to } \\
\text { women to reduce maternal mortality } \\
(2004-05) \text {. }\end{array}$ & $\begin{array}{l}\text { - Number of trained Midwives or AHM } \\
\text { or nurses. }\end{array}$ & & - $\mathrm{MOH}$ \\
\hline & & $\begin{array}{l}\text { Coaching classes and alternative } \\
\text { actions to increase females in } \\
\text { teaching and civil service (ongoing). }\end{array}$ & $\begin{array}{l}\text { - Proportion females in civil service } \\
\text { and teaching. }\end{array}$ & & $\begin{array}{l}\text { - MOES, Pvt. } \\
\text { Institute }\end{array}$ \\
\hline & & $\begin{array}{l}\text { Eliminate legal discrimination } \\
\text { (ongoing). }\end{array}$ & - Legal ammendment. & & $\begin{array}{l}\text { - MOWSW, } \\
\text { Women } \\
\text { Commission }\end{array}$ \\
\hline & & $\begin{array}{l}\text { - Legal and other changes to prevent } \\
\text { violence against women (2003-04). }\end{array}$ & $\begin{array}{l}\text { - Number of violence cases reported } \\
\text { and mitigation program. }\end{array}$ & & $\begin{array}{l}\text { - MOWSW, } \\
\text { Women } \\
\text { Commission }\end{array}$ \\
\hline
\end{tabular}




\begin{tabular}{|c|c|c|c|c|c|}
\hline Objective & Strategies & Activities & Intermediate indicators & Outcome & $\begin{array}{l}\text { Responsible } \\
\text { Agency }\end{array}$ \\
\hline & & $\begin{array}{l}\text { - Action Plan for gender } \\
\text { mainstreaming developed and } \\
\text { implemented (FY onwards) }\end{array}$ & $\begin{array}{l}\text { - Number of scholarship for higher } \\
\text { education to girls. }\end{array}$ & & - MOES \\
\hline & & $\begin{array}{l}\text { - Special scholarship program for } \\
\text { higher education (2003/04 ongoing). } \\
\text { - Special monitoring system in } \\
\text { improving gender equality (2004). }\end{array}$ & - Monitoring reports/analysis. & & $\begin{array}{l}\text { - MOWSW, } \\
\text { Women } \\
\text { Commission }\end{array}$ \\
\hline \multirow{7}{*}{$\begin{array}{l}\text { Mainstreaming the } \\
\text { deprived } \\
\text { communities. }\end{array}$} & - Empowerment & $\begin{array}{l}\text { - Incentives to increase proportion of } \\
\text { deprived children in education } \\
\text { (ongoing). }\end{array}$ & - Scholarship increased. & \multirow{7}{*}{$\begin{array}{l}\text { - Proportion of deprived } \\
\text { communities below } \\
\text { poverty line declines } \\
\text { significantly. } \\
\text { - Human development } \\
\text { indicators of deprived } \\
\text { communities improvers. } \\
\text { - Proportion of socially } \\
\text { excluded people } \\
\text { increased in socio- } \\
\text { economic and political } \\
\text { activities. } \\
\text { - Derived communities } \\
\text { empowered. }\end{array}$} & - MOES \\
\hline & & $\begin{array}{l}\text { - Affirmative actions to increase the } \\
\text { proportion of people recruited in } \\
\text { teaching and public service (2004). }\end{array}$ & $\begin{array}{l}\text { Number of Dalits in teaching and } \\
\text { public agencies. }\end{array}$ & & $\begin{array}{l}\text { - MOES, Dalit } \\
\text { Commission }\end{array}$ \\
\hline & & $\begin{array}{l}\text { - Special emphasis in skill training, } \\
\text { income generating activities and } \\
\text { special scholarship program for } \\
\text { higher education (ongoing). }\end{array}$ & $\begin{array}{l}\text { Number of scholarship and training } \\
\text { award to dalits and deprived janajati } \\
\text { groups. }\end{array}$ & & - PSC \\
\hline & & $\begin{array}{l}\text { - Legal and other constraints } \\
\text { removed (ongoing). }\end{array}$ & - Legal ammendment. & & - MOEC, CTEVT \\
\hline & & $\begin{array}{l}\text { - VDC and DDCs to focus on the } \\
\text { mainstreaming of deprived } \\
\text { communities (2003/04). }\end{array}$ & $\begin{array}{l}\text { - Training and guidelines for targetting } \\
\text { programs in VDCs/DDCs. }\end{array}$ & & $\begin{array}{l}\text { - MOLD, Dalit } \\
\text { Commission }\end{array}$ \\
\hline & & $\begin{array}{l}\text { - Special infrastructure, income } \\
\text { generating and human development } \\
\text { activities for deprived communities } \\
\text { and areas. }\end{array}$ & - Monitoring reports/analysis. & & - MOLD \\
\hline & & $\begin{array}{l}\text { - Special monitoring system in } \\
\text { improving the status of derived } \\
\text { community (2004). }\end{array}$ & & & \\
\hline
\end{tabular}


Civil Service Reform

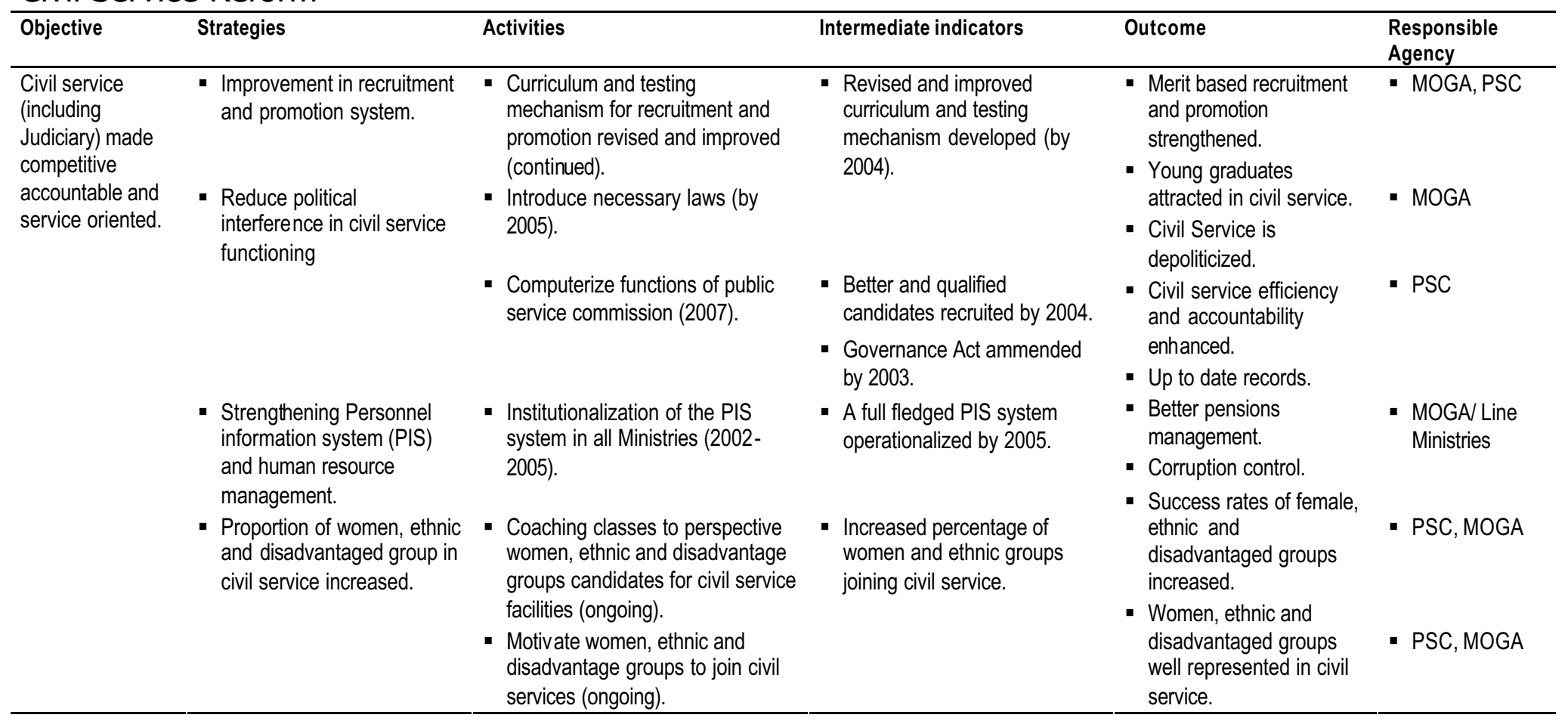




\section{Anticorruption}

\begin{tabular}{|c|c|c|c|c|c|}
\hline Objective & Strategies & Activities & Intermediate indicators & Outcome & $\begin{array}{l}\text { Responsible } \\
\text { Agency }\end{array}$ \\
\hline \multirow[t]{3}{*}{$\begin{array}{l}\text { Ensure efficiency } \\
\text { of resources use } \\
\text { and improve } \\
\text { service delivery }\end{array}$} & $\begin{array}{l}\text { - Preventive actions for anti - } \\
\text { corruption strengthened and } \\
\text { implemented. }\end{array}$ & $\begin{array}{l}\text { - Anti-corruption strategy adopted } \\
\text { and implemented (2003). } \\
\text { - National Vigilance Center activated } \\
\text { and strengthened (2003). } \\
\text { - Public Department (PWD) } \\
\text { directives implemented 2003). } \\
\text { - Anti money laundering Act enacted } \\
\text { (2004). }\end{array}$ & $\begin{array}{l}\text { - Draft procurement Act prepared } \\
\text { by April } 2004 . \\
\text { - Technical Audit Agencies } \\
\text { - } \text { established and made operational. } \\
\text { - Increased quality of public } \\
\text { construction works. } \\
\text { - Number of corruption cases } \\
\text { registered in the court increase. }\end{array}$ & $\begin{array}{l}\text { - Corruption reduced. } \\
\text { - New procurement } \\
\text { Act effective } \\
\text { - Resources } \\
\text { efficiency improved. } \\
\text { - Delivery of services } \\
\text { effective. } \\
\text { - Enhance integrity in } \\
\text { public service. }\end{array}$ & $\begin{array}{l}\text { - Cabinet } \\
\text { Secretariat, } \\
\text { CIAA } \\
\text { - PM's Office } \\
\text { - MOPPW } \\
\text { - NRB, MOF }\end{array}$ \\
\hline & $\begin{array}{l}\text { - Action against corruption } \\
\text { strengthened. }\end{array}$ & $\begin{array}{l}\text { - CIAA continued to be active } \\
\text { (continued). }\end{array}$ & $\begin{array}{l}\text { - More corruption cases prosecuted } \\
\text { and convicted. } \\
\text { - Prompt decisions by the courts. }\end{array}$ & $\begin{array}{l}\text { - Delivery of justice } \\
\text { improves. }\end{array}$ & - CIAA \\
\hline & $\begin{array}{l}\text { - Judicial system } \\
\text { strengthened. }\end{array}$ & $\begin{array}{l}\text { - Judicial system strengthened } \\
\text { through training and by improving } \\
\text { management (continued). }\end{array}$ & $\begin{array}{l}\text { - Number of pending judicial cases } \\
\text { decreased. }\end{array}$ & & - MOLJ/SC \\
\hline
\end{tabular}

\section{Decentralization}

\begin{tabular}{|c|c|c|c|c|c|}
\hline Objective & Strategies & Activities & Intermediate indicators & Outcome & $\begin{array}{l}\text { Responsible } \\
\text { Agency }\end{array}$ \\
\hline $\begin{array}{l}\text { Enhancing } \\
\text { development } \\
\text { process with the } \\
\text { participation and } \\
\text { empowerment of } \\
\text { people at large in } \\
\text { the governance. }\end{array}$ & $\begin{array}{l}\text { - Devolve service delivery } \\
\text { functions to local bodies }\end{array}$ & $\begin{array}{l}\text { DIDO transfers to local bodies } \\
\text { (2003/04). } \\
\text { - Education, health, postal service } \\
\text { transfer to local bodies (ongoing). } \\
\text { - Agriculture and small irrigation } \\
\text { services transfer to local bodies } \\
\text { (2004). } \\
\text { - Rural roads transfer to local } \\
\text { bodies (2003 onwards). }\end{array}$ & $\begin{array}{l}\text { - At least } 800 \text { primary schools } \\
\text { handed over to communities } \\
\text { (first year) } \\
\text { - Health post of at least } 10 \\
\text { districts each year transferred } \\
\text { to communities } \\
\text { - Agriculture service centers } \\
\text { transfer to local bodies. } \\
\text { - Local road tolls handed over } \\
\text { to Road User Groups in } 20 \\
\text { districts for the maintenance } \\
\text { of roads. }\end{array}$ & $\begin{array}{l}\text { - Service delivery improves } \\
\text { - Electronic MIS } \\
\text { operational zed in } 60 \\
\text { districts. } \\
\text { - Increase share of local } \\
\text { revenue in budget } \\
\text { expenditure. } \\
\text { - Transparency and } \\
\text { accountability improved } \\
\text { - Ownership in } \\
\text { programmes/projects } \\
\text { increased. }\end{array}$ & $\begin{array}{l}\text { - MOLD, DDC, } \\
\text { VDC } \\
\text { - MOLD, MOES, } \\
\text { MOH, DPS } \\
\text { - MOLD, MOAC, } \\
\text { DOI } \\
\text { - MOLD, DOR }\end{array}$ \\
\hline
\end{tabular}




\begin{tabular}{|c|c|c|c|c|c|}
\hline Objective & Strategies & Activities & Intermediate indicators & Outcome & $\begin{array}{l}\text { Responsible } \\
\text { Agency }\end{array}$ \\
\hline & & $\begin{array}{l}\text { - Reconcile conflicting Acts and } \\
\text { Regulations (2003 onwards). }\end{array}$ & $\begin{array}{l}\text { - Preparations to reconcile } \\
\text { conflicting Acts and } \\
\text { Regulations }\end{array}$ & $\begin{array}{l}\text { - Citizen's charter in all the } \\
\text { DDCs and Municipalities } \\
\text { prepared. }\end{array}$ & - MOGA, MOLJ \\
\hline & \multirow[t]{3}{*}{ - Capacity building } & $\begin{array}{l}\text { - Local services cadre constituted } \\
\text { (2004). }\end{array}$ & $\begin{array}{l}\text { - Local services cadre designed } \\
\text { in the first year }\end{array}$ & & - MOGA, MOLD \\
\hline & & $\begin{array}{l}\text { Enhance planning, management } \\
\text { and evaluation capacities of local } \\
\text { bodies (continued). }\end{array}$ & $\begin{array}{l}\text { - District profile of } 20 \text { districts } \\
\text { for DPP completed in the first } \\
\text { year. } \\
\text { - Electronic MIS operational in } \\
25 \text { districts }\end{array}$ & & - MOLD \\
\hline & & $\begin{array}{l}\text { - Train and equip local bodies } \\
\text { offices (continued). }\end{array}$ & $\begin{array}{l}\text { - DPP (districts periodic plans) } \\
\text { all districts brought outs. }\end{array}$ & & - MOLD \\
\hline & \multirow[t]{6}{*}{ - Fiscal decentralization } & $\begin{array}{l}\text { - Central grants allocated to local } \\
\text { bodies on poverty based formula } \\
\text { (FY 03/04) }\end{array}$ & $\begin{array}{l}\text { Central grants allocated to } \\
\text { local bodies on poverty based } \\
\text { formula begins. }\end{array}$ & & $\begin{array}{l}\text { MOF, NPC, } \\
\text { MOLD }\end{array}$ \\
\hline & & $\begin{array}{l}\text { Improve revenue collection } \\
\text { (ongoing). }\end{array}$ & $\begin{array}{l}\text { - Increase share of loca } \\
\text { revenue in budget expenditure } \\
\text { - Fiscal arrears reduced }\end{array}$ & & - MOF \\
\hline & & $\begin{array}{l}\text { - Fiscal management, auditing } \\
\text { accounting system (ongoing). }\end{array}$ & $\begin{array}{l}\text { - Transparency, auditing and } \\
\text { accountability improved. } \\
\text { - Public Audit of development } \\
\text { projects practiced }\end{array}$ & & $\begin{array}{l}\text { MOF, FCGO, } \\
\text { MOLD }\end{array}$ \\
\hline & & $\begin{array}{l}\text { - Road map for fiscal } \\
\text { decentralization (2003). }\end{array}$ & $\begin{array}{l}\text { - Road map for fiscal } \\
\text { decentralization adopted by } \\
\text { FY 02/03 }\end{array}$ & & $\begin{array}{l}\text { - Fiscal } \\
\text { Commission }\end{array}$ \\
\hline & & $\begin{array}{l}\text { - Fiscal framework introduced in } \\
\text { pilot basis }(2003 / 04)\end{array}$ & $\begin{array}{l}\text { - Fiscal framework introduced } \\
\text { in pilot basis in } 5 \text { districts by } \\
\text { FY 2003/04 }\end{array}$ & & $\begin{array}{l}\text { - Fiscal } \\
\text { Commission }\end{array}$ \\
\hline & & $\begin{array}{l}\text { - Preparation of citizen's charter } \\
(2003 / 04) \text {. }\end{array}$ & $\begin{array}{l}\text { - Citizen Character in } 15 \\
\text { districts prepared by mid-July } \\
2003 .\end{array}$ & & $\begin{array}{l}\text { - MOH A, Line } \\
\text { ministries }\end{array}$ \\
\hline
\end{tabular}




\section{Human Rights}

\begin{tabular}{|c|c|c|c|c|c|}
\hline Objective & Strategies & Activities & Intermediate indicators & Outcome & $\begin{array}{l}\text { Responsible } \\
\text { Agency }\end{array}$ \\
\hline \multirow{3}{*}{$\begin{array}{l}\text { Promotion of } \\
\text { human fights for } \\
\text { the dignity of } \\
\text { people. }\end{array}$} & $\begin{array}{l}\text { - Acts and laws made } \\
\text { compatible with } \\
\text { international conventions. }\end{array}$ & $\begin{array}{l}\text { - Formulate and amend major Acts } \\
\text { and regulations (continued). }\end{array}$ & $\begin{array}{l}\text { - Number of human rights } \\
\text { violation investigation cases } \\
\text { increased. }\end{array}$ & $\begin{array}{l}\text { - Human Rights violation } \\
\text { cases decreased. }\end{array}$ & - HRC \\
\hline & - Institutional strengthening. & $\begin{array}{l}\text { - Strengthen Human Rights } \\
\text { commission, women commission } \\
\text { and Dalit Commission } \\
\text { (continued). }\end{array}$ & $\begin{array}{l}\text { - Human rights action plan } \\
\text { prepared by } 2003 \text {. }\end{array}$ & $\begin{array}{l}\text { - Reduction in } \\
\text { discrimination violation } \\
\text { and exploitation cases. }\end{array}$ & - HRC, WC, DC \\
\hline & & $\begin{array}{l}\text { - Establish and strengthen human } \\
\text { rights cells in major government } \\
\text { agencies (2003/04) }\end{array}$ & $\begin{array}{l}\text { - Support the capacity building } \\
\text { of human right cells. }\end{array}$ & $\begin{array}{l}\text { - Empowerment of people } \\
\text { to exercise their rights. }\end{array}$ & - $\mathrm{HRC}$ \\
\hline
\end{tabular}

\section{Integrated Security Development Program}

\begin{tabular}{|c|c|c|c|c|}
\hline Objective & Strategies & Activities & Intermediate indicators & Responsible Agency \\
\hline $\begin{array}{l}\text { Enhance security } \\
\text { and expand } \\
\text { development } \\
\text { activities. }\end{array}$ & $\begin{array}{l}\text { Enhance the security umbrella } \\
\text { and the sense of security and } \\
\text { peace to continue and expand } \\
\text { development activities and } \\
\text { service delivery. }\end{array}$ & $\begin{array}{l}\text { - Provide security to big projects. } \\
\text { - Enhance internal security and } \\
\text { development program strategic } \\
\text { locations and violence-affected } \\
\text { areas. }\end{array}$ & & $\begin{array}{l}\text { - MOHA, MOLD } \\
\text { - MOHA }\end{array}$ \\
\hline $\begin{array}{l}\text { Rehabilitation of } \\
\text { victims of violence }\end{array}$ & $\begin{array}{l}\text { - Rehabilitation of the victims of } \\
\text { violence }\end{array}$ & $\begin{array}{l}\text { - Rehabilitation of the victims of } \\
\text { violence. }\end{array}$ & & - MOHA, MOLD \\
\hline
\end{tabular}




\section{Key Actions of the Immediate Action Plan, 2002 (IAP)}

\section{Area/Action}

\section{Prioritizing Public Expenditures}

Prioritization of all expenditures-especially development activities - to make the budget more realistic and reflect increased security requirements.

Resource allocations to be made consistent with decentralization by:

1. Allocating block grants to local bodies in FY 03 in an amount not less than FY 02 allocations.

2. Channeling funds to agricultural extension, sub-health posts and basic and primary education through local bodies.

3. Developing poverty -based formula for block grant allocations to local bodies and implement in FY 04 budget.

Priority projects (P1s) to be assured of full funding, with release of funds to be tied to meeting agreed performance indicators.

\section{Measures for Improving Service Delivery}

\section{Education}

- Formulation of procedures for transferring management of primary schools to communities.

- Begin the initial phase of transferring public primary schools $b$ community management and block grants to School Management Committees (SMCs).

- Recruitment of primary school teachers handed over to SMCs.

- Freeze on recruitment of primary school teachers by central Government.

Health

- Management of sub-health posts (SHPs) by Local Health Management Committees.

- VDC verification of staff attendance at SHPs before issuance of pay checks.

- Compulsory public notices in SHPs stating the range of services, fees and hours of operation.

\section{Civil Service Reform}

4. Gradual elimination of vacant civil service positions.

\section{Measures for Fighting Corruption and Improving Accountability}

- Publish annual budget and report of actual expenditure (by local bodies and by line agencies). District analysis to be carried out at least quarterly.

- Make arrangements for posting budget allocations and expenditures at DDC/VDC offices, SHPs and schools.

- Carrying out expenditure tracking to establish extent to which public funds are actually reaching the points of service delivery.

- No significant increase in the arrears of public utilities (electricity, telecommunications and drinking water).

- Adoption of time-bound action plan for implementing major recommendations of Country Procurement Assessment Review (CPPR).

- Public Works Guidelines (PWGs) to be made operational.

- Adoption of time-bound action plan for implementing major recommendations of Country Financial Accountability Assessment (CFAA).

- Develop comprehensive Anti-Corruption Strategy (ACS) and make progress in its implementation. 
Annex 3

Table A3.1: Growth Rate of GDP and Projection of Annual Macro Economic Indicators of the Tenth Plan (at 6.2 percent economic growth rate)

\begin{tabular}{|c|c|c|c|c|c|c|}
\hline & $2001 / 02$ & $2002 / 03$ & 2003/04 & 2004/05 & 2005/06 & 2006/07 \\
\hline 1. Growth rate of GDP (\%) & -0.61 & 3.3 & 6.1 & 6.5 & 7.5 & 7.5 \\
\hline 2. Fiscal deficit (\% of GDP) & -5.2 & -5.6 & -5.3 & -5 & -5 & -5.3 \\
\hline 3. Internal borrowing ( $\%$ of GDP) & 2.6 & 3.1 & 2.4 & 1.8 & 1.6 & 1.4 \\
\hline 4. Revenue ( $\%$ of GDP) & 12 & 11.8 & 12.3 & 12.9 & 13.5 & 14 \\
\hline 5. Changes in GDP deflater & 3.5 & 3.7 & 4.7 & 4.7 & 4.6 & 4.6 \\
\hline
\end{tabular}

Table A3.2: Estimates of Projected sources and expenditure of the Tenth Plan (at constant price : for 6.2 percent economic growth rate) (Rs. Billion)

\begin{tabular}{|c|c|c|c|c|c|c|}
\hline & $2001 / 02$ & $2002 / 03$ & $2003 / 04$ & $2004 / 05$ & $2005 / 06$ & $2006 / 07$ \\
\hline 1. Total Expenditure & 81.05 & 86.31 & 91.66 & 98.26 & 108.45 & 120.51 \\
\hline - Regular & 49.15 & 54.97 & 54 & 53 & 54.06 & 55.14 \\
\hline - Development & 31.9 & 31.34 & 37.66 & 45.26 & 54.39 & 65.37 \\
\hline 2. Sources of financing expenditure & 0 & 0 & 0 & 0 & 0 & 0 \\
\hline - Revenue & 50.45 & 51.11 & 56.54 & 63.17 & 71.08 & 79.26 \\
\hline - Foreign grant & 8.7 & 11.09 & 10.77 & 10.6 & 10.79 & 11.23 \\
\hline - Deficit & 21.9 & 24.11 & 24.36 & 24.49 & 26.58 & 30.03 \\
\hline 3. Sources of financing deficit & 0 & 0 & 0 & 0 & 0 & 0 \\
\hline - Foreign loan & 10.95 & 10.61 & 13.16 & 15.9 & 18.38 & 22.1 \\
\hline - Internal borrowing & 10.95 & 13.5 & 11.19 & 8.59 & 8.2 & 7.93 \\
\hline - Cash balance (-saving) & 0.95 & 0 & 0 & 0 & 0 & 0 \\
\hline
\end{tabular}


Table A3.3: Estimates of Projected sources and expenditure of the Tenth Plan (at current price : for 6.2 percent economic growth rate) (Rs. Billion)

\begin{tabular}{|c|c|c|c|c|c|c|}
\hline & $2001 / 02$ & $2002 / 03$ & $2003 / 04$ & $2004 / 05$ & $2005 / 06$ & $2006 / 07$ \\
\hline 1. Total Expenditure & 81.05 & 89.5 & 99.52 & 111.7 & 128.96 & 149.89 \\
\hline - Regular & 49.15 & 57 & 58.63 & 60.25 & 64.28 & 68.58 \\
\hline - Development & 31.9 & 32.5 & 40.89 & 51.45 & 64.68 & 81.3 \\
\hline \multicolumn{7}{|c|}{ 2. Sources of financing expenditure } \\
\hline - Revenue & 50.45 & 53 & 61.39 & 71.81 & 84.52 & 98.58 \\
\hline - Foreign grant & 8.7 & 11.5 & 11.69 & 12.05 & 12.83 & 13.96 \\
\hline \multicolumn{7}{|l|}{ 3. Sources of financing deficit } \\
\hline - Foreign loan & 10.95 & 11 & 14.29 & 18.07 & 21.85 & 27.48 \\
\hline - Internal borrowing & 10.95 & 14 & 12.15 & 9.77 & 9.75 & 9.86 \\
\hline - Cash balance (-saving) & 0.95 & 0 & 0 & 0 & 0 & 0 \\
\hline
\end{tabular}

Table A3.4: Growth Rate of GDP and Projection of Annual Macro Economic Indicators (for 4.3 economic growth rate)

\begin{tabular}{|c|c|c|c|c|c|c|}
\hline & $2001 / 02$ & $2002 / 03$ & $2003 / 04$ & $2004 / 05$ & $2005 / 06$ & $2006 / 07$ \\
\hline 1. Growth rate of GDP (\%) & -0.61 & 2 & 4 & 4.5 & 5 & 6 \\
\hline 2. Fiscal deficit ( $\%$ of GDP) & 5.2 & 5.5 & 5.2 & 4.9 & 4.5 & 4.3 \\
\hline 3. Internal borrowing ( $\%$ of GDP) & 2.6 & 3.1 & 2.6 & 2.1 & 1.3 & 0.8 \\
\hline 4. Revenue ( $\%$ of GDP) & 12 & 11.8 & 12.1 & 12.4 & 12.6 & 12.9 \\
\hline 5. Changes in GDP deflater & 3.5 & 3.7 & 4.7 & 4.7 & 5 & 5 \\
\hline
\end{tabular}


Table A3.5: Estimates of Projected sources and expenditure of the Tenth Plan (at constant price : for 4.3 percent economic growth rate) (Rs. Billion)

\begin{tabular}{|c|c|c|c|c|c|c|}
\hline & $2001 / 02$ & $2002 / 03$ & $2003 / 04$ & $2004 / 05$ & $2005 / 06$ & $2006 / 07$ \\
\hline 1. Total Expenditure & 81.05 & 81.58 & 86.67 & 91.49 & 95.45 & 101.06 \\
\hline - Regular & 49.15 & 53.62 & 54.43 & 55.86 & 56.35 & 57.65 \\
\hline - Development & 31.9 & 27.97 & 32.24 & 35.63 & 39.11 & 43.42 \\
\hline \multicolumn{7}{|c|}{ 2. Sources of financing expenditure } \\
\hline - Revenue & 50.45 & 50.43 & 53.97 & 57.62 & 61.98 & 67.29 \\
\hline - Foreign grant & 8.7 & 7.71 & 9.49 & 11.08 & 11.61 & 11.58 \\
\hline - Deficit & 21.9 & 24.43 & 23.21 & 22.78 & 21.87 & 22.22 \\
\hline - Foreign loan & 10.95 & 9.93 & 11.6 & 13.2 & 15.56 & 17.93 \\
\hline - Internal borrowing & 10.95 & 13.5 & 11.6 & 9.59 & 6.31 & 4.29 \\
\hline - Cash balance (-saving) & 0.95 & 0 & 0 & 0 & 0 & 0 \\
\hline
\end{tabular}

Table A3.6: Estimates of Projected sources and expenditure of the Tenth Plan (@ current price : for 4.3 percent economic growth rate) (Rs. Billion)

\begin{tabular}{|c|c|c|c|c|c|c|}
\hline & $2001 / 02$ & $2002 / 03$ & $2003 / 04$ & $2004 / 05$ & $2005 / 06$ & $2006 / 07$ \\
\hline 1. Total Expenditure & 81.05 & 84.6 & 94.1 & 104 & 113.5 & 125.7 \\
\hline - Regular & 49.15 & 55.6 & 59.1 & 63.5 & 67 & 71.7 \\
\hline - Development* & 31.9 & 29 & 35 & 40.5 & 46.5 & 54 \\
\hline \multicolumn{7}{|c|}{ 2. Sources of financing expenditure } \\
\hline - Revenue & 50.45 & 52.3 & 58.6 & 65.5 & 73.7 & 83.66 \\
\hline - Foreign grant & 8.7 & 8 & 10.3 & 12.6 & 13.8 & 14.4 \\
\hline - Deficit & 21.9 & 24.3 & 25.2 & 25.9 & 26 & 27.64 \\
\hline - Foreign loan & 10.95 & 10.3 & 12.6 & 15 & 18.5 & 22.3 \\
\hline - Internal borrowing & 10.95 & 14 & 12.6 & 10.9 & 7.5 & 5.34 \\
\hline - Cash balance (-saving) & 0.95 & 0 & 0 & 0 & 0 & 0 \\
\hline
\end{tabular}

*Share of development expenditure is estimated to be Rs. 205 billion at current price for the plan period.

120 